\title{
Sechstes Kapitel: Ausbau der Wiedergutmachung in der Bundesrepublik Deutschland bis 1953
}

\section{Ausbau der Ländergesetzgebung oder Vereinheitlichung durch den Bund?}

\section{Die Länder und die Kursbestimmung der Bundesressorts}

Durch die Gründung der Bundesrepublik wurde auch die Frage der Vereinheitlichung der bisher auf Länderebene geschaffenen, höchst ungleichen Wiedergutmachungsregelungen akut. Doch standen die diesbezüglichen Bemühungen im Zeichen einer bemerkenswerten Reziprozität: Für ein bundeseinheitliches Entschädigungsrecht setzten sich hauptsächlich in- und ausländische Verfolgtenverbände sowie die Alliierte Hohe Kommission ein. Protagonisten einer Vereinheitlichung des Rückerstattungsrechts waren hingegen in erster Linie die Restitutionspflichtigen sowie ihre Interessenvertreter in Verbänden und Parlamenten, die sich davon eine Milderung insbesondere des USzonalen Rückerstattungsgesetzes versprachen. Demgegenüber strebten die Verfolgtenverbände und die Alliierten für diesen Bereich die Beibehaltung der bisherigen zonalen Gesetze sowie eine Regelung der Rückerstattungsansprüche gegen das Deutsche Reich an. Diese gegensätzlichen Interessen bildeten das Grundmaterial für komplizierte Konstellationen und Koalitionen.

Besonders die FDP machte sich in jener Zeit zum Sprachrohr der zahllosen Beschwerden und Klagen über eine ungerechte Durchführung der Rückerstattung, mit denen Abgeordnete aller Parteien und Regierungsstellen bestürmt wurden. So forderte ihre Bundestags-Fraktion am 4. November 1949 die Bundesregierung in einem Antrag dazu auf, mit den Besatzungsmächten über ein ersatzweises einheitliches Rückerstattungsrecht zu verhandeln und vorläufig ein einstweiliges Moratorium für alle schwebenden Verfahren zu erwirken ${ }^{1}$. Im Bundeskabinett waren die Auffassungen jedoch zunächst gespalten ${ }^{2}$. Während Adenauer eine schleunige Abwicklung der Rückerstattung nach geltendem Besatzungsrecht befürwortete, beklagten Vizekanzler Blücher und Finanzminister Schäffer „die groben Ungerechtigkeiten und die Gefahren für die Wirtschaft “3 . Bundesjustizminister Dehler erkundigte sich deshalb im Auftrag des Kabinetts in einem Rundbrief an die Justizministerien der Bundesländer vom 6. Februar

\footnotetext{
1 Deutscher Bundestag, 1. Wp. 1949-1953, Drucksache Nr. 159, 4. 11. 1949, Antrag der Abgeordneten Nöll v.d. Nahmer usw. betr. Vereinheitlichung des Rückerstattungsrechts, Anlagen-Bd. I.

2 Protokoll der 32. Kabinettsitzung am 21.12. 1949, in: Die Kabinettsprotokolle der Bundesregierung, hrsg. v. Bundesarchiv v. H. Booms, Bd. 1: 1949, bearb. v. Ulrich Enders u. Konrad Reiser, Boppard a.Rh. 1982, S. 277.

${ }^{3}$ Note von Bundesjustizminister Dehler, 21. 12. 1949, BA, B 141/407.
} 
1950, ob die Länder zum gegenwärtigen Zeitpunkt eine Vereinheitlichung der alliierten Rückerstattungsgesetze für zweckmäßig hielten ${ }^{4}$.

Ein ähnliches Schreiben sandte Dehler am 4. Mai auch an das Koordinierungsbüro der Interministeriellen Arbeitsgemeinschaft für Wiedergutmachungs- und Entschädigungsfragen in der Bundesrepublik Deutschland. Von dort wünschte er überdies eine Stellungnahme zu der Frage, inwieweit es zu einem innerdeutschen Ausgleich zugunsten sogenannter loyaler Rückerstattungspflichtiger kommen sollte bzw. auf welchem Wege „das Problem der Rechtsnachfolge für Verbindlichkeiten des früheren deutschen Reichs und der ehemaligen NSDAP gelöst werden könnte". Hier wurde bereits deutlich, daß der Bundesjustizminister, der die Aussichten einer Änderung der alliierten Restitutionsgesetze skeptisch beurteilte ${ }^{5}$, die Befriedigung der Ansprüche der Rückerstattungsgeschädigten auf dem Wege ihrer Verknüpfung mit den Reichsforderungen der Verfolgten des Nationalsozialismus anstrebte. Zugleich erkundigte er sich aber auch nach der Auffassung des Koordinierungsbüros zu einem einheitlichen Entschädigungsgesetz für das gesamte Bundesgebiet ${ }^{6}$.

Bei diesen Umfragen ergab sich, daß die Länder zwar zumeist prinzipiell eine Änderung der bestehenden Rückerstattungsgesetze wünschten, doch angesichts der starren Haltung der Alliierten erschien dies der Mehrheit als unerreichbar ${ }^{7}$. Statt dessen plädierte aber insbesondere das Koordinierungsbüro dafür, schleunigst ein Ergänzungsgesetz zur Regelung der Rückerstattungsansprüche gegen das Reich zu schaffen ${ }^{8}$. Für den Bereich der Entschädigung lehnte hingegen die Mehrzahl der Länder eine Vereinheitlichung auf Bundesebene ab, allenfalls wünschte sie ein Dachgesetz zur Angleichung der Fristen und Zuständigkeiten. Eine abweichende Haltung nahmen hier allerdings einige Länder der britischen Besatzungszone ein; vor allem Niedersachsen, aber auch Schleswig-Holstein und Nordrhein-Westfalen drängten auf ein Bundesentschädigungsgesetz ${ }^{9}$. Nicht von ungefähr waren dies gerade die Länder, die noch keine eigenen Entschädigungsgesetze besaßen und deshalb diese Aufgabe nun gerne an den Bund delegiert hätten.

Der Wunsch der Ländermehrheit ging dagegen zu dieser Zeit dahin, die Entschädigung auf dem Verwaltungswege weiterzuentwickeln sowie fehlende Gesetze auf Länderebene zu vervollständigen und so eine legislative Behandlung der Materie durch den Bund zu vermeiden. Ein wichtiges Motiv war gewiß, die Verfolgten nicht erneut in Unsicherheit über die Durchführung der bestehenden Gesetze zu stürzen. Hinzu trat aber das Bestreben der Länder, in diesem Bereich die bisherige Selbständigkeit gegenüber dem Bund zu bewahren. So meinte auch Auerbach, man müsse „dem Bunde beweisen, daß wir als Länder die Wiedergutmachung handhaben können. Ich glaube

${ }^{4}$ Dehler an die Justizministerien der Länder, 6. 2. 1950, BA, B 136/1124.

5 Ebenda.

6 Dehler an das Koordinierungsbüro der Interministeriellen Arbeitsgemeinschaft für Wiedergutmachungs- und Entschädigungsfragen in der Bundesrepublik Deutschland, 4.5. 1950, BayMJ 1101a, H. 4.

7 Siehe zu den Antworten der Länder auf die Anfrage Dehlers BayMJ, 1101a, H. 4.; Vormerkung Rotberg (bayer. Justizministerium), 6.4. 1950, B 141/402; Auerbach (Präsident des Koordinierungsbüros) an Dehler, 27.5. 1950, BA, B 126/12523.

8 Auerbach an Dehler, 27.5. 1950, BA, B 126/12523.

9 Werner Hofmeister (niedersächs. Justizminister) an Dehler, 6.3. 1950, BayMJ, 1101a, H. 4; sowie am 24.6. 1950, BA, B 126/12523. Vgl. dazu auch Ernst Féaux de la Croix, Vom Unrecht zur Entschädigung: Der Weg des Entschädigungsrechts, in: ders. u. Helmut Rumpf, Der Werdegang des Entschädigungsrechts unter national- und völkerrechtlichem und politologischem Aspekt, S. 51. 
nicht, „daß der Bund sich eignet, dieses Gesetz, wie wir es haben, weiter auszubauen." 10

Nunmehr entschied sich auch das Bundesjustizministerium dafür, die alliierten Rückerstattungsgesetze nicht anzutasten und die Entschädigung weiterhin den Ländern zu überlassen ". Demgegenüber vertrat der Wiedergutmachungsreferent des Bundesfinanzministeriums, Ministerialrat Friedrich Kuschnitzky, zunächst die Auffassung, gewisse Fragen der Entschädigung seien so vordringlich, „daß der zu ihrer Lösung verfassungsmäßig berufene deutsche Gesetzgeber kaum länger in abwartender Haltung verharren“ könne. „Wie tägliche Eingaben beweisen“, so Kuschnitzky, „erwarten weite Kreise der Rechtsuchenden im Inland wie im Ausland von der Bundesrepublik, deren führende Staatsmänner bei jeder Gelegenheit betonen, die neue Bundesrepublik sei Rechtsfortsetzerin des früheren Deutschen Reiches, die baldige Herstellung einer Rechtseinheit vor allem auf dem Gebiet der Wiedergutmachung, auf dem es sich ja nicht nur um Rechtsfragen, sondern um Ehrenfragen der Nation handelt. “12

Diese Äußerungen standen vor dem Hintergrund der am 5. Mai 1950 durch die Alliierte Hohe Kommission an die Bundesregierung ergangenen Aufforderung, Gesetze auszuarbeiten, um eine Anzahl von gravierenden Mißständen im Bereich der Entschädigung für Verfolgte des Nationalsozialismus zu beseitigen. Das alliierte Schreiben bemängelte neben den als Resultat der auseinanderfallenden Ländergesetzgebung bestehenden Entschädigungslücken und der ungleichmäßigen finanziellen Belastung der Länder vor allem auch die fehlende Gleichstellung der DP's mit den deutschen Verfolgten $^{13}$.- Die deutsche Reaktion ging aus einer Serie von Besprechungen der Bundesministerien der Justiz, des Innern, der Finanzen, der Wirtschaft und für den Marshallplan hervor; sie ist bezeichnend für die mittlerweile bestehenden deutschen Spielräume gegenüber alliierten Forderungen. Alle beteiligten Ressorts erachteten es für aussichtslos, die Alliierten zu einer Änderung der bestehenden Rückerstattungsgesetze zu bewegen, weshalb insbesondere das Bundesjustizministerium erneut für einen innerdeutschen Ausgleich für sogenannte Restitutionsgeschädigte ${ }^{14}$ warb. Nahm man also auf deutscher Seite von der Vereinheitlichung des Rückerstattungsrechts überwiegend schweren Herzens Abstand, war umgekehrt im Bereich der Entschädigung ein solcher Verzicht erwünscht: Allein der Vertreter Schäffers plädierte bemerkenswerterweise zunächst auch hier für "eine einheitliche und erschöpfende Regelung durch Bundesgesetz “ ${ }^{15}$.

Doch nachdem alle anderen Ressorts bekundeten, daß es hierfür zu spät sei ${ }^{16}$, schwenkte auch das Bundesfinanzministerium auf diese Linie ein. Künftig war es der standhafteste Verfechter der am 21. Juni 1950 gefaßten Beschlüsse, wonach „von jeder die Ländergesetzgebung ersetzenden oder erübrigenden Gesetzgebung des Bundes abzusehen“ sei. Allenfalls sollte ein Dachgesetz erlassen werden, zunächst wollte man

10 Protokoll über die Sitzung des Koordinierungsausschusses der 11 Länder am 17.3. 1950, BayMJ 1091SA. Vgl. dazu auch Protokoll vom 25. 5. 1950, BayMJ 1101a, H. 4; Féaux de la Croix, Vom Unrecht zur Entschädigung, S. 47.

11 Dehler an Staatssekretär Otto Lenz (Bundeskanzleramt), 1.5. 1950, BA, B 136/1124.

12 Vormerkung von Ministerialrat Friedrich Kuschnitzky (Bundesfinanzministerium), 12.5. 1950, BA, B 126/ 12523.

13 J.E. Slater (Generalsekretär der AHK) an Herbert Blankenhorn, 5.5. 1950, BA, B 126/12523.

14 Kurzprotokoll über die interministerielle Referentenbesprechung im Bundesjustizministerium am 16. 5. 1950, BA, B 126/12523.

15 Kurzprotokoll über die interministerielle Referentenbesprechung im Bundesjustizministerium am 19.5. 1950, BA, B 126/12523.

16 Ebenda. 
aber den Erfolg der von den Ländern auf dem Verwaltungswege angekündigten Koordinierungsmaßnahmen abwarten. Dabei beriefen sich die Bundesressorts ausdrücklich darauf, daß man sich dem mehrheitlichen Wunsch der Bundesländer füge. Bundesfinanzminister Schäffer, dessen Haus nunmehr federführend für die Entschädigung war, sollte einen Kabinettsbeschluß herbeiführen, auf dessen Grundlage man dann der Alliierten Hohen Kommission die gewünschte Antwort erteilen würde ${ }^{17}$.

\section{Bundesregierung gegen Bundesgesetze}

Nachdem sich die Bundesressorts darauf verständigt hatten, im Bereich der Entschädigung keine Schritte zu unternehmen, schien Eile nicht erforderlich und die Alliierte Hohe Kommission wurde erst einmal mit einem hinhaltenden Zwischenbescheid abgespeist ${ }^{18}$. In dieser Haltung ließen sich Schäffer und Dehler auch nicht beirren, als Auerbach, diesmal namens der Arbeitsgemeinschaft für Freiheit, Recht und Menschenwürde, im Juli von seiner bisherigen Position abrückte und ein bundeseinheitliches Entschädigungsgesetz auf der Basis des US-Zonen-Gesetzes forderte ${ }^{19}$. Dabei konnten sich die Minister insbesondere auf das Koordinierungsbüro der elf Länder berufen, das weiterhin an der Länderzuständigkeit festhielt. Dort wurde schließlich unter Einfluß Küsters am 23. November ein ausdrücklicher Beschluß gefaßt, wonach das Rückerstattungsrecht abschließend durch die Militärregierungsgesetze geregelt und andererseits die Entschädigung auch künftig der Landesgesetzgebung überlassen bleiben sollte. ${ }^{20}$ Zudem arbeitete dieses Ländergremium an einem internen Verwaltungsabkommen, durch das die bisher uneinheitlichen Stichtage koordiniert und Zuständigkeitslücken geschlossen werden sollten, um zumindest einem Teil der bisherigen Beschwerden die Grundlage zu entziehen. Doch zeigten die langwierigen Verhandlungen bis zum $\mathrm{Zu}$ standekommen dieses Abkommens deutlich, welche Grenzen hier der Länderinitiative gesetzt waren ${ }^{21}$.

In der Frage der Rückerstattung verliefen die Fronten jedoch anders. Nachdem es intern unter allen damit befaßten amtlichen deutschen Stellen als ausgemacht galt, daß an eine Abmilderung der alliierten Rückerstattungsgesetze nicht zu denken sei, drängten sowohl das Koordinierungsbüro als auch Dehler auf eine vorgezogene Regelung der rückerstattungsrechtlichen Reichsverbindlichkeiten ${ }^{22}$. Während es aber den Wiedergutmachungsexperten der Länder in erster Linie um die Ansprüche der Verfolgten des Nationalsozialismus aus der sogenannten „Dritten Masse“ ging, zielte der Bundesjustizminister erneut vor allem auf die Rückgriffsansprüche der „loyalen Rückerstattungspflichtigen“" gegen das Reich bzw. die Bundesrepublik. Letztere wurden dabei

17 Kurzprotokoll über die am 21.6. 1950 stattgefundene interministerielle Rererentenbesprechung zu Fragen der Rückerstattung und Entschädigung sowie Aktenvermerk Kuschnitzky vom 21.6. 1950, BA, B 126/12523.

18 Dittmann an Oberst G.P. Glain (Generalsekretär der AHK), 21.6. 1950, BA, B 126/12523.

19 Koordinierungsbüro der Interministeriellen Arbeitsgemeinschaft für Wiedergutmachungs- und Entschädigungsfragen in der Bundesrepublik Deutschland, Rundschreiben Nr. 27/50, 3. 7. 1950, BayMJ, 1091 SA. Siehe auch Dehler an Schäffer, 3. 8. 1950, BA, B 141/408; Schäffer an Dehler, 7.9. 1950, BA, B 141/408.

20 Vormerkung Kuschnitzky, 25.11. 1950, BA, B 126/12523.

21 Siehe Protokoll über die Sitzung des Koordinierungsausschusses der 11 Länder am 25. 5. 1950, BayMJ 1101a, H. 4; Koordinierungsbüro der Interministeriellen Arbeitsgemeinschaft für Wiedergutmachungs- und Entschädigungsfragen in der Bundesrepublik Deutschland, Rundschreiben Nr. 28/50, 12.7. 1950, BayMJ 1991 SA. Zum Abkommen über die Bereinigung von Stichtagslücken und der Doppelzuständigkeiten in den Entschädigungsgesetzen vom 9.10. 1951 vgl. auch Féaux de la Croix, Vom Unrecht zur Entschädigung, S.61.

${ }^{22}$ Dehler an Schäffer, 3.8. 1950, BA, B 141/408. 
zum Motor der Ansprüche der Verfolgten, da es offensichtlich zu weit gegangen wäre, die Ansprüche der Rückerstattungsgeschädigten vor denen der Opfer des Nationalsozialismus zu befriedigen. Derartige Koppelungsgeschäfte wurden charakteristisch für die Bemühungen um den Ausbau der Wiedergutmachungsgesetzgebung auf Bundesebene. Doch war Schäffer nicht bereit, die rückerstattungsrechtlichen Verbindlichkeiten des Reiches vorab zu regeln, da dies "nicht aus dem Gesamtproblem der Reichsverbindlichkeiten herausgelöst werden sollte " ${ }^{23}$. Damit wandte sich der Bundesfinanzminister gleichermaßen gegen Ansprüche der Verfolgten wie der Rückerstattungsgeschädigten.

Die im Bundesjustizministerium entwickelten Pläne, die rückerstattungsrechtlichen Verpflichtungen vorab zu regeln und bei dieser Gelegenheit auch die Ansprüche der loyalen Rückerstattungspflichtigen zu regeln, schienen dort angesichts der heftigen innenpolitischen Wellen, die die Durchführung der alliierten Rückerstattungsgesetze schlugen, und angesichts der Aussichtlosigkeit einer Änderung dieser Gesetze als einzig gangbarer Weg, hier zu schlichten. In der Tat betonte McCloy in einer Rundfunkansprache am 8. Oktober erneut das Festhalten an der alliierten Kontrolle im Bereich der Rückerstattung ${ }^{24}$. Doch unverdrossen begehrte zwei Tage später die Bundestagsfraktion der CDU/CSU von der Bundesregierung in einem Antrag Auskunft darüber, was sie zu tun gedenke, „um die offenkundigen Härten des Militärregierungsgesetzes Nr. 59 zu beheben“. Dabei wollte sie insbesondere wissen, ob diese Schritte zur Abänderung des Gesetzes zugunsten gutgläubiger Erwerber unternommen habe bzw. einen Ausgleich ihrer Ansprüche aus öffentlichen Mitteln erwäge ${ }^{25}$.

Aus außenpolitischen Gründen waren der Bundesregierung derartige Bekundungen des Deutschen Bundestages äußerst unangenehm. Zu Recht fürchtete sie, man werde im Ausland derartige Bestrebungen sehr genau registrieren, wodurch das Klima für Milderungen der Rückerstattungspraxis bei den bevorstehenden Verhandlungen um die Revision des Besatzungsstatuts beeinträchtigt würde ${ }^{26}$. Deshalb hatte auch der BundestagsAusschuß für Rechtswesen und Verfassungsrecht, der den FDP-Antrag vom 4. November 1949 behandelte, auf Wunsch der Regierung die Beratungen ausgesetzt, um deren außenpolitische Kreise nicht zu stören ${ }^{27}$. Aus demselben Grund wies Dehler in seiner Antwort vor dem Bundestag am 4. November 1950 namens der Bundesregierung alle Hoffnungen auf eine Änderung der alliierten Rückerstattungsgesetze nachdrücklich zurück $^{28}$. Seine Ansprache war mindestens ebenso an das Ausland adressiert wie an den Bundestag, und tatsächlich registrierte HICOG befriedigt, daß die Bonner Regierung hier erstmals in dieser kontroversen Angelegenheit offen Stellung bezogen habe ${ }^{29}$. Umgekehrt wurde Dehler für seine Ausführungen auf deutscher Seite heftig gescholten. Die Bayerische Hausbesitzer Zeitung etwa ernannte ihn quasi zum Justizminister der

${ }^{23}$ Schäffer an Dehler, 7.9. 1950, BA, B 141/408.

24 Vgl. Neue Zeitung, 10.10. 1950, „Freiheit und Frieden nur durch gemeinsame Anstrengungen“.

25 Deutscher Bundestag, 1. Wp. 1949-1953, Drucksache Nr. 1455, Anfrage Nr. 125 der Fraktion der CDU/CSU betr. Rückerstattungsgesetz Nr. 59 und V.O. Nr. 120, 10.10. 1950, Anlagen-Bd. 7.

26 Dehler an MdB Nöll v.d. Nahmer, 17. 1. 1951, BA, B 126/12360.

27 Carlo Schmid, Deutscher Bundestag, 120. Sitzung am 22.2. 1951, Stenographische Berichte, Bd. 6, S. 4594.

${ }^{28}$ Deutscher Bundestag, 1. Wp. 1949-1953, Drucksache Nr. 1567, Der Bundesminister der Justiz (Dehler) an den Präsidenten des Deutschen Bundestags, 4.11. 1950, betr. Anfrage Nr. 125 der Fraktion der CDU/CSU, Anlagen-Bd. 7

29 Office of the United States High Commissioner for Germany, Office of Economic Affairs, Property Division, Report for the Month Ending November 30, 1950, USNA, RG 59, 262.0041/12-1350. Auch Bruno Weil von der Axis Victims League äußerte sich positiv über die Ansprache Dehlers. Vgl. ders. an Henry Byroade (State Department/Bureau of German Affairs), 18.12. 1950, USNA, RG 59, 262.0041/12-1850. 
Alliierten und bezichtigte ihn wütend der Kapitulation „im Angesicht des ungeheuren, an zahlreichen hilf- und rechtlosen Staatsbürgern sich vollziehenden Unrechts vor den von ihm befürchteten Angriffen aus dem Ausland “ ${ }^{30}$. Doch hatte Dehler tatsächlich nur ausgesprochen, was im Kreise aller verantwortlichen deutschen Stellen schon seit geraumer Zeit begriffen worden war. Umso dringlicher war für ihn die Frage eines von deutscher Seite zu schaffenden Ausgleichs für die sogenannten gutgläubigen Rückerstattungspflichtigen.

$\mathrm{Daß}$ an den alliierten Rückerstattungsgesetzen nicht mehr zu rütteln war, bestätigte die Alliierte Hohe Kommission der Bundesregierung bald darauf auch noch einmal expressis verbis. Zugleich drang sie erneut auf deren beschleunigte Abwicklung. In ihrem Schreiben vom 21. November wies sie aber auch darauf hin, daß sie „besonders an der Notwendigkeit eines Bundesentschädigungsgesetzes interessiert " sei und bat um die Übersendung eventuell vorhandener Gesetzentwürfe ${ }^{31}$. Nicht wissen konnte die Bundesregierung allerdings, daß hinter den Kulissen erhebliche alliierte Differenzen darüber bestanden, welche Maßnahmen im einzelnen im Zusammenhang der geforderten bundesdeutschen Entschädigungsregelung verlangt werden sollten. Die im Entwurf des Schreibens zunächst vorhandenen diesbezüglichen Hinweise waren deshalb getilgt worden, um eine alliierte Verständigung abzuwarten ${ }^{32}$.

Aber auch der der Bundesregierung nahestehende Bund der Verfolgten des Naziregimes (BVN) hatte sich in einer Eingabe vom 5. Dezember für ein Bundesentschädigungsgesetz ausgesprochen ${ }^{33}$. Diese Forderung erhob am 15. Dezember erstmals auch der Bundestag, der an diesem Tage den mündlichen Bericht des Ausschusses zum Schutze der Verfassung über den Abschluß der Entnazifizierung gebilligt hatte. Dort wurde, wie gesagt, auch eine bundeseinheitliche Entschädigungsregelung nach dem Vorbild des US-Zonen-Gesetzes angeregt ${ }^{34}$. Als Bundesinnenminister Lehr sowie Finanzstaatssekretär Hartmann vor dem Bundestag eindringlich dafür plädierten, nicht seitens des Bundes in die Entschädigung einzugreifen, um die erfolgreiche Bearbeitung dieser Materie durch die Länder nicht zu gefährden, fügte Berichterstatter Hermann Brill jedoch beinahe entschuldigend hinzu, daß dieser Punkt rein tendenziell gemeint sei. Man habe im Ausschuß nur an eine Rahmengesetzgebung des Bundes gedacht, in der nicht das materielle Recht im einzelnen geregelt wäre, sondern nur der Kreis der Berechtigten und die Termine, die zu beachten seien, bundeseinheitlich festgesetzt sein sollten ${ }^{35}$.

Immerhin brachten alle diese Anstöße die Haltung der beteiligten Bundesministerien vorübergehend etwas ins Wanken, und im Hause Schäffers wurde sogar kurzzeitig erwogen, den Erlaß eines Rahmengesetzes vorzuschlagen ${ }^{36}$. Doch Mitte Januar 1951 waren diese Zweifel wieder verflogen und das Bundesfinanzministerium gab die Devise aus, zumindest vorläufig gebe es keinen Grund, von den Referentenbeschlüssen vom

\footnotetext{
30 Ulrich König, Eine Gefahr für den inneren Frieden, in: Bayerische Hausbesitzer Zeitung. Offizielles Organ des Landesverbandes Bayerischer Haus- und Grundbesitzer Vereine e.V., 2. Jg., Nr. 8, 15.4. 1951.

31 Slater an Dittmann (Bundeskanzleramt), 21.11. 1950, BA, B 126/12523.

${ }^{32}$ McCloy an Acheson, 6.11. 1950, USNA, RG 59, 262.0041/11-250. Vgl. auch unten, Abschnitt V. 5.

33 Vorlage Gumbels für Adenauer, 20.12. 1950, BA, B 136/1124.

${ }^{34}$ Mündlicher Bericht des Ausschusses zum Schutze der Verfassung, Deutscher Bundestag, 1. Wp. 1949-1953, Drucksache Nr. 1658, 24. 11. 1950, Abs. Vb, Beilagen-Bd. 8. Vgl. dazu auch Fünftes Kapitel, Abschnitt IV.3.

35 Deutscher Bundestag, 108. Sitzung am 15.12. 1950, Stenographische Berichte, Bd. 5, S. 4068 f.

36 Vorlage Gumbels für Adenauer, 20.12. 1950, BA, B 136/1124.
} 
21. Juni 1950 abzurücken ${ }^{37}$. Bundeskanzleramtsreferent Karl Gumbel stellte für die entscheidende Kabinettssitzung am 30. Januar 1951 Argumente für die Annahme der Vorlage Schäffers zusammen. Dabei spielte weiterhin eine wichtige Rolle, daß die Länder selbst überwiegend keine Regelung durch den Bund wünschten. Doch rückten nun zunehmend auch eigene Motive des Bundes in den Vordergrund. So sei es mit einem Rahmengesetz wohl nicht getan, da man damit die Rechtsungleichheit unter den Ländern nicht beseitigen könne. Bei einem umfassenden Bundesentschädigungsgesetz drohe jedoch, so Gumbel, die Gefahr, daß einige rechtliche Dämme bersten könnten. Insbesondere sah er das Territorialitätsprinzip gefährdet und befürchtete darüber hinaus auch ein Präjudiz für die Haftung des Bundes für die Reichsverbindlichkeiten ${ }^{38}$. Offensichtlich dämmerte der Bundesregierung, daß die Bundesrepublik auch hinsichtlich der Wiedergutmachung mehr war als nur die Summe von zwölf Bundesländern und dies zu weitergehenden Ansprüchen führen würde.

Im Sinne dieser Empfehlungen beschloß das Bundeskabinett am 30. Januar die Vorlage Schäffers, wonach „vorerst von einer über das Gesetz zur Regelung der Wiedergutmachung nationalsozialistischen Unrechts für Angehörige des öffentlichen Dienstes hinausgehenden, die Wiedergutmachungsgesetze der Länder abändernden oder sie erübrigenden Bundesgesetzgebung abzusehen “ 39 sei. Das Wort „vorerst“ sollte dabei signalisieren, daß sich diese Haltung ändern könnte, sofern die Anstrengungen der Länder nicht erfolgreich seien ${ }^{40}$. Am 20. Februar wurde auch die Alliierte Hohe Kommission offiziell von diesem Beschluß informiert ${ }^{41}$.

\section{Initiativen im Bundestag}

Zwei Tage, nachdem die Bundesregierung der Alliierten Hohen Kommission mitgeteilt hatte, daß sie vorläufig nicht an die Ausarbeitung eines Bundesentschädigungsgesetzes denke, befaßte sich der Bundestag mit einer Interpellation der SPD-Fraktion, in der die Bundesregierung aufgefordert wurde, eben dieses zu tun. Außerdem schlug die SPD hier vor, den Staat Israel als Repräsentanten des erbenlosen jüdischen Eigentums anzuerkennen ${ }^{42}$. Carlo Schmid begründete den Antrag vor dem Bundestag und prangerte dabei die Verschiedenheit der Entschädigungsregelungen in den einzelnen Ländern an, die entgegen den Beteuerungen der Ländermehrheit und den Hoffnungen der Bundesregierung nur unzulänglich auf dem Wege neuer Ländergesetzgebung und Verwaltungsvereinbarungen vereinheitlicht werden könnten. $\mathrm{Da}$ es „ein unmöglicher $\mathrm{Zu}$ stand“ sei, „daß es ausschließlich vom Zufall des Wohnsitzes abhängen soll, ob ein Opfer des Nationalsozialismus Wiedergutmachung bekommt oder nicht", forderte er dringend den Erlaß eines Bundesentschädigungsgesetzes. Doch sei die „ursprüngliche

37 Vormerkung Gumbels, 18.1. 1951, BA, B 136/1124; Schäffer, Entwurf eines Kabinettsbeschlusses, 18.1. 1951 , BA, B 126/12360.

38 Vermerk Gumbels für die Kabinettssitzung, Zu Punkt 8, 26.1. 1951, BA, B 136/1124.

39 Vgl. Schäffer, Entwurf eines Kabinettsbeschlusses, 18.1. 1951 (Anm. 37); Protokoll der 126. Kabinettssitzung am 30. 1. 1951, in: Die Kabinettsprotokolle der Bundesregierung, hrsg. f. d. Bundesarchiv v. Hans Booms, Bd. 4: 1951, bearb. v. Ursula Hüllbüsch, Boppard a.Rh. 1988, S. 122 f.

40 Vormerkung Gumbels, 18. 1. 1951 (Anm. 37).

41 William G. Daniels (HICOG) an State Department, 8.3. 1951, USNA, RG 59, 262.0041/3-851.

42 Deutscher Bundestag, 1. Wp. 1949-1953, Drucksache Nr. 1828, Interpellation der SPD vom 24. 1. 1951 betr. Vorlage des Entwurfs eines Wiedergutmachungsgesetzes, Anlagen-Bd. 9; Deutscher Bundestag, 120. Sitzung am 22. 2. 1951, Stenographische Berichte, Bd. 6, S. 4589-4599. 
Bereitschaft einer Art von fiskalischem Geiz gewichen". Besonders kritisierte er dabei die Befürchtungen der Bundesregierung, daß bei einer Übernahme der Entschädigung auf den Bund „ein Run sämtlicher anderer Gläubiger des Deutschen Reiches ausgelöst werden könnte", weshalb diese Last bei den Ländern besser aufgehoben sei. Doch seien, so Schmid, derartige fiskalische Rechenkunststücke zur Schonung des Bundessäckels angesichts des elementaren Phänomens „Konzentrationslager“ fehl am Platze. Demgegenüber forderte er eine „Rangordnung unter den Gläubigern unseres Vaterlandes Deutschland“", bei der die Opfer des Nationalsozialismus einen ersten Platz einnehmen sollten. Dabei hob er die Juden besonders hervor, weshalb der Staat Israel durch ein Bundesgesetz Rechtsnachfolger für alle erbenlosen Rückerstattungs- und Wiedergutmachungsansprüche werden sollte ${ }^{43}$. Dieser Vorschlag, der auf den jüdischen SPDBundestagsabgeordneten Jakob Altmaier zurückging ${ }^{44}$, kollidierte allerdings direkt mit den Interessen der jüdischen Nachfolgeorganisationen.

Demgegenüber verteidigte Finanzstaatssekretär Hartmann die Linie des Kabinettsbeschlusses vom 30. Januar, wonach man von einem Bundesentschädigungsgesetz absehen wolle. Allerdings wies er darauf hin, daß die Bundesregierung einen eigenen Entwurf vorlegen würde, falls die Bemühungen der Länder zur Vereinheitlichung auf dem Gesetzes- oder Verwaltungswege zu keinem befriedigenden Ergebnis führten ${ }^{45}$. Im Rechtsausschuß des Bundestags ergänzte Ministerialdirektor Roemer - er war mittlerweile vom bayerischen in das Bundesjustizministerium gewechselt - ein weiteres Argument der Bundesregierung gegen die Diskussion eines Bundesentschädigungsgesetzes: „Das werde nämlich zur Folge haben, daß die Länder der britischen Zone, die die ganze Zeit über schon auf ein finanzielles Einspringen des Bundes hofften und deshalb ihre eigenen gesetzgeberischen Maßnahmen verzögert haben, nun erst recht auf der Stelle treten würden“46. Am 10. Mai bekräftigte Adenauer schließlich gegenüber dem Bundestag den Kabinettsbeschluß vom 30. Januar, wonach die Bundesregierung „die Vorlage eines Bundesgesetzes nur dann vertreten (könnte), wenn der Ausgleich unter den Ländern wider Erwarten nicht gelingen sollte ${ }^{\alpha 47}$.

Für einige Zeit war nun der Rechtsausschuß des Bundestag der Brennpunkt der weiteren Entwicklung. Bei diesen Ausschußberatungen wurde das Prinzip der „Koppelungsgeschäfte" ganz besonders deutlich. Die von der SPD geforderte Diskussion eines Bundesentschädigungsgesetzes war nur um das Zugeständnis vor allem an die CDU/ CSU möglich, daß zugleich über eine innerdeutsche Ausgleichsregelung für die Rückerstattungsgeschädigten beraten werde. Die Unionsparteien standen in dieser Frage unter ständig wachsendem Druck ${ }^{48}$. Deshalb einigten sich die Mitglieder des Ausschusses bald darauf, daß Rückerstattung und Entschädigung gleichzeitig durch ergänzende Bundesgesetze geregelt werden müßten ${ }^{49}$.

${ }^{43}$ Deutscher Bundestag, 120. Sitzung am 22. 2. 1951, Stenographische Berichte, Bd. 6, S. $4591 \mathrm{ff}$.

44 Vgl. Willy Albrecht, Ein Wegbereiter: Jakob Altmaier und das Luxemburger Abkommen, in: Wiedergutmachung in der Bundesrepublik Deutschland, hrsg. v. Ludolf Herbst u. Constantin Goschler, München 1989, S. 207.

45 Deutscher Bundestag, 120. Sitzung am 22.2. 1951, Stenographische Berichte, Bd. 6, S. 4593 f.

46 Protokoll der 98. Sitzung des Bundestags-Ausschusses für Rechtswesen und Verfassungsrecht, 18. 4. 1951, BA, B 126/12523. Ähnlich äußerte sich dort auch Kuschnitzky.

${ }^{47}$ Deutscher Bundestag, 1. Wp. 1949-1953, Drucksache Nr. 2241, Adenauer an den Präsidenten des Deutschen Bundestags, 10.5. 1951, Anlagen-Bd. 11.

$\$ 8$ Vormerkung Gumbels, 24. 10. 1951, BA, B 136/1125.

49 Protokolle des Bundestags-Ausschusses für Rechtswesen und Verfassungsrecht, 16.5. und 18. 5. 1951, BA, B 
Engagierten sich so die Unionsvertreter im Rechtsausschuß hauptsächlich für ein „Rückerstattungsausgleichsgesetz“, dem ein Großteil dieser Beratungen galt ${ }^{50}$, lag den SPD-Abgeordneten, vor allem Carlo Schmid und Adolf Arndt, primär an einem Bundesentschädigungsgesetz. Sie drangen wiederholt darauf, daß man bei der Wiedergutmachung nicht darauf warten dürfe, was die Alliierten von den Deutschen verlangten, vielmehr müsse diese wichtige Materie in eigener Zuständigkeit der Deutschen geregelt werden. So forderte etwa Carlo Schmid, die deutsche Seite müsse einen eigenen Entwurf fertigstellen, um „dann mit diesem Entwurf auf den Petersberg zu gehen und zu sagen: Das wollen wir an Stelle des bisher geltenden Rechtes setzen “51.

Gegenüber den Vorstellungen der SPD, die auf eine umfassende Gesamtregelung der Entschädigung auf Bundesebene hinausliefen, verteidigten die Vertreter der Koalitionsparteien zunächst die abwartende Haltung der Regierung. Schützenhilfe erhielten sie dabei unter anderem von Otto Küster, der die Beibehaltung der Entschädigung auf Länderebene auch vor dem Rechtsausschuß verteidigte ${ }^{52}$ und in einem ausführlichen Memorandum für Adenauer erklärte: „Durchweg aber ist die Lage heute so, daß es sich verbietet, von Bundes wegen neu anzufangen, wenn nicht der hochempfindliche und seiner Natur nach der größten Beschleunigung bedürftige Vorgang Wiedergutmachung um eines ungewissen Erfolges willen in ein lebensgefährliches Stocken geraten soll“ ${ }^{* 53}$. Darüber hinaus forderte er aber auch die finanzielle Unterstützung der Länder durch den Bund bei der Entschädigung sowie ein Bundesgesetz zur Regelung der sogenannten Ansprüche der „Dritten Masse“ (d.h. der geldlichen Rückerstattungsansprüche gegen das Deutsche Reich).

Am 6. Dezember erstellte der vom Rechtsausschuß zur Beratung dieser Frage eingesetzte Unterausschuß schließlich einen vorläufigen Bericht über die bisherigen Beratungen. Wesentliche Fortschritte waren nicht erzielt worden, vielmehr hatten sich Koalitionsparteien und SPD-Opposition in einige grundsätzliche Konflikte verbissen. Einig war man sich geworden, daß ein ergänzendes Gesetz im Bereich der Rückerstattung einen Ausgleich für die gröbsten Härten der als unverrückbar angesehenen alliierten Rückerstattungsgesetze schaffen sollte. Daneben wurde ein Rahmengesetz des Bundes im Bereich der Entschädigung angeregt, wenngleich dessen Konturen unklar geblieben waren. Während die Koalitionsparteien und das Bundesfinanzministerium den Bund weiterhin so weit als möglich aus der finanziellen Verantwortung heraushalten wollten und allenfalls ein Rahmengesetz zur Vereinheitlichung der Fristen, der Regelung der DP-Ansprüche und der Höchstgrenzen der Entschädigung wünschten, machte sich Arndt namens der SPD dafür stark, daß die ganze Entschädigung, abgesehen von der Haftentschädigung, durch den Bund geregelt werden sollte ${ }^{54}$.

So wurde Ende 1951 im Bundeskanzleramt das Fazit gezogen, daß man in der bereits seit zwei Jahren verhandelten Frage, ob der Bund Maßnahmen zur Wiedergutmachung

126/12523; Winckler (bayer. Bevollmächtigter beim Bund) an das bayerische Justizministerium, 21.5. 1951, BayMJ 1101a, H. 4.

50 Aufzeichnung von Kuschnitzky, 7.11. 1951, BA, B 126/12523.

51 Protokoll der 98. Sitzung des Bundestags-Ausschusses für Rechtswesen und Verfassungsrecht, 18.4. 1951, BA, B 126/12523.

52 Protokoll der 100. Sitzung des Bundestags-Ausschusses für Rechtswesen und Verfassungsrecht, 25.4. 1951, BA, B 126/12523.

53 Otto Küster an Adenauer, 12.7. 1951, BA, B 136/1124.

${ }^{54}$ Auszug aus dem Stenographischen Protokoll der 141. Sitzung des Bundestags-Ausschusses für Rechtswesen und Verfassungsrecht, 6.12. 1951, BA, B 136/1125. 
ergreifen solle, abgesehen von der Wiedergutmachung für den öffentlichen Dienst, noch nicht viel weiter gekommen sei. Doch bestanden hier mittlerweile erhebliche Bedenken über die Weisheit dieser Politik. Die Erklärung Adenauers vom 27. September über das Verhältnis zu den Juden und das damit verbundene Bekenntnis zur Wiedergutmachung habe Erwartungen geweckt, die "sich aber in naher Zukunft nicht erfüllen werden, wenn die Wiedergutmachung in bisheriger Weise weiter behandelt wird. Das Bundesfinanzministerium“, so Bundeskanzleramtsreferent Gumbel, „scheint die Erklärung des Herrn Bundeskanzlers dahin auszulegen, daß eine Wiedergutmachung nur im Rahmen der finanziellen Möglichkeiten des Bundes in Aussicht gestellt worden sei. Dies bedeutet aber, daß unter den gegenwärtigen Umständen eine Wiedergutmachung durch den Bund überhaupt ausgeschlossen ist." 55 Dies beschrieb ziemlich präzise die tatsächliche Position des Bundesfinanzministeriums. Unbeirrt vertrat es die Auffassung, Ansprüche gegen das ehemalige Reich aus dem Entschädigungs- und Rückerstattungsrecht sollten nicht vorweg behandelt, sondern in einem allgemeinen Gesetz über Reichsverbindlichkeiten geregelt werden ${ }^{56}$.

Deshalb bat auch Dehler am 20. Dezember Adenauer, ein gemeinsames Gespräch mit seinem Ministerkollegen Schäffer zu arrangieren, um die bestehenden tiefgreifenden Differenzen, die sich aus dessen kategorischer Vertagung der Rückerstattungsansprüche gegen das Reich sowie der Ansprüche bislang nicht entschädigter Verfolgter des Nationalsozialismus ergaben, auszuräumen ${ }^{57}$. Der Bundeskanzler hatte seinerseits bereits in einer Besprechung mit den Alliierten Hohen Kommissaren am 25. Oktober signalisiert, daß wahrscheinlich ein Rahmengesetz des Bundes im Bereich der Entschädigung kommen werde ${ }^{58}$. So mehrten sich Ende 1951 die Anzeichen, daß die bisherige abwartende Haltung des Bundes, die sich im Prinzip immer noch auf dem Boden des Kabinettsbeschlusses vom 30. Januar bewegte, allmählich aufweichte. Gumbel warnte Staatssekretär Otto Lenz eindringlich, daß die Schuld an der bisherigen Misere ohne Zweifel der Bundesregierung zugeschoben werde: „Ich glaube, daß man die Dinge nicht so weiter treiben lassen kann, sondern die Bundesregierung klipp und klar erklären muß, ob und was zur Durchführung der Wiedergutmachung geschehen wird. “59 Doch bildete der Widerstand des Bundesfinanzministeriums vorläufig ein unüberwindbares Hindernis für alle derartigen Bestrebungen.

\section{Das Bundesgesetz zur Wiedergutmachung für den öffentlichen Dienst: Ein Alibi für das $131 \mathrm{er}-$ Gesetz?}

Während also Ende 1951 bei der Bundesregierung allmählich die Auffassung reifte, daß man wohl mindestens ein Rahmengesetz zur Vereinheitlichung der unterschiedlichen Entschädigungsgesetze der Länder werde schaffen müssen, bestand für eine spezielle

55 Gumbel an Staatsekretär Lenz, 11. 12. 1951, BA, B 136/1125.

56 Vormerkung Gumbels, 24. 10. 1951, BA, B 136/1125.

57 Dehler an Adenauer, 20.12. 1951, BA, B 136/1125.

58 Aufzeichnung Hallsteins über Besprechung Adenauers mit den Alliierten Hohen Komissaren vom 25.10. 1951, in: Adenauer und die Hohen Kommissare, 1949-1951, hrsg. v. Hans-Peter Schwarz in Verbindung mit Reiner Pommerin, bearb. v. Frank-Lothar Kroll u. Manfred Nebelin, München 1989, S.559.

59 Gumbel an Lenz, 11.12. 1951, BA, B 136/1125. 
Gruppe der Verfolgten bereits eine umfassende Regelung: Am 11. Mai 1951 war das Gesetz zur Regelung der Wiedergutmachung nationalsozialistischen Unrechts für Angehörige des öffentlichen Dienstes (BWGöD) in Kraft getreten, am selben Tag wie das Gesetz zur Regelung der Rechtsverhältnisse der unter Artikel 131 des Grundgesetzes fallenden Personen - und hier liegt auch bereits der Schlüssel zur Beantwortung der Frage, warum es zu so einer schnellen Sonderregelung für verfolgte Beamte kam ${ }^{60}$.

Bereits am 11. November 1949 hatte der Bundestags-Ausschuß für Beamtenrecht in einem mündlichen Bericht das Parlament dazu aufgefordert, die Bundesregierung mit dem Entwurf eines Gesetzes zu beauftragen, „das die Wiedergutmachungsansprüche der durch den Nationalsozialismus benachteiligten Angehörigen des öffentlichen Dienstes regelt" ${ }^{61}$. Im Anschluß daran forderte der Bericht zugleich auch den Entwurf eines Gesetzes zur Regelung der Rechtsverhältnisse und Versorgungsansprüche der sogenannten 131er. Dies war genaugenommen auch der Kern des Berichts, der auf einen Antrag der FDP zur Versorgung ehemaliger Berufssoldaten und ihrer Angehörigen zurückging ${ }^{62}$. Die Regelung der Ansprüche der nach einer Zählung von Januar 1950 etwa 450.000 unter den Artikel 131 GG fallenden Personen - darunter als größte Gruppe ehemalige Berufssoldaten, gefolgt von Beamten aus den deutschen Ostgebieten, der DDR und anderen Staaten sowie im Zuge der Entnazifizierung entlassenen Beamten aus den Westzonen - war die vordringliche beamtenrechtliche Streitfrage der frühen fünfziger Jahre ${ }^{63}$. Diese Gruppe hatte etwa seit 1948 mit großem Nachdruck auf ihre Ansprüche gepocht, und einer der Erfolge war der Grundgesetzartikel 131, der die Bundesrepublik dazu verpflichtete, ihre Rechtsverhältnisse durch ein Bundesgesetz zu regeln ${ }^{64}$.

Daß überhaupt die Verlegenheit entstand, ehemals verfolgte und die nach dem Krieg vertriebenen und entlassenen Beamten (d.h. genaugenommen, auch die im öffentlichen Dienst tätigen Angestellten und Arbeiter) in einen Zusammenhang zu stellen, rührte zunächst daher, daß die bislang bestehenden Ländergesetze die außerhalb des Gebietes der Bundesrepublik verfolgten deutschen Beamten meist nicht berücksichtigten. So bestand die Gefahr, daß man die unter Artikel 131 GG fallenden Personen, die dem NS-Regime bis zum Schluß gedient hatten und zum Teil selbst Nationalsozialisten gewesen waren, günstiger stellen würde als die häufig schon 1933 durch das Gesetz zur Wiederherstellung des Berufsbeamtentums geschädigten Beamten. Da dies auch aus Gründen der politischen Symbolik nicht akzeptabel war, mußte also zugleich eine entsprechende ergänzende Regelung für die durch den Nationalsozialismus geschädigten Beamten geschaffen werden. Auslöser war aber die Entwicklung im Bereich der 131er. Auch hier lag also wieder eine Art von „Koppelungsgeschäft“ vor.

${ }^{60}$ So bereits Otto Gnirs, Die Wiedergutmachung im öffentlichen Dienst, in: Hugo Finke u. a., Entschädigungsverfahren und sondergesetzliche Entschädigungsregelungen, München 1987, München 1987, S.266; Udo Wengst, Beamtentum zwischen Reform und Tradition. Beamtengesetzgebung in der Gründungsphase der Bundesrepublik Deutschland 1948-1953, Düsseldorf 1988, S. 222-235.

61 Deutscher Bundestag, 1. W p. 1949-1953, Drucksache Nr. 216, mündlicher Bericht des Ausschusses für Beamtenrecht über den Antrag der Fraktion der Freien Demokratischen Partei, Drucksache Nr. 96, betr. Wiederherstellung der staatsbürgerlichen Gleichberechtigung für Militär-Pensionäre und deren Hinterbliebene, 11. 11. 1949, Anlagen-Bd. 1.

62 Deutscher Bundestag, 1. Wp. 1949-1953, Drucksache Nr. 96, Antrag der Fraktion der FDP betr. Wiederherstellung der staatsbürgerlichen Gleichberechtigung für Militärpensionäre und deren Hinterbliebene, 13.10. 1949, Anlagen-Bd. 1.

${ }^{63}$ Vgl. Bernd Wunder, Geschichte der Bürokratie in Deutschland, Frankfurt a.M. 1986, S. 164 u. $166 \mathrm{f}$.

${ }^{64}$ Vgl. dazu Wengst, Beamtentum, S. 58-65. 
Im Bundesinnenministerium wurde nunmehr ein Entwurf zur Regelung der Wiedergutmachung für den öffentlichen Dienst ausgearbeitet, der allerdings nur die bestehenden Ländergesetze ergänzen sollte und deshalb darauf abzielte, die bislang meist unberücksichtigten Beamten aus den Gebieten außerhalb der Bundesrepublik gleichzustellen. Zugleich schien es aber Bundesinnenminister Heinemann politisch gerechtfertigt, den durch nationalsozialistische Verfolgungsmaßnahmen benachteiligten Angehörigen des öffentlichen Dienstes eine Vorrangstellung gegenüber den übrigen Verdrängten einzuräumen ${ }^{65}$. In diesem Punkt kam es jedoch zu längeren Konflikten mit dem Bundesfinanzministerium, das dafür eintrat, die Wiedergutmachungsregelung einfach an den entsprechenen Entwurf des Gesetzes zur Regelung der Ansprüche nach Artikel 131 GG anzuhängen ${ }^{66}$. Bedenken wegen der kategorialen Verschiedenheit dieser Ansprüche existierten hier offenbar nicht. Nach wiederholten Beratungen im Kabinett und Überarbeitungen des Entwurfs ${ }^{67}$ konnte sich aber Heinemann mit seiner Grundkonzeption durchsetzen, und am 16. August überwies die Bundesregierung schließlich den Entwurf eines Gesetzes zur vorläufigen Regelung der Wiedergutmachung nationalsozialistischen Unrechts für verdrängte Angehörige des öffentlichen Dienstes an den Bundestag ${ }^{68}$.

Doch auch wenn die Wiedergutmachungsregelung für den öffentlichen Dienst nun unter der Flagge eines selbständigen Entwurfes segelte, diktierte die Entwicklung im Bereich des 131-Gesetzes weiterhin Tempo und Umfang. Am 13. September 1950 fand die erste Lesung des Entwurfs eines Gesetzes zur Regelung der Rechtsverhältnisse der 131 er im Bundestag statt, tags darauf die des Wiedergutmachungsgesetzes für den öffentlichen Dienst. Zwar wies auch Staatssekretär Ritter von Lex, der den Entwurf namens des Bundesinnenministers vor dem Bundestag vertrat, in seiner Rede darauf hin, daß es einem Gebot der Gerechtigkeit entspreche, das Gesetz über die Wiedergutmachung für den öffentlichen Dienst vor dem zur Regelung der Ansprüche aus Art. 131 GG zu verabschieden ${ }^{69}$. Doch auf der parlamentarischen Agenda war die Reihenfolge gerade umgekehrt.

$\mathrm{Daß}$ nunmehr im Sog der 131er-Regelung eine Vorabregelung für einen speziellen Kreis der Opfer des Nationalsozialismus getroffen werden sollte, schuf eine komplizierte politische Situation. Karl Weber erklärte namens der CDU/CSU-Fraktion, es ginge grundsätzlich nicht an, daß die Angehörigen des öffentlichen Dienstes vorweg und bevorzugt entschädigt würden, wenn auch andererseits zuzugestehen sei, „daß in diesen Fällen das begangene Unrecht durchweg besonders in die Augen springt und der Kreis der Geschädigten leichter abzugrenzen und damit die finanzielle Auswirkung besser zu überblicken“ $\operatorname{se}^{70}$. Doch räumte auch er ein, daß es "nicht angängig“ sei, „nunmehr, nachdem im Rahmen des Art. 131 die Ansprüche der entnazifizierten Beam-

${ }^{65}$ Heinemann, 25.3. 1950, in: Die Kabinettsprotokolle der Bundesregierung, hrsg. f.d. Bundesarchiv v. Hans Booms, Bd. 2: 1950, bearb.v. Ulrich Enders u. Konrad Reiser, Boppard a.Rh. 1984, Anm. 11, S. 327.

$66 \mathrm{Vgl}$. Wengst, Beamtentum, S. $223 \mathrm{f}$.

67 58. Kabinettssitzung am 13.4. 1950, in: Kabinettsprotokolle der Bundesregierung, Bd. 2, S. 309; 59. Kabinettssitzung am 21.4. 1950, ebenda, S.327f.; 70. Kabinettssitzung am 31.5. 1950, ebenda, S.415; 75. Kabinettsitzung am 20.6. 1950, ebenda, S. 468; 82. Kabinettssitzung am 11.7. 1950, ebenda, S. 527.

${ }_{68}$ Deutscher Bundestag, 1. Wp. 1949-1953, Drucksache Nr. 1287, Adenauer an Präsidenten des Bundestags, 16. 8. 1950, Anlage: Entwurf eines Gesetzes zur vorläufigen Regelung der Wiedergutmachung nationalsozialistischen Unrechts für verdrängte Angehörige des öffentlichen Dienstes, Anlagen-Bd. 5.

${ }^{69}$ Deutscher Bundestag, 85. Sitzung am 14.9. 1950, Stenographische Berichte, Bd. 5, S. 3211.

70 Ebenda, S. 3212. 
ten geregelt werden, diejenigen, die durch den Nationalsozialismus geschädigt worden sind, noch schlechter zu stellen" ${ }^{71}$. Hermann Brill unterstrich gleichfalls den Wunsch, daß Angestellte der früheren politischen Parteien, der Gewerkschaftsverbände, sozialer Vereinigungen usw. in diese Regelung aufgenommen werden sollten ${ }^{72}$.

Auch der Bundestags-Ausschuß für Beamtenrecht, dem der Entwurf zur weiteren Beratung vorlag, war sich der politischen Symbolik bewußt, die sich aus der Parallelität des Wiedergutmachungsgesetzes für den öffentlichen Dienst mit der 131er-Regelung ergab. Deshalb übernahm er die Forderung, daß dieses Gesetz mit Vorrang vor dem $131 \mathrm{er}-$ Gesetz verabschiedet werden müsse ${ }^{73}$. Zugleich stellte er Grundsätze zur weiteren Behandlung des Entwurfes auf, die die bisherige Konzeption grundlegend veränderten. Am wichtigsten war in diesem Zusammenhang, daß nicht nur, wie bisher geplant, das bestehende Länderrecht ergänzt, sondern eine endgültige und umfassende Regelung der Wiedergutmachungsansprüche aller Angehörigen des öffentlichen Dienstes geschaffen werden sollte. Auch dies geschah im Hinblick auf die entsprechende Regelung zugunsten der 131er. Dabei sollten folgende Grundsätze gelten: Volle Anrechnung der verlorenen Dienstzeit auf das Besoldungsdienstalter und die ruhegehaltsfähige Dienstzeit, Anerkennung der einer normalen Dienstlaufbahn entsprechenden Beförderungen sowie Berechnung des Ruhegehaltes nach den im Augenblick der Schädigung geltenden Rechtsgrundsätzen ${ }^{74}$.

Ein Unterausschuß des Ausschusses für Beamtenrecht machte sich zunächst an die Arbeit, doch gingen die weiteren Beratungen des Entwurfs bald auf das Bundesinnenund das Bundesfinanzministerium unter Heranziehung der zuständigen Länderministerien über $^{75}$. Dieses ungewöhnliche Verfahren diente dazu, die Angelegenheit zu beschleunigen und damit nicht in Verzug gegenüber dem Gesetz zur Regelung der Ansprüche aus Artikel 131 GG zu geraten ${ }^{76}$. Der Ausschuß für Beamtenrecht, der anschließend den Entwurf noch einmal behandelte, legte das Ergebnis am 31. Januar vor und bat den Bundestag um seine Zustimmung. Der Wunsch des Ausschusses nach einem „Vollgesetz“" war hier erfüllt worden und ebenso auch die übrigen zu Beginn der Beratungen aufgestellten Forderungen. Die Hauptgrundsätze der erreichten Regelung waren demgemäß, daß die verfolgten Beamten ein Recht auf Wiedereinstellung hatten, und zwar in einer Position, die sie auf einer hypothetischen Dienstlaufbahn erreicht hätten. Entgangene Beförderungen wurden also nachgeholt. Außerdem sollte ihnen eine Entschädigung für die beschäftigungslose Zeit zustehen, allerdings erst für die Zeit ab $1950^{77}$.

Bei der zweiten und dritten Lesung des Entwurfes vor dem Bundestag am 15. Februar und 5. April 1951 begründete der Berichterstatter des Ausschusses für Beamtenrecht, Oskar Wackerzapp (CDU), die Tatsache, daß hier nur ein kleines Teilstück der Wiedergutmachung vorab geregelt werde, ähnlich wie vor ihm Weber mit den besonders

71 Deutscher Bundestag, 85. Sitzung am 14.9. 1950, Stenographische Berichte, Bd. 5, S. 3212.

72 Ebenda, S. 3214.

${ }^{73}$ Kurzprotokoll der 61. Sitzung des Bundestags-Ausschusses für Beamtenrecht, 3.11. 1950, IfZ-Archiv, Dm 001.

74 Ebenda.

75 114. Kabinettssitzung am 1. 12. 1950, in: Kabinettsprotokolle der Bundesregierung, Bd. 2, S. 858.

76 Vgl. Wengst, Beamtentum, S. 229.

77 Deutscher Bundestag, 1. Wp. 1949-1953, Drucksache Nr.1882, Mündlicher Bericht des Ausschusses für Beamtenrecht über den Entwurf eines Gesetzes zur Regelung der Wiedergutmachung nationalsozialistischen Unrechts für Angehörige des öffentlichen Dienstes, Anlagen-Bd. 9. 
günstigen Voraussetzungen in diesem Bereich, da hier ein gewisser Schematismus herrsche und insbesondere auch die finanziellen Auswirkungen übersehbar seien. Damit rechtfertigte er auch, daß die Behandlung dieser Gruppe „im allgemeinen umfassender und vollständiger sein (dürfte), als dies für alle übrigen geschädigten Gruppen möglich sein wird." Dies war aber nur die halbe Wahrheit, denn vorrangig ging es darum, daß hier ein Vergleichsstandard für das, wie es hieß, "große Heer der heimatvertriebenen und verdrängten Beamten ..., die ebenfalls, wenn auch auf anderer Grundlage, wohlbegründete Ansprüche anzumelden haben ${ }^{478}$, geschaffen werden sollte.

Da der Gesetzgeber offensichtlich bereit war, die Ansprüche der 131er generell großzügiger zu regeln als die der Verfolgten, mußte er auf dem begrenzten Gebiet der Wiedergutmachung für den öffentlichen Dienst eine Inkonsequenz begehen und eine Regelung treffen, die vorteilhafter war als die für die übrigen Verfolgten. Hier wurde also gerade so viel getan wie nötig war, um den Vorwurf zu vermeiden, daß die verfolgten Beamten schlechter gestellt würden als die vertriebenen und entnazifizierten. Die relativ großzügige Wiedergutmachungsregelung für verfolgte Beamte war damit im Grunde ein Alibi für die Regelung der 131er-Ansprüche, die wenn schon nicht moralische, so gewiß doch faktische Priorität genossen. So endete Wackerzapp seine Rede mit der Feststellung, daß durch die Wiedergutmachung für den öffentlichen Dienst nunmehr die Bahn frei sei für den baldigen Erlaß des großen Gesetzes nach Art. 131 ${ }^{79}$. Demgegenüber forderte Otto Arnholz (SPD) in diesem Zusammenhang die Bundesregierung dazu auf, daß sie „unverzüglich den Entwurf eines umfassenden Wiedergutmachungsgesetzes vorlegt und sich nicht der Gefahr des Vorwurfs aussetzt, sie zögere mit einer solchen Vorlage so lange, bis die meisten Wiedergutmachungsberechtigten verstorben seien ${ }^{\alpha 80}$.

Am 5. April 1951, also wunschgemäß noch vor dem 131er-Gesetz, nahm der Bundestag das BWGöD an ${ }^{81}$. Doch türmten sich zuletzt noch Hindernisse im Bundesrat auf. Hauptquelle dieser Turbulenzen war Otto Küster, der bereits am 30. November 1950 beim Bundesinnenministerium gegen den Entwurf protestiert hatte. In der Hauptsache richteten sich die Einwände dagegen, daß an Stelle des ursprünglich geplanten subsidiären Gesetzes, das nur die Lücken in der bestehenden Ländergesetzgebung schließen wollte, nun ein umfassendes Wiedergutmachungsgesetz für den öffentlichen Dienst gesetzt werden sollte. Küster wollte es statt dessen lieber bei der ursprünglichen Konzeption belassen. „Es kommt hinzu," schrieb er, „daß es gegenüber der öffentlichen Meinung ein schlechtes Bild gibt, wenn wieder einmal ein umfassender Gesetzgebungsakt zu Gunsten der öffentlichen Bediensteten erginge, der diesen ganzen Personenkreis, sonst aber niemand erfaßt. ${ }^{~} 82$

Seinen Widerstand gegen die Pläne der Bundesregierung setzte Küster auch im Bundesrat fort, hier als Berichterstatter des Rechtsausschusses. Dieser plädierte schließlich in der Bundesrats-Sitzung am 19. April dafür, den Vermittlungsausschuß anzurufen ${ }^{83}$.

\footnotetext{
78 Deutscher Bundestag, 118. Sitzung am 15.2. 1951, Stenographische Berichte, Bd. 6, S. 4510.

79 Ebenda

${ }^{80}$ Deutscher Bundestag, 130. Sitzung am 5.4. 1950, Stenographische Berichte, Bd. 6, S. 4972.

81 Ebenda. Die Schlußabstimmung über das Gesetz zur Regelung der Ansprüche aus Artikel 131 GG fand am 10.4. 1951 statt. Siehe Deutscher Bundestag, 136. Sitzung am 10.4. 1951, Stenographische Berichte, Bd. 6, S. 5099-5104.

82 Küster an Bundesinnenministerium, 30. 11. 1950, HessHStA, Abt. 503, Nr. 473.

${ }^{83}$ Sitzungsberichte des Deutschen Bundesrats, 54. Sitzung am 19.4 1951, S. $265 \mathrm{ff}$.
} 
Küster erläuterte die Gründe des Rechtsausschusses, wobei er erneut Übertreibungen des Wiedergutmachungsgedankens zugunsten der Beamten kritisierte. So forderte er eine Abschwächung der vorgesehenen großzügigen Regelung der aus politischen Gründen unterbliebenen Beförderung sowie eine Einschränkung der Fälle, in denen dienstfähige Beamte, die aber keinen Dienst versahen, dennoch volle Bezüge oder volle Ruhebezüge bekommen sollten, ohne daß ihnen das anderweitig erzielte Einkommen angerechnet würde. „In diesen Fällen“, so Küster, „geschieht also sehr viel mehr, als daß der Schaden wiedergutgemacht wird. Das ist umso weniger mit dem gesamten Recht der Wiedergutmachung in Einklang zu bringen, als auf allen anderen Gebieten die Wiedergutmachungsansprüche nicht entfernt voll befriedigt werden. " Heftig beklagte er, daß etwa Hinterbliebene von Getöteten oder solche Personen, die durch Verletzungen in Konzentrationslagern bleibende Gesundheitsschäden erlitten hätten, äußerst kleine Entschädigungen erhielten, während auf der anderen Seite jemand, der z.B irgendwo Generaldirektor geworden sei, daneben dennoch das volle Gehalt eines Ministerialdirektors vom Staat erhielte. Zugleich kritisierte er aber unter anderem auch, daß der Anspruch der emigrierten verfolgten Beamten aus dem Gesetz zu Unrecht herausgelassen worden sei, obwohl die Länder zum Teil bereits anders verfuhren ${ }^{84}$.

Küster, der in der Beamtenrechtsdiskussion auch generell eine kritische Haltung einnahm ${ }^{85}$, prangerte zu Recht die entstehenden Disproportionalitäten im Bereich der Wiedergutmachung an. Während auf der einen Seite gegenüber den Verfolgten des Nationalsozialismus ständig mit der finanziellen Notlage des Staates argumentiert wurde, um die Bescheidenheit der Entschädigungsleistungen zu rechtfertigen, erfolgte auf der anderen Seite für den öffentlichen Dienst eine großzügige Regelung. Dies lag zum einen daran, daß zumindest Bundesinnenminister Heinemann zunächst geglaubt hatte, die finanzielle Gesamtbelastung aus dieser Regelung werde sich in maßvollen Grenzen halten ${ }^{86}$, zumal die Länder ja bereits einen Großteil der Aufgabe erledigt hätten ${ }^{87}$. Tatsächlich erreichten die Aufwendungen aus diesem Gesetz bis 1986 nach einer annähernden Schätzung des Bundesfinanzministeriums ein Volumen von ca. fünf Mrd.

${ }^{84}$ Ebenda, S. 266. Diese Frage wurde später durch das am 18.3. 1952 ergangene Gesetz zur Regelung der Wiedergutmachung nationalsozialistischen Unrechts für die im Ausland lebenden Angehörigen des öffentlichen Dienstes geregelt, allerdings nur, sofern diese in Ländern lebten, die die Bundesrepublik diplomatisch anerkannten. Vgl. Bundesgesetzblatt (BGBl), Teil I, Nr.10, 21.3. 1952, S. 137f.; 182. Kabinettssitzung am 26. 10. 1952, in: Kabinettsprotokolle der Bundesregierung, Bd. 4, S. 721.

85 So begründete Küster seine Weigerung, sich in Baden-Württemberg verbeamten zu lassen, am 2.10. 1952 auf folgende Weise: „Ausschlaggebend ist meine Überzeugung, daß das z.Z. in voller Reaktion begriffene Beamtenrecht dem deutschen Staatswesen zum Verhängnis werden wird, wenn es nicht von der Wurzel her reformiert wird. Es kann nicht dabei bleiben, daß einerseits der Beamte nur im Weg der Strafe entlassen werden kann und daß andererseits das Aufkündigen des Dienstes mit dem Verlust der Alters- und Familienversorgung bestraft wird." Vgl. Anlage 1 zu den Verhandlungen des Landtags von Baden-Württemberg, 43. Sitzung, 5.8. 1954, S. 1834.

${ }^{86}$ In der Kabinettssitzung am 20.6. 1950 schätzte Heinemann, daß etwa 600 Personen im Bereich der Bundesverwaltung unter diese Regelung fallen würden. Vgl. Kabinettsprotokolle der Bundesregierung, Bd. 2, S. 468. Diese Ziffer beruhte allerdings noch auf der Voraussetzung, daß nur ein Ergänzungsgesetz zu den bereits bestehenden Länderregelungen geschaffen würde. Tatsächlich waren es bis 1986 über 10.000 positiv entschiedene Fälle. Vgl. Deutscher Bundestag, 10. Wp. 1982-1986, Drucksache Nr.6287, Bericht der Bundesregierung über Wiedergutmachung und Entschädigung für nationalsozialistischen Unrecht sowie über die Lage der Sinti, Roma und verwandter Gruppen vom 31. 10. 1986, S. 25, Anlagen Bd. 341. Für eine Zwischenbilanz vom Sommer 1954 siehe auch Mitteilungsblatt des Beirats für Wiedergutmachung, Nr. 91/92, August/Sept. 1954, "Die Wiedergutmachung für Angehörige des öffentlichen Dienstes vor dem Abschluß“. Demzufolge waren bis dahin 2.500 Personen nach dem BGWöD zu ihrem Recht gekommen.

${ }^{87}$ Bayerischer Ministerrat, 10.4. 1951, IfZ-Archiv, NL Hoegner, ED 120, Bd. 367. 
$\mathrm{DM}^{88}$. Der Hauptgrund für diese Großzügigkeit im speziellen Fall der verfolgten Beamten war jedoch, um es noch einmal zu wiederholen, daß hier ein Vergleichsstandard für die Regelung der Ansprüche nach Artikel 131 GG geschaffen wurde.

Auch im Bundesrat offenbarte sich zuletzt noch einmal die politische Vorrangigkeit der 131er-Regelung: Dieses Gesetz, das Ministerpräsident Hans Ehard zufolge „wenigstens den Anfang einer Befriedung im Innern ${ }^{89}$ schaffen sollte, konnte aus Gründen der politischen Symbolik nicht vor dem BWGöD erlassen werden. Deshalb zog der Bundesrat der schnelleren Verabschiedung des $131 \mathrm{er}-$ Gesetz zuliebe die vorgesehene Anrufung des Vermittlungs-Ausschusses in der Frage des BWGöD zurück ${ }^{90}$. Damit stand der Verkündung beider Gesetze am 11. Mai 1951 nichts mehr im Wege ${ }^{91}$.

Wurde somit dem Wiedergutmachungsgesetz für den öffentlichen Dienst ein symbolischer Vorrang eingeräumt, so genoß das $131 \mathrm{er}-\mathrm{Gesetz}$ die faktische Priorität. Dies zeigte sich auch bei den künftigen Novellierungen des BWGöD, die nicht etwa an die Entwicklung der späteren Bundesentschädigungsgesetzgebung, sondern an die des 131 er-Gesetzes gekoppelt wurden. Dadurch verschärften sich die Diskrepanzen zwischen der Wiedergutmachung für Beamte und der für die übrigen Verfolgten noch weiter. Zum Beispiel wurden die Anmeldefristen nach dem BWGöD sachlich und zeitlich parallel zum 131er-Gesetz im Verlaufe einiger Novellierungen praktisch ganz aufgehoben, während die strengen Ausschlußfristen des Bundesentschädigungsgesetzes bestehen blieben ${ }^{92}$ - wer dort zu spät kam, bekam gar nichts. Auch Klagen vor dem Bundesverfassungsgericht auf Verletzung des Gleichheitsgrundsatzes blieben erfolglos ${ }^{93}$.

Den politischen Vorrang des 131er-Gesetzes gegenüber dem BWGöD bestätigt auch die Praxis dieser Regelungen. Die Wiedereinstellung - der Kernpunkt der beiden Gesetze - funktionierte, Klagen aus dem Verfolgtenkreis zufolge, bei den vertriebenen und entnazifizierten Beamten erheblich besser als bei den verfolgten. Ungleichbehandlung zwischen beiden Gruppen entstand dabei schon allein durch den Instanzenweg: Wurden Anträge von 131ern direkt durch die Zweigstellen der Oberfinanzdirektionen anerkannt, fungierten diese bei den Berechtigten nach BWGöD nur als Anmeldebehörden, die Entscheidungsbefugnis lag hingegen ausschließlich bei den entsprechenden Bundesbehörden. In einem konkreten Fall durchwanderten die Akten eines nach diesem Gesetz klagenden ehemaligen Polizeibeamten binnen eines Jahres 15 Behörden in der ganzen Bundesrepublik, ohne daß es zu einer Entscheidung gekommen wäre ${ }^{94}$.

${ }^{88}$ Deutscher Bundestag, Drucksache Nr.10/6287, S.25. Genaue Zahlenangaben sind nicht möglich, da die Ausgaben aufgrund des BWGöD bei einer Vielzahl von Dienstbehörden anfallen. Berücksichtigt werden muß, daß unter diesem auch die Versorgungszahlungen für frühere Bedienstete jüdischer Gemeinden oder öffentlicher Einrichtungen enthalten sind, die aus dem Haager Protokoll Nr. 1 mit der Claims Conference resultieren.

89 Sitzungsberichte des Deutschen Bundesrats, 55. Sitzung, 27.4. 1951, S. 292.

90 Sitzungsberichte des Deutschen Bundesrats, 54. Sitzung, 19.4 1951, S. $266 \mathrm{f}$ u. 55. Sitzung, 27.4 1951, S. 292 298; Deutscher Bundestag, 1. Wp. 1949-1953, Drucksache Nr. 2223, Ehard an Adenauer, 27.4. 1951, Anlagen-Bd. 11.

91 Gesetz zur Regelung der Wiedergutmachung nationalsozialistischen Unrechts für Angehörige des öffentlichen Dienstes v. 11.5. 1951, in: BGBI I, Nr. 21, 12.5. 1951, S. 291-296; Gesetz zur Regelung der Rechtsverhältnisse der unter Artikel 131 des Grundgesetzes fallenden Personen v. 11.5. 1951, in: BGBI I, Nr. 22, 13.5. 1951, S. 307-322.

92 Vgl. Wengst, Beamtentum, S.76; Gnirs, Wiedergutmachung im öffentlichen Dienst, S. $300 \mathrm{f}$.

93 Vgl. Gnirs, Wiedergutmachung im öffentlichen Dienst, S. 301; Georg Herbert, Entschädigungsrechtsprechung und Grundgesetz, in: Rechtsprechung zum Wiedergutmachungsrecht (RzW) 30 (1979), S. 81-94.

94 Friedrich Zietsch (bayer. Finanzminister) an Bundesinnenminister Lehr, 29.9. 1952, BA, B 106/62773. 
Zudem haperte es manchenorts an einer loyalen Durchführung der Wiedereinstellung der verfolgten Beamten. Wie Eugen Budde namens des BVN beklagte, gebe es „Pg-Mehrheitsgruppen in einigen Behörden, die dies verhindern wollen, um insbesondere die höheren Etatstellen unter sich verteilen zu können “95. Ein prominentes Beispiel dafür war das Auswärtige Amt ${ }^{96}$, wo der hohe Anteil ehemaliger Nationalsozialisten unter den Mitarbeitern schließlich sogar einen eigenen Bundestags-Untersuchungsausschuß veranlaßte ${ }^{97}$. Als bei einer Umfrage unter den Bundesressorts nach der Zahl der bei ihnen beschäftigten Berechtigten nach dem BWGöD gefragt wurde, gab wiederum ausgerechnet das Auswärtige Amt die mit weitem Abstand höchste Zahl an. Auch im Bundesinnenministerium, das die Umfrage veranstaltet hatte, schüttelte man über diese erstaunliche Auskunft den Kopf ${ }^{98}$.

Das Bundeskabinett kam dem Drängen des BVN auf Erlaß von Richtlinien zur Verbesserung dieser Situation nur zum Teil nach"9. Die Klagen über die Bevorzugung ehemaliger Pg-Beamter gegenüber den ehemals verfolgten Beamten bei der Wiedereinstellung hielten zunächst auch weiterhin an ${ }^{100}$. So trägt das BWGöD ein Janusgesicht: Betrachtet man es aus der Perspektive der Wiedergutmachung für die übrigen Verfolgten des Nationalsozialismus, so erscheint die darunter fallende Gruppe der verfolgten Beamten als außerordentlich privilegiert. Aus der Perspektive der 131er-Regelung fallen hingegen die Benachteiligungen dieser Gruppe ins Auge, die weniger im Text des Gesetzes, als in der Praxis hie und da auftraten. Dies entspricht im ganzen dem Charakter des BWGöD als einem kompensatorischen Ausgleich für die Regelung der 131erAnsprüche.

\section{Wiedergutmachung und Souveränität: Rückerstattung und Entschädigung bei der Revision des Besatzungsstatuts}

\section{Alliierte Konflikte um ein deutsches Wiedergutmachungsprogramm}

Neben diesen innenpolitischen Vorgängen gewannen aber zu Beginn der fünfziger Jahre erneut außenpolitische Faktoren erheblichen Einfluß auf die weitere Entwicklung der Wiedergutmachung in der Bundesrepublik. Wesentliche Anstöße erfolgten vor allem im Rahmen der Verhandlungen über den Deutschlandvertrag und die Ablösung der alliierten Vorbehaltsrechte im Besatzungsstatut. Von Anfang an hatte bei den Alliierten das Ziel bestanden, diese Reservatrechte im Zuge einer Selbstliquidation schrittweise aufzugegeben ${ }^{101}$. Auf der Londoner Konferenz der drei Außenminister im Mai

95 Eugen Budde (BVN) an die Innenministerien der Länder, 7. 12. 1950, HessHStA, Abt. 503, Nr. 473.

96 Budde an Hallstein, 22. 12. 1951 (Abschrift von Lütsches, 28. 12. 1951), BA, B 106/62773.

97 Siehe dazu Deutscher Bundestag, 1. Wp. 1949-1953, Drucksache 3465, Schriftlicher Bericht des Untersuchungsausschusses (47.Ausschuß) gem. Antrag der Fraktion der SPD betr. Prüfung, ob durch die Personalpolitik Mißstände im Auswärtigen Dienst eingetreten sind (Drs. 2680), 18.6. 1952, Anlagen-Bd. 18.

98 Vorlage von Hermann (Bundesinnenministerium) an Lehr, 19.3. 1952, BA, B 106/62773.

99 118. Kabinettssitzung am 21.12. 1950, in: Kabinettsprotokolle der Bundesregierung, Bd. 2, S. $907 ; 164$. Kabinettsssitzung am 26.7. 1951, ebenda, Bd. 4, S.564. Vgl. auch Mitteilungsblatt des Landesausschusses der politisch Verfolgten, Nr.51, 1.3. 1951, „Bevorzugte Einstellung politisch Verfolgter in den Bundesdienst“.

$100 \mathrm{Vgl}$. Mitteilungsblatt des Beirats für Wiedergutmachung, Nr.64, Mai 1952, „Ein Jahr Wiedergutmachung für Angehörige des öffentlichen Dienstes. Ein Gesetz, das niemand befriedigt “"

101 Vgl. Ludolf Herbst, Option für den Westen. Vom Marshallplan bis zum deutsch-französischen Vertrag, München 1989, S. 111; Elmer Plischke, Revision of the Occupation Statute for Germany. September 21, 1949 
1950 wurde deshalb die Gründung der Intergovernmental Study Group on Germany (ISG) beschlossen, die Vorschläge über das Vorgehen bei der zu gegebener Zeit avisierten Ablösung des Besatzungsstatuts ausarbeiten sollte ${ }^{102}$.

Von Juli 1950 bis Mai 1951 berieten die Delegationen der drei Westmächte in London über diese Fragen, wobei sie in ständigem Meinungsaustausch mit ihren heimischen Regierungen sowie der Alliierten Hohen Kommission in Deutschland standen. $\mathrm{Zu}$ einem der schwierigsten Punkte entwickelte sich bald die vorgesehene Ablösung der alliierten Vorbehaltsrechte im Bereich der „internal restitution“, die seit November in einem speziellen Unterausschuß, dem Restitution Committee, verhandelt wurde ${ }^{103}$. Die Schwierigkeiten entstanden hauptsächlich bei der Frage der Entschädigung, denn obgleich die Hohen Kommissare am 5. Mai 1950 gemeinschaftlich ein bundeseinheitliches Entschädigungsgesetz gefordert hatten ${ }^{104}$, waren sich die Alliierten allenfalls über die Notwendigkeit einer Bundesregelung, aber keineswegs über deren Umfang einig.

Das State Department und ebenso McCloy hielten im Prinzip eine Ausweitung des Entschädigungsgesetzes der US-Zone auf Bundesebene für die beste Lösung ${ }^{105}$. Die Vorstellungen der Briten und Franzosen liefen hingegen auf eine wesentliche Erweiterung des Kreises der Anspruchsberechtigten hinaus, denn sie wünschten, daß auch nichtdeutsche Verfolgte des Nationalsozialismus in eine künftige Bundesregelung aufgenommen würden. Paris sprach dabei nur von Verfolgungen auf deutschem Boden einschließlich der eingegliederten Gebiete und dachte dabei in erster Linie an die französischen Zwangsarbeiter. London hingegen wollte deutsche Handlungen in den vom Deutschen Reich besetzten Gebieten mit einschließen ${ }^{106}$. Dies hätte die Sprengung des strengen Territorialitätsprinzips, das sich in der Bundesrepublik bislang entwickelt hatte, bedeutet. Die USA widersetzten sich jedoch den Wünschen ihrer Partner nach Ausdehnung des entschädigungsberechtigten Personenkreises. Im State Department hieß es, daß die Bundesrepublik durch ein derartig ausgeweitetes Entschädigungsprogramm finanziell weit überfordert würde, wobei der Gedanke an die künftigen Verteidigungslasten der Bundesrepublik ein wichtige Rolle spielte. Hier wurde strikt zwischen Schäden in Folge rassischer, religiöser und politischer Verfolgung und solchen, die auf Kriegsfolgen zurückgingen, unterschieden. Letztere waren nach amerikanischer Auffassung durch das Pariser Reparationsabkommen größtenteils endgültig geregelt und durften deshalb nicht zum Gegenstand einer solchen Entschädigungsregelung wer$\operatorname{den}^{107}$.

- March 7, 1951, Historical Division, Office of the Executive Secretary, Office of the U.S. High Commission for Germany, 1952, S. 15.

102 Siehe dazu Foreign Relations of the United States (FRUS), 1950, Bd. IV: Central and Eastern Europe; The Soviet Union, Washington 1980, S.737f. (Editorial Note). Vgl. auch Plischke, Revision of the Occupation Statute, S. $15 f$.

103 Amerikanischer Delegierter war Jacques Reinstein, der bereits an den ersten Entschädigungsdiskussionen des State Department 1943/44 sowie bei der Verhandlung des Pariser Reparationsabkommens 1945/46 beteiligt gewesen war.

104 Vgl. oben, Abschnitt I. 1.

105 Siehe dazu etwa State Department an Embassy London, 28. 8. 1950, USNA, RG 59, 262.0041/8-2950; McCloy an Acheson, 8.12. 1950, USNA, RG 59, 262.0041/12-850.

106 Douglas (London) an Acheson, 1.8. 1950, USNA, RG 59, 396.1-ISG/8-150; Holmes (London) an Acheson, 7.9. 1950, USNA, RG 59, 396.1-ISG/9-450.

107 Acheson an Embassy London, 4.12. 1950, USNA, RG 59, 396.1-ISG/11-2650; Frederick A.O. Schwarz (HICOG/General Counsel) an State Department, 24.11. 1953, Enclosure C: Chronological Developments Leading to the Allied-German Agreement set forth in Chapter Four "Compensation for Victims of Nazi Persecution" of the Settlement Convention, USNA, RG 59, 262.0041/9-2453. 
London und Paris akzeptierten schließlich widerwillig, daß die Entschädigung für nationalsozialistische Verfolgung und für Kriegsfolgen strikt voneinander abgegrenzt werden sollten. Das bedeutete den Ausschluß der französischen Zwangsarbeiter und aktiven Widerstandskämpfer, deren Schicksal als „normale“ Kriegsfolge definiert wurde. Doch bestanden die Franzosen dafür auf der Einbeziehung von etwa 300.000 französischen Juden und ca. 280.000 politischen Verfolgten, zu denen sie unter anderem Geiseln, die unter Verletzung der Haager Konvention verfolgt worden waren, rechneten. Die Briten hielten ihrerseits daran fest, daß die Bundesrepublik alle Personen entschädigen müsse, die auf dem Reichsgebiet einschließlich Österreichs oder ElsaßLothringens und jedes anderen annektierten Gebiets verfolgt worden waren und die nun auf dem Gebiet der Bundesrepublik oder eines westlichen Lands einschließlich Österreichs lebten. Zudem lehnte London wie Paris strikt ab, irgendwelchen Vorschlägen zuzustimmen, die Personen diskriminierten, die auf deutschem Boden aus rassischen, religiösen oder politischen Gründen verfolgt worden waren. Die Franzosen standen hierbei nach eigenem Bekunden unter erheblichem innenpolitischen Druck, weshalb sie eher bereit waren, das ganze Projekt einer bundeseinheitlichen Entschädigungsregelung fallen zu lassen als einer solchen Diskriminierung zuzustimmen. Die Betroffenheit reichte hier bis in höchste politische Kreise. So war etwa Pierre de Gaulle, der Bruder von General de Gaulle, ein Opfer deutscher Sippenhaft gewesen, und auch etwa Léon Blum oder der Erzbischof von Montaubon hatten zu den politischen Gefangenen des Deutschen Reiches gezählt ${ }^{108}$. Aber auch die britische Delegation verwies darauf, daß ihre Position durch Zugeständnisse an britische Gruppen festgelegt sei ${ }^{109}$, wozu etwa Emigranten und ehemalige Angehörige der polnischen Exilarmee gehörten ${ }^{110}$.

So steckten die Verhandlungen der ISG Ende 1950 vor allem in der Frage des Entschädigungsgesetzes in einer Sackgasse ${ }^{111}$. Der Zwischenbericht des Fachausschusses an den Koordinierungsausschuß vom 24. November nannte als notwendige Bedingungen für die Aufhebung der Vorbehaltsrechte den „Erlaß eines zufriedenstellenden Entschädigungsgesetzes durch die Bundesrepublik“, wobei die Bedeutung des Begriffes „zufriedenstellend“ ungeklärt blieb. Damit hatte sich der Ausschuß zu einer diplomatischen Leerformel geflüchtet, um die tatsächliche Uneinigkeit notdürftig zu kaschieren. Eindeutig war hingegen die Forderung, die Bundesrepublik müsse die bestehende alliierte Gesetzgebung im Bereich der inneren Rückerstattung beibehalten und durchführen $^{112}$. Auch als Ende Januar 1951 die Verhandlungen im Restitution-Committee der ISG wiederaufgenommen wurden, blieben die alliierten Differenzen in der Frage der Entschädigung bestehen. Weiterhin versuchten die USA in erster Linie eine Ausdehnung des Standards der US-Zone auf die übrigen Zonen zu erreichen ${ }^{113}$, während vor allem die Briten hartnäckig an der Einbeziehung im Ausland lebender Verfolgter, besonders der DP's und Emigranten, festhielten ${ }^{114}$. Auch die französischen Delegierten

108 Siehe dazu Hermann Brill im Protokoll der 267. Sitzung des Bundestags-Ausschusses für Rechtswesen und Verfassungsrecht, 13.6. 1953, BA, B 136/620.

${ }^{109}$ Douglas (London) an Acheson, 13.11. 1950, USNA, RG 59, 396.1-ISG/11-1350.

110 F.A.O. Schwarz an State Department, 24.9. 1953, USNA, RG 59, 262.0041/9-2453.

111 Julius C. Holmes (London) an Acheson, 19. 11. 1950, USNA, RG 59, 396.1-ISG/11-1950.

112 Holmes an Acheson, 25. 11. 1950, USNA, RG 59, 396.1-ISG/11-2450.

113 Acheson an US-Botschaft in London und HICOG Frankfurt, 26. 1. 1951, USNA, RG 59, 262.0041/1-1251.

114 Walter A. Gifford (London) an Acheson, 7.3. 1951, USNA, RG 59, 396.1-ISG/3-751. 
blieben dabei, keine alliierte Forderung nach Entschädigung zu akzeptieren, die nicht alle Verfolgten des Nationalsozialismus - d. h. auch ihre Landsleute - einschloß ${ }^{115}$.

Weniger Schwierigkeiten bereitete die Frage der Rückerstattung. Wie gesagt, waren sich die drei Mächte bereits zu Beginn der Gespräche darüber einig geworden, daß die unveränderte Durchführung der alliierten Rückerstattungsgesetze gewährleistet bleiben müsse. Allerdings kam das Restitution Committee zu der Auffassung, daß die „alliierten Review Boards über die innere Rückerstattung nach der Beendigung der Vorbehaltsrechte nicht erhalten bleiben können" ${ }^{116}$. Hier waren die Alliierten also zu einem gewissen Entgegenkommen gegenüber den deutschen Wünschen bereit. Doch wurde jede mögliche Abschwächung der bisherigen Regelungen von heftigen Protesten der jüdischen Organisationen begleitet, die diese Verhandlungen aufmerksam beobachteten und durch zahlreiche Petitionen und Delegationen zu beeinflussen suchten ${ }^{117}$.

Der Abschlußbericht der ISG an die Regierungen zur Frage der Vorbehaltsrechte im Bereich der Restitutionen vom 4. Mai 1951 empfahl schließlich, die Bundesregierung zu verpflichten, alle bestehenden alliierten Gesetze und Bestimmungen im Bereich der inneren Rückerstattung zu erhalten und durchzuführen. Allerdings schlug er vor, an Stelle der bisherigen zonalen obersten Boards of Review ein gemeinsames gemischtes Gericht zu setzen, in dem auch eine deutsche Minderheitsbeteiligung vorgesehen war. In der Frage der Entschädigung konnte der Bericht jedoch nur einen Fehlschlag vermelden, da sich das Restitution Committee bis zum Schluß nicht zu einigen vermocht hatte, welche Maßnahmen von den Deutschen zur Beseitigung der Lücken der Entschädigungsgesetzgebung gefordert werden sollten. Weiterhin lehnten die USA, die vor allem die finanzielle Belastung der Bundesrepublik im Auge hatten, die aus dem starken Druck heimischer Verfolgtengruppen resultierenden Wünsche ihrer Alliierten ab, die eine wesentliche Ausweitung des entschädigungsberechtigten Kreises zur Folge gehabt hätten. So blieb als Minimalkonsens nur die Feststellung, daß in den vertraglichen Abmachungen über die ,internal restitution“ die Bundesregierung verpflichtet werden sollte, ,jegliche zu diesem Zeitpunkt existierende Entschädigungsgesetzgebung zu erhalten und durchzuführen “118. Deutliches Zeichen der alliierten Ratlosigkeit war, daß sie sich Fortschritte bei der Einigung auf einen gemeinsamen Standpunkt ausgerechnet aus Anstößen bei den kommenden Gesprächen mit der deutschen Seite erhofften ${ }^{119}$.

Von Mai bis August 1951 führte ein Sonderausschuß der Alliierten Hohen Kommission mit der durch Wilhelm Grewe geleiteten deutschen Delegation zur Ablösung des Besatzungsstatuts Vorgespräche über die Beendigung der alliierten Vorbehaltsrechte ${ }^{120}$. Wilhelm Grewe, Professor für öffentliches Recht und Völkerrecht in Freiburg, sprach in seinen Erinnerungen von einer anfänglich bedrückenden Atmosphäre: „Nach dem 10. Mai 1951 fuhr ich mit meinen Begleitern regelmäßig einmal in der Woche zur Sitzung

115 Gifford an Acheson, 19.4. 1951, USNA, RG 59, 396.1-ISG/4-1951.

116 Holmes an Acheson, 12.12. 1950, USNA, RG 59, 396.1-ISG/12-1150.

117 Siehe als ein Beispiel unter vielen American Jewish Committee, American Joint Distribution Committee, Jewish Agency for Palestine, World Jewish Congress an McCloy, 31.7. 1951, USNA, RG 59, 262.0041/8251; sowie Unterlagen in YIVO-Archiv, RG 347, AJC-Records, GEN-10, Box 282 u. 291.

118 Intergovernmental Study Group on Germany, Report to Governments by Heads of Delegations on the Reserved Power with Respect to Restitution, (IGG/P(51)89 Final), Appendix I, 4.5. 1951, USNA, RG 59, 396.1-[SG/7-2751.

119 Siehe dazu auch Gifford an Acheson, 19.4. 1951, USNA, RG 59, 396.1-ISG/4-1951.

120 Vgl. dazu Kabinettsprotokolle der Bundesregierung, Bd. 4, Einleitung, S. XXIX. 
auf den Petersberg. Was sich dort abspielte, verdient allerdings kaum die Bezeichnung 'Verhandlung'. "121 Tatsächlich ging es den Alliierten in diesen Gesprächen in erster Linie darum, die deutschen Positionen zu ihren eigenen Vorschlägen kennenzulernen. Doch die von Grewes Ausführungen suggerierte absolute Bedeutungslosigkeit der deutschen Vorstellungen trifft zumindest für den Bereich der Wiedergutmachung nicht zu.

So waren die Alliierten zur Klärung der bei den ISG-Verhandlungen offen gebliebenen Fragen geradezu brennend an der deutschen Haltung zur Rückerstattung und Entschädigung interessiert. Doch zu ihrer Enttäuschung wollte Grewe, dessen Verhandlungsführung durch einen im Auswärtigen Amt gebildeten Koordinierungsausschuß unter Leitung Walter Hallsteins gelenkt wurde ${ }^{122}$, am 18. Juli keine Stellungnahme zu dieser Frage abgeben, da der Rechtsausschuß des Bundestages seine gegenwärtig laufenden Beratungen noch nicht abgeschlossen habe ${ }^{123}$. Bei dieser Haltung blieb er auch, als ihm zwei Wochen später ein Memorandum der Alliierten Hohen Kommission zur Frage der Rückerstattung und Entschädigung, das sich weitgehend im Rahmen des ISG-Berichtes bewegte und somit den Umfang der geforderten Erweiterungen der Entschädigung nicht näher definierte ${ }^{124}$, zur Begutachtung vorgelegt wurde ${ }^{125}$.

Ähnlich einsilbig verhielt sich Grewe gegenüber den geforderten Verbesserungen der Entschädigung für DP's, die im Zusammenhang der Ablösung des Artikels 2(d) des Besatzungsstatuts, der die alliierten Vorbehaltsrechte im Bereich dieser Personengruppe regelte, stand. Bereits auf der New Yorker Außenministerkonferenz im September 1950 hatten die Alliierten ein Programm zum weiteren Abbau der Kontrollen des Besatzungsstatuts erstellt, das zugleich mit der ersten Revision des Besatzungsstatuts am 7. März 1951 als Decision No. 10 der Alliierten Hohen Kommission bekannt gemacht wurde. Diese forderte unter anderem als Voraussetzung für den Verzicht auf den Artikel 2(d) auch vorherige Maßnahmen der Bundesregierung zugunsten der Entschädigung der Opfer des Nationalsozialismus aus dem Kreis der DP's ${ }^{126}$. Am 5. Juli wurden Grewe und seine deutschen Kollegen erneut mit diesem Wunsch konfrontiert. Sie waren aber auch jetzt nicht bereit, eine Stellungnahme abzugeben, da die Angelegenheit noch im Zusammenhang der Entschädigungsgesetzgebung für deutsche Verfolgte beraten werde ${ }^{127}$.

Die Alliierte Hohe Kommission bilanzierte die Ergebnisse dieser Vorgespräche in einem Bericht an die drei Außenminister, in dem der alliierte und der deutsche Standpunkt in der Frage der Rückerstattung und Entschädigung sowie auch in der speziellen Frage der Entschädigung der DP's gegenübergestellt wurde. Entsprechend den Be-

121 Wilhelm G. Grewe, Rückblenden, 1976-1951, Frankfurt a.M. usw. 1979, S. 134.

122 Vgl. ebenda, S. $130 \mathrm{f}$.

123 Extract from SPCOM/FED/M (51)8, 18.7. 1951, USNA, RG 59, Records of the Central European Division 1944-53, Occupation Statute, Box 5.

124 Appendix "E“ to SPCOM/FED/M (51) 10, Internal Restitution, 1.8. 1951, USNA, RG 59, Records of the Central European Division 1944-53, Occupation Statute, Box 5.

125 Extract from SPCOM/FED/M (51)10, 3.8. 1951, USNA, RG 59, Records of the Central European Division 1944-53, Occupation Statute, Box 5.

126 Decision No. 10. Program for the Revision of Occupation Controls, Art. 2(b), in: Plischke, Revision of the Occupation Statute, S. 80. Vgl. dazu auch François-Poncet an Adenauer, 20.3. 1951, Anlage: Relinquishment of the Reserved Powers under Paragraph 2(d) of the Occupation Statute, USNA, RG 59, Records of the Central European Division 1944-53, Occupation Statute, Box 5.

127 SPCOM/FED/Memo (51)12, 6.7. 1951, USNA, RG 59, Records of the Central European Division 1944-53, Occupation Statute, Box 5. 
schlüssen der Brüsseler Außenministerkonferenz vom Dezember 1950 sollten die alliierten Vorbehaltsrechte im Bereich der Rückerstattung und Entschädigung künftig durch vertragliche Abmachungen mit der Bundesrepublik ersetzt werden. Soweit es die Forderung nach Verbesserung der Entschädigung betraf, verwiesen die Hohen Kommissare auf die ungelösten Streitpunkte der ISG. Auch im Bereich der Rückerstattung hielten sie sich an die bereits in London beschlossenen Grundsätze, abgesehen von einer nicht unbedeutenden Erweiterung: Sie forderten, daß die Bundesregierung verpflichtet werden müsse, für die geldlichen Rückerstattungsansprüche gegen das Reich aufzukommen - hier bestand bislang noch eine empfindliche Lücke im Rückerstattungsrecht. Für die deutsche Delegation vermerkte der Bericht hingegen nur, sie habe in diesen Punkten "keine Position“ eingenommen ${ }^{128}$. Entsprechend verhielt es sich auch bei der Zusammenstellung der Positionen zur Verbesserung der Entschädigung im Bereich der DP's ${ }^{129}$.

Hier zeigte sich nun in aller Deutlichkeit die Krux dieser Beratungen: Es existierte keine offizielle deutsche Politik zu diesen Fragen, die über ein bloßes Reagieren hinausgegangen wäre. Die Wiedergutmachungspolitik der Bundesregierung, das wird im folgenden wiederholt deutlich werden, erschöpfte sich überwiegend darin, Forderungen abzuwarten und dann soweit als möglich herunterzuhandeln. Die deutsche Seite hatte damit die Chance vertan, zu diesem Zeitpunkt die Initiative bei der Gestaltung der Konturen einer künftigen bundeseinheitlichen Entschädigungsregelung zu übernehmen, was angesichts der gegebenen Uneinigkeit der Alliierten, die geradezu auf solche Impulse gewartet hatten, sicherlich präjudizierende Wirkung gehabt hätte.

Im September 1951 trafen in Washington die Außenminister der drei westlichen Alliierten zusammen, um die Ergebnisse der Vorbesprechungen mit den Deutschen zu beraten. Bei dieser Gelegenheit beschlossen sie die endgültigen Anweisungen an die Hohen Kommissare über das weitere Vorgehen bei den bevorstehenden Verhandlungen über die Ablösung des Besatzungsstatuts durch einen Deutschlandvertrag. Dabei beabsichtigten die Alliierten, in einer Reihe von Zusatzverträgen ihre bisherigen Vorbehaltsrechte durch vertragliche Abmachungen zu ersetzen, wozu auch die inneren Restitutionen gehörten. Die Beschlüsse der drei alliierten Außenminister vom 13. September 1951 auf diesem Gebiet waren das erste und zugleich auch letzte Beispiel einer gemeinsamen alliierten grundsätzlichen Stellungnahme zur Frage der Wiedergutmachung.

Was die Rückerstattung anbelangte, so folgten die drei Außenminister den Empfehlungen, die aus den vorausgegangenen ausführlichen Beratungen resultierten. In erster Linie sollte die Durchführung der alliierten Rückerstattungsgesetze in den vertraglichen Abmachungen mit der Bundesrepublik gesichert werden, und zwar auf dem Mindestniveau der gegenwärtigen Gesetze. Bei der Entschädigung standen die Außenminister dagegen vor der Notwendigkeit, Kompromisse in den offen gebliebenen Fragen zu finden. Die Hohen Kommissare wurden daher angewiesen, vertraglich festzulegen, daß in den Ländern, in denen noch keine Entschädigungsgesetze bestanden, solche geschaffen werden sollten. Zudem sollte garantiert werden, daß die Entschädigungsgesetzge-

${ }^{128}$ Report of the Allied High Commission Concerning the Establishment of a new Relationship between the Allied Powers and Germany, 9. 8. 1951, Annex 7c: Internal Restitution (Occupation Statute, Para 2(b)), USNA, RG 59, 762A.00/8-951.

129 Ebenda, Annex 7(g), Displaced Persons and Refugees (Occupation Statute, Para. 2(d)). 
bung in der gesamten Bundesrepublik auf dem bisher günstigsten Niveau vereinheitlicht, durchgeführt und garantiert werde. Dies implizierte die Ausweitung der USZonen-Regelung auf das gesamte Bundesgebiet. Die umstrittene Einbeziehung ausländischer Verfolgter in die Entschädigung war dagegen in eine Formulierung gekleidet, die wortreich ihre tatsächliche Unverbindlichkeit vernebelte: „The High Commissioners should inform the Federal Chancellor and other appropriate German leaders that in the view of the Three Foreign Ministers, the failure of the Federal Republic thus far to provide any significant measure of compensation to victims of Nazi persecution, including those resident abroad, constitutes a major obstacle to the acceptance of the German people by the free peoples of the world as equal partners in their activities." Es sollte deshalb, so die Außenminister, nicht nötig sein, daß die alliierten Regierungen explizite Forderungen aufstellen müßten, die zur Erfüllung dieser moralischen Verpflichtung der deutschen Regierung erforderlich seien ${ }^{130}$.

Damit hatten sich die USA, die den Entwurf dieser Erklärung geliefert hatten ${ }^{131}$, weitgehend durchgesetzt: Die Ausweitung des Standards des US-Zonen-Gesetzes auf die Bundesrepublik war praktisch zur verbindlichen Verpflichtung erhoben worden, während die von britischer und französischer Seite geforderte Einbeziehung ausländischer Verfolgter nur als moralischer Imperativ und nicht als konkrete Verpflichtung formuliert war. Amerikanische Bedenken über die deutsche finanzielle Leistungsfähigkeit hatten hier den Ausschlag gegeben. Zudem wuchs im State Department das Bedürfnis, die Verantwortung für die Entschädigung der Verfolgten des Nationalsozialismus so weit als möglich auf die Deutschen abzuwälzen, nicht zuletzt, um sich endlich dem als lästig empfundenen Druck der Wiedergutmachungslobby zu entziehen ${ }^{132}$. Hierbei gerieten die USA aber in Konflikt mit ihren britischen und französischen Alliierten, die im Zuge der Ablösung des Besatzungsstatuts gern noch einige offene Rechnungen beglichen hätten. Dieser Gegensatz wurde auch durch die in Washington versammelten Außenminister nicht endgültig bereinigt.

130 Beschlüsse der drei Außenminister in Washington vom 13.9. 1951, zit. nach Aide-Memoire von Geoffrey W. Lewis (State Department) an Henri Ruffin (franz. Botschaft), 13. 10. 1953, USNA, RG 59, 262.0041, Box 1053. Der Vergleich mit dem in FRUS abgedruckten Entwurf der Beschlüsse vom 10.9. ergibt in den hier interessierenden Passagen wörtliche Übereinstimmung. Vgl. Draft Instructions From the Three Foreign Ministers to the AHC, Punkt 18 (Internal Restitution), 10. 9. 1951, in: FRUS 1951, Bd. III/1: European Security and the German Question, Washington, D.C., 1981, S. 1205.

131 State Department, Bureau of German Affairs, Draft Directive From the Foreign Ministers to the Allied High Commission on Contractual Arrangements, 21.8. 1951, WNRC, RG 466, Records of the U.S. High Commissioner for Germany (McCloy Papers), Box 30. Zur weiteren Entwicklung dieser Auffassung siehe auch Draft Instructions From the Three Foreign Ministers to the Allied High Commission, (WFM T-5a), 10.9. 1951, in: FRUS 1951 III/1, S. 1205.

132 Vgl. dazu unten, S. 250. 


\section{Die deutsch-alliierten Verhandlungen über das Überleitungsabkommen}

Am 24. September informierten die Hohen Kommissare Adenauer persönlich über den Inhalt der Washingtoner Außenminister-Beschlüsse ${ }^{133}$. Danach verhandelten sie bis zum 14. November mit der Bundesregierung über die Entwürfe eines Generalvertrags sowie einer Anzahl zusätzlicher Abkommen ${ }^{134}$. Schließlich ging es um die aus Krieg und Besatzung resultierenden Fragen, worunter auch die Rückerstattung und Entschädigung fielen. Die Gespräche im Bonner Vorort Mehlem verliefen auf drei Ebenen: Auf der untersten Ebene wurden Verhandlungsgruppen zur Behandlung der Einzelprobleme eingerichtet, dazu gehörte auch ein Ausschuß für „Innere Rückerstattung und Innere Wiedergutmachung “, der auf deutscher Seite durch Legationsrat von Trützschler ${ }^{135}$ vom Auswärtigen Amt und auf alliierter durch Eli W. Debevoise, dem Rechtsberater des amerikanischen Hohen Kommissars, geleitet wurde. Ungelöste Fragen gelangten vor den Koordinierungsausschuß, was auch dort strittig blieb, wurde schließlich zwischen Adenauer und den Hohen Kommissaren besprochen ${ }^{136}$.

Im Spätherbst 1951 überreichten die Alliierten die Entwürfe für Teil III (Rückerstattung) und Teil IV (Entschädigung) des Vertrages zur Regelung aus Krieg und Besatzung entstandener Fragen. Sie beruhten auf den Beratungen der ISG in London sowie dem Bericht der Hohen Kommissare an die Außenminister. In manchen Details gingen diese Entwürfe ein Stück über den Washingtoner Kompromiß hinaus und brachten einige der dort abgeblockten britischen und französischen Vorschläge wieder aufs Tapet. Der Entwurf für Teil III bestimmte in sieben Artikeln die Aufrechterhaltung und Durchführung der alliierten Rückerstattungsgesetze sowie die Verpflichtung der Bundesrepublik zur Übernahme der Rückerstattungsverbindlichkeiten des Deutschen Reiches ${ }^{137}$. Der Entwurf für Teil IV sah hingegen die deutsche Verpflichtung vor, eine angemessene Entschädigung für körperliche oder seelische Verletzung, Freiheitsberaubung, Schädigung der finanziellen Aussichten und des Eigentums (mit Ausnahme des wiederauffindbaren Eigentums) für Opfer des Nationalsozialismus ohne Diskriminierung irgendwelcher Gruppen oder Klassen zu gewährleisten. Dazu sollte die Bundesrepublik unter anderem die Länderentschädigungsgesetze beibehalten sowie „eine bundesgesetzliche Regelung zur Änderung oder totalen Ablösung dieser Vorschriften“ bewerkstelligen, „wobei die bisher geltende günstigste Landesregelung maßgebend sein sollte“ ${ }^{138}$.

133 Statement by André François-Poncet (HICOG-Chairman) to Adenauer Concerning the Agreements Reached at Washington, 24.9. 1951, in: FRUS 1951 III/2, S. 1532.

134 Vgl. Kabinettsprotokolle der Bundesregierung, Bd. 4, Einleitung, S. XXX.

135 Blankenhorn hatte zunächst die Ansprüche des Bundesfinanzministeriums auf Besetzung dieses Postens abgeblockt. Dort bestand eine „äußerst reservierte Haltung“ gegenüber den Forderungen der AHK. Siehe v. Trützschler an Hallstein, 27.10. 1951, PA/AA, II 241-27g, Bd. 1. Gleichwohl spielte das Bundesfinanzministerium, das in diesem Ausschuß durch Ministerialrat Kuschnitzky vertreten war, bei diesen Gesprächen eine sehr dominante Rolle.

136 Grewe, Rückblenden, S. 146f. Vgl. zu den Verhandlungen auch Ernst Féaux de la Croix, Internationalrechtliche Grundlagen der Wiedergutmachung, in: ders. u. Helmut Rumpf, Der Werdegang des Entschädigungsrechts unter national- und völkerrechtlichem und politologischem Aspekt, München 1985, S. 128-136.

137 Alliierter Entwurf zur Erörterung mit der deutschen Berichterstattergruppe, SPCOM/P(51)23(C), 8.11. 1951, Abkommen über Maßnahmen und gewisse Interessen der drei Mächte und die Übertragung bestimmter Befugnisse auf die Bundesrepublik, Teil III, Innere Restitution, PA/AA, II 241-27 g, Bd. 1.

138 Alliierter Entwurf zur Erörterung mit der deutschen Expertengruppe, SPCOM/P(51)23(D), 29. 10. 1951, Vereinbarung über Maßnahmen und einzelne Interessen der drei Mächte und die Übertragung bestimmter Verantwortlichkeiten auf die Bundesrepublik, Teil IV, Entschädigung für die Opfer der Nazi-Verfolgung, PA/AA, II 241-27 g, Bd. 1 . 
Zunächst waren die Deutschen nur widerwillig bereit, diese Fragen überhaupt mit den Alliierten zu diskutieren, sie bezweifelten, ob diese in den Geltungsbereich des Besatzungsstatuts fielen ${ }^{139}$. Da die alliierten Entwürfe bei den am 1. Dezember beginnenden Besprechungen im Ausschuß für Innere Wiedergutmachung fertig auf dem Tisch lagen, blieb den Deutschen schließlich aber nichts anderes übrig, als zu versuchen, „dem alliierten Entwurf einige „Giftzähne zu ziehen und ihn den deutschen Vorstellungen anzunähern" ${ }^{140}$, wie Grewe mit Bezug auf das Gesamtpaket der alliierten Forderungen formulierte. Dabei kristallisierten sich alsbald einige zentrale Konfliktpunkte heraus.

Im Bereich der Entschädigung war vor allem die Frage der Einbeziehung der sogenannten Nationalverfolgten kontrovers. Sie ließ die Verhandlungen im Januar 1952 ins Stocken geraten. Die Alliierten hatten auf britische und französische Veranlassung hin zunächst gefordert, daß „Verfolgung aus Gründen der Nationalität“ unter die Entschädigungsgründe aufgenommen werden sollte, um eine angemessene Entschädigung für Verfolgte im Ausland und Flüchtlinge (einschließlich nichtrepatriierbarer Polen usw.) zu erreichen. Dagegen wehrte sich die deutsche Delegation mit Händen und Füßen. Schließlich schlug sie einen Kompromiß vor, wonach Nationalverfolgte nur unter der Bedingung entschädigt werden sollten, daß ihnen unter schwerer Mißachtung der Menschenrechte ein dauernder Gesundheitsschaden zugefügt worden sei. Falls jedoch ihr Heimatstaat bereits Entschädigung für Kriegs- und Besatzungsschäden geleistet habe, sollten die Betroffenen nur entschädigt werden, sofern sie als politische Flüchtlinge nicht mehr länger unter dem Schutz ihres Heimatstaates stünden ${ }^{141}$.

Die deutsche Delegation stützte ihre Auffassung mit ähnlichen Argumenten, wie sie in den vorangegangenen interalliierten Verhandlungen auch von den USA gegen den von Paris und London geförderten Wunsch nach Einbeziehung der Nationalverfolgten vorgebracht worden waren: Eine Entschädigungspflicht bestehe nicht, wenn die Verfolgungen kriegsbedingt gewesen seien, zumal solche Forderungen im Rahmen der Reparationsabkommen von Potsdam und Paris kollektiv geregelt worden seien. Der Kern der Argumentation war auch hier, daß zwischen den Folgen des Krieges und denen der nationalsozialistischen Verfolgung streng unterschieden werden müsse ${ }^{142}$. Auch Otto Küster hatte in dieser Frage der deutschen Delegation den Rücken gestärkt und geschrieben, durch die Einbeziehung der Nationalverfolgten würden „die beiden grundverschiedenen Vorstellungen Wiedergutmachung und Kriegsentschädigung miteinander vermengt und die Wiedergutmachung würde ... im allgemeinen Bewußtsein zu einer Folge des verlorenen Kriegs“ “143. Daß gleichwohl für einen kleinen Kreis der Nationalverfolgten eng begrenzte Leistungen angeboten wurden, war demnach in den

139 Report by the Allied High Commission for Germany to the Foreign Ministers of the United States, France, and the United Kingdom on the Status of Contractual Negotiations with the Federal Republic of Germany, 17. 11. 1951, in: FRUS 1951 11I/2, S. 1589. Zu diesen häufig wiederkehrenden deutschen Bedenken vgl. auch Fünftes Kapitel, Abschnitt II. 2.

140 Grewe, Rückblenden, S. 146.

141 Niederschriften über die Besprechungen des Unterausschusses „Innere Rückerstattung und Innere Wiedergutmachung“, 1.12. u. 14. 12.1951 sowie 9.1. u. 15.1. 1952, PA/AA, Il 241-27g, Bd. 1 u. 2; Chronological Developments Leading to the Allied-German Agreement set forth in Chapter Four "Compensation for Victims of Nazi Persecution" of the Settlement Convention, Encl. C. zu F.A.O. Schwarz an State Department, 24.9. 1953, S. 4, USNA, RG 59, 262.0041/9-2453.

142 Ebenda.

143 Küster an Auswärtiges Amt, z.Hd. Wolff (Bundesfinanzministerium) u. Roemer (Bundesjustizministerium), 21. 12. 1951, PA/AA, II $241-27 \mathrm{~g}, \mathrm{Bd}$. 1 . 
Augen der deutschen Delegation eine Übererfüllung des rechtlich Gebotenen, die allein auf humanitären Erwägungen beruhe ${ }^{144}$.

Vor allem die französische Delegation, die in dieser Frage strikte Anweisungen ihrer Regierung besaß, lief gegen diese Auffassung Sturm. Ihr war besonders daran gelegen, die Ansprüche zahlreicher französischer Verfolgter, die wegen ihrer Nationalität in deutsche Konzentrationslager verschleppt worden waren, wenigstens zum Teil durchzusetzen ${ }^{145}$. Wähnten sich die Deutschen in dieser Frage einer alliierten Einheitsfront gegenüber, klafften die Meinungen ihrer Verhandlungspartner tatsächlich weiterhin stark auseinander. Washington war in diesem Punkt der heimliche Verbündete Bonns. Dort teilte man die rechtlichen Bedenken gegen die Einbeziehung der Nationalverfolgten und befand sogar: „Moreover, the German formulation by providing for compensation to political refugees who cannot share in the reparations share of their governments is more generous than the U.S. would have demanded but is a welcome addition. "146

Am liebsten hätte das State Department auch den Zusatz gestrichen, die Entschädigung müsse "angemessen" sein, denn damit, so Acheson, würden sich die Alliierten nur unnötigerweise Schwierigkeiten aufhalsen, indem sie in der Frage, was angemessen sei und was nicht, eine gewisse Mitverantwortung übernähmen. Dagegen wollte das State Department endlich von seiner Rolle als Adressat für Wiedergutmachungsforderungen loskommen: "The Department feared that the inclusion of this word in Chapter Four of the Settlement Convention would continue to subject the U.S. to pressure from many sources to force and amendment of the German Compensation Laws. “ ${ }^{147}$ Nachdem aber die deutsche Delegation dem französischen Drängen in dieser Frage nachgegeben hatte, verzichtete McCloy auf weiteren Widerstand, da die Streichung des ,angemessen" zu diesem Zeitpunkt den Deutschen Anlaß zu Fehlinterpretationen gäbe ${ }^{148}$.

Mit der Forderung nach genereller Einbeziehung der Nationalverfolgten konnte sich die französische Delegation jedoch nicht durchsetzen, zumal auch die Briten sich schließlich der amerikanischen Auffassung annäherten ${ }^{149}$. So verständigten sich die Alliierten auf einen Kompromiß, der im Prinzip die deutsche Formulierung in etwas weiter gefaßter Form übernahm, worauf auch eine Einigung mit den Deutschen nicht mehr schwierig war. Statt „unter gröblicher Mißachtung der Menschenrechte", wie diese vorgeschlagen hatten, einigte sich der Ausschuß auf „unter Mißachtung der Men-

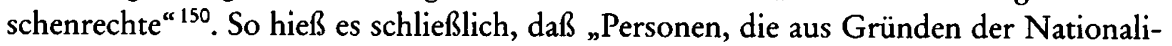
tät unter Mißachtung der Menschenrechte verfolgt wurden und gegenwärtig politische Flüchtlinge sind, die den Schutz ihres früheren Heimatlandes nicht mehr genießen, eine angemessene Entschädigung erhalten, soweit ihnen ein dauernder Gesundheitsschaden zugefügt worden ist ${ }^{\alpha 151}$.

Was vordergründig wie ein Verhandlungserfolg der deutschen Delegation aussah,

144 Niederschriften über die Besprechungen des Unterausschusses „Innere Rückerstattung und Innere Wiedergutmachung“, 9.1. u. 15.1. 1952, PA/AA, II 241-27g, Bd. 2; Chronological Developments Leading to the Allied-German Agreement, 24.9. 1953 (Anm. 141).

145 Draft Minutes of Allied-German Meeting held at Mehlem on February 1, 1952, zit. nach Chronological Developments Leading to the Allied-German Agreement, 24.9. 1953 (Anm. 141), S. 5.

$146 \mathrm{Vgl}$. Acheson an HICOG Bonn, 24. 1. 1952, USNA, RG 59, 262.0041/1-2552.

147 Ebenda.

148 McCloy an Acheson, 1.2. 1952, USNA, RG 59, 262.0041/2-152.

149 Ebenda.

150 Niederschrift über die 7. Besprechung des Unterausschusses „Innere Rückerstattung und Innere Wiedergutmachung" am 27.2. 1952, PA/AA, II 241-27g, Bd. 3.

151 Vertrag zur Regelung aus Krieg und Besatzung entstandener Fragen, Vierter Teil, Entschädigung für Opfer 
war in erster Linie auf die Tatsache zurückzuführen, daß die amerikanische Position in diesem Punkt weitgehend identisch mit der deutschen war, auch wenn dies durch den Zwang zu einem geschlossenen alliierten Auftreten gegenüber den Deutschen nach außen hin nicht so deutlich geworden war. Die Franzosen fanden sich aber mit dieser Niederlage nicht endgültig ab, und so erklärte der französische Delegierte Patey, seine Regierung behalte sich vor, "nach Unterzeichnung des Vertragswerkes in einem Brief an den Herrn Bundeskanzler alle Rechte geltend zu machen, auf die die französische Regierung glaubt, bei einer endgültigen Schuldenregelung mit der Bundesrepublik (möglicherweise in einem Friedensvertrag) Anspruch zu haben“152.

Schwieriger als die Einigung auf die deutschen Maßnahmen im Bereich der Entschädigung war die Verständigung bei der Rückerstattung. Auch die deutsche Delegation empfand es als „auffallend, daß die Alliierten das Schwergewicht auf die Restitutionen und nicht auf die Entschädigung legen“. Dahinter vermutete sie zu Recht den in dieser Frage stärkeren Druck interessierter Kreise in Washington und London ${ }^{153}$. Hinzu kam, daß in der Frage der Entschädigung weiterhin beträchtliche interalliierte Differenzen bestanden, was auch auf ihr gemeinsames Auftreten gegenüber den Deutschen ausstrahlte.

Die Auseinandersetzung um die Rückerstattung konzentrierte sich vor allem auf zwei Punkte. Ein erstes großes Problem ergab sich aus der Zusammensetzung der obersten Rückerstattungsgerichte, in denen bislang in der amerikanischen und britischen Zone ausschließlich alliierte Richter saßen, während in der französischen Zone eine gemischte deutsch-französische Kammer existierte. Bei den alliierten Verhandlungen der ISG in London sowie der Hohen Kommissare hatte sich ein Konsens herausgebildet, nach Möglichkeit ein gemischtes deutsch-alliiertes oberstes Rückerstattungsgericht einzurichten, wobei jedoch die alliierten Richter die Mehrheit behalten sollten. Gegen diese Pläne unternahmen die jüdischen Organisationen und ihnen gewogene Abgeordnete des US-Kongresses eine Vielzahl von Interventionen im State Department und bei den Hohen Kommissaren. Dazu gehörte auch ein Besuch von Vertretern mehrerer jüdischer Organisationen am 18. September im State Department, bei dem diese darauf drängten, daß die bisherigen alliierten Gerichte auch künftig beibehalten werden sollten. Doch Jacques Reinstein aus der Deutschlandabteilung verteidigte die geplanten gemischten Gerichte und unterstrich, wenn es nach ihm ginge, erhielten die Deutschen sogar Parität bei der Besetzung dieser Kammern: „Persons intimately familiar with the German scene are convinced that Allied courts are untenable, and accordingly the Department is not prepared to demand them. “154

Eine gute Woche später sprach auch eine Abordnung einer Anzahl amerikanischer Verfolgten-Organisationen in dieser Sache vor. Wie Henry Byroade, der Leiter der Deutschlandabteilung, bei dieser Gelegenheit erklärte, akzeptierte das State Department zwar ihre Forderung nach Beibehaltung der alliierten Rückerstattungsgesetze

der nationalsozialistischen Verfolgung, Abs.1, Verträge der Bundesrepublik Deutschland, Serie A: Multilaterale Verträge, Nr. 62-68, Bd. 7, hrsg. v. Auswärtigen Amt, Bonn usw. 1957, S. 279.

152 Niederschrift über die 7. Besprechung des Unterausschusses „Innere Rückerstattung und Innere Wiedergutmachung" am 27.2. 1952, PA/AA, II 241-27g, Bd. 3.

153 Aufzeichnung v. Brückner für v. Trützschler, 20.12. 1951, PA/AA, II 241-27g, Bd. 1.

154 Department of State, Memorandum of Conversation, 18.9. 1951, Lewis, Reinstein u. Baker (State Department) mit Seymour Rubin (AJDC), Bowles (WJC), Rock (JRSO), USNA, RG 59, 262.0041/9-1851. 
sowie nach einem Verbot eines Wiederaufrollens bereits abgewickelter Fälle, doch die Forderung, die alliierten Gerichte beizubehalten, schlug er auch ihnen ab. Verständnis dafür versuchte er durch Hinweise auf den politischen Hintergrund zu gewinnen: Der kritische Punkt der Überleitungsverträge sei die Zustimmung des Bundestags. „If the government should fail on that vote, the coalition would be destroyed and it is extremely doubtful that we could get a better government. Furthermore the defense of Europe may hang on this vote ${ }^{* 155}$. Um angesichts des massiven Drängens dieser Organisationen wenigstens guten Willen zu zeigen, teilte das State Department McCloy mit, man halte die Beibehaltung der alliierten Gerichte zwar nicht für opportun, doch könne er auf eigene Verantwortung einen Versuch in dieser Richtung unternehmen ${ }^{156}$. Weder die Briten noch die Franzosen waren von dieser Idee angetan, doch willigten sie ein, wenigstens einen Versuchsballon zu starten. Da sich dabei herausstellte, daß die Fortführung alliierter oberster Rückerstattungsgerichte nach dem Ende des Besatzungsstatuts für die Deutschen absolut indiskutabel war, wurde dieser Gedanke, der ohnehin auch auf alliierter Seite keine Freunde besaß, jedoch schnell begraben ${ }^{157}$.

Aber auch so war die Pille für die Deutschen bitter genug. Als die alliierte Delegation ihnen am 18. Dezember im Ausschuß für Innere Wiedergutmachung das geplante Statut eines obersten Rückerstattungsgerichts mit gemischter Zusammensetzung, aber alliierter Majorität vorlegte, herrschte dort herbe Enttäuschung, und so wurde die Frage an den Lenkungsausschuß weitergeleitet ${ }^{158}$. Briten und Franzosen waren ohnehin geneigt, den Deutschen in diesem Punkt nachzugeben und ein paritätisch besetztes deutschalliiertes Gericht mit neutralem Vorsitz hinzunehmen, wie sie in internen alliierten Diskussionen zu verstehen gaben. Überdies hatte bereits der Abschlußbericht der Hohen Kommissare nach den Vorgesprächen einen Verhandlungsspielraum in dieser Frage konzediert ${ }^{159}$. Doch beharrte die amerikanische Delegation zunächst weiter auf der ursprünglich vorgeschlagenen Konzeption, die eine alliierte Majorität vorsah ${ }^{160}$. Schließlich kam die Frage auf der Tagesordnung der Besprechungen zwischen Adenauer und den Hohen Kommissaren. Dabei schlug der Bundeskanzler vor, ein paritätisch besetztes deutsch-alliiertes Gericht mit einem neutralen Vorsitzenden zu schaffen. Dies sei nötig, „um zu verhindern, daß der Antisemitismus wieder neuen Auftrieb erhalte" ${ }^{161}$. Auf Wunsch McCloys fragte das State Department Goldmann, Blaustein sowie den Kongreßabgeordneten Javits, ob sie Adenauers Forderung zustimmen könnten. Gleichwohl hielten diese an einer alliierten Majorität fest, woran auch der Hinweis auf die angebliche Antisemitismus-Gefahr nichts änderte. Javits erklärte ausdrücklich, er

155 Department of State, Memorandum of Conversation, 27.9. 1951, Byroade, Lewis u. Baker (State Department) $\mathrm{m}$. Jacob K. Javits (Kongreßabgeordneter/New York), Stein, Callman, Muller u. Prager (American Federation of Jews from Central Europe), Weil u. Higgins (Axis Victims League), Weigert (Association of Former European Jurists), USNA, RG 59, 262.0041/9-2751.

156 State Department an McCloy, 29. 9. 1951, WNRC, RG 466, McCloy Papers, Box 32.

157 McCloy an Acheson, 15.12. 1951, USNA, RG 59, 262.0041/12-1551.

158 Niederschrift über die 3. Besprechung des Unterausschusses „Innere Rückerstattung und Innere Wiedergutmachung" am 18.12. 1951, PA/AA, Il 241-27g, Bd. 1; McCloy an Acheson, 20.12. 1951, USNA, RG 59, 262.0041/12-2051.

159 Report of the Allied High Commission Concerning the Establishment of a new Relationship between the Allied Powers and Germany, 9.8. 1951 (Anm. 128).

160 McCloy an Acheson, 22. 12. 1951, USNA, RG 59, 262.0041/12-2251.

161 Protokoll der Besprechung Adenauers mit den Hohen Kommissaren v. 8. 1. 1952, in: Adenauer und die Hohen Kommissare 1952, hrsg. v. Hans-Peter Schwarz in Verb. m. Rainer Pommerin, bearb. v. FrankLothar Kroll u. Manfred Nebelin, München 1990, S.2f. 
wolle dieses Risiko eingehen ${ }^{162}$, und Blaustein und Goldmann ergänzten, mit einem gewissen Maß an deutschem Antisemitismus müsse man so oder so rechnen ${ }^{163}$.

Doch gestalteten sich die Verhandlungen weiterhin dadurch kompliziert, daß Adenauer ein Junktim mit einer anderen zentralen Streitfrage herstellte, nämlich mit der alliierten Forderung nach der Übernahme der rückerstattungsrechtlichen Verbindlichkeiten des Deutschen Reiches. Auch hier war es auf den unteren Verhandlungsebenen zu keiner Einigung gekommen, denn die deutsche Delegation hatte verlangt, diese Forderung durch den Zusatz „entsprechend ihrer Zahlungsfähigkeit und dem Grundgesetz" einzuschränken. Sie stellte sich auf den Standpunkt, die rückerstattungsrechtlichen Verpflichtungen dürften nur im Gesamtzusammenhang aller anderen finanziellen Verpflichtungen der Bundesrepublik, einschließlich des Abkommens über die Auslandsschulden und des Verteidigungsbeitrags, gesehen werden. Auch Hallstein lehnte es $\mathrm{ab}$, für diese Frage eine vorgezogene Sonderregelung zu treffen, gab es doch nach seiner Auffassung eine ganze Reihe von Verpflichtungen, die genau so wichtig seien ${ }^{164}$. Diese Position fand ihre Hauptstütze in Schäffer und dem von ihm geleiteten Bundesfinanzministerium ${ }^{165}$. Dehler und das Bundesjustizministerium traten hingegen mittlerweile intern für eine Vorabregelung der Reichsverbindlichkeiten ein - nicht zuletzt deshalb, weil sie in diesem Zusammenhang die Rückgriffsansprüche der deutschen Rückerstattungsgeschädigten gegen das Reich regeln wollten ${ }^{166}$.

Während also die deutsche Seite der Rückerstattung für Verfolgte des Nationalsozialismus keine höhere Priorität gegenüber anderen dringenden finanziellen Verpflichtungen einräumte, unterschied sich der alliierte Standpunkt davon zumindest graduell. Auch hier wurde zwar nach einem Interessenausgleich gesucht, doch bestand gleichwohl die Auffassung, daß diese Forderungen vorab erfüllt werden sollten. Dazu trug erneut der Wunsch nach Beruhigung dieser konfliktreichen Materie bei. So telegraphierte Acheson an HICOG: „Reason for settling this category of claims ahead of others is that these claims form part of complex of persecutee problems and will remain source of pressure and trouble until settled “ ${ }^{167}$. Konzessionen sollten deshalb allenfalls beim Zahlungsmodus, nicht aber im Grundsätzlichen gemacht werden.

Auch diese Frage mußte schließlich auf höchster Ebene beraten werden. Die deutschen Widerstände resultierten dabei hauptsächlich daraus, daß nach Auskunft ihrer Experten für diesen Bereich mit einer Summe von fünf bis sieben Mrd. DM zu rechnen sei $^{168}$, während die alliierten Experten mit einem Betrag von maximal einer Mrd. DM kalkulierten ${ }^{169}$. Bei der Besprechung mit den Hohen Kommissaren am 22. Januar 1952

162 Acheson an HICOG, 11.1. 1952, WNRC, RG 466, McCloy Papers, Box 36.

16.3 Department of State, Memorandum of Conversation, Lewis mit Goldmann und Blaustein, 14.1. 1952, USNA, RG 59, 262.0041/1-1452.

${ }^{16+}$ HICOG an State Department, 19.1. 1952, USNA, RG 466, McCloy Papers, Box 35. Siehe auch Niederschrift der 2. Besprechung des Unterausschusses „Innere Rückerstattung und Innere Wiedergutmachung” am 14. 12. 1951, PA/AA, II 241-27g, Bd. 1; Auszug aus der kurzen Niederschrift über die 7. Besprechung des Hauptausschusses am 19.1. 1952, PA/AA, II 241-27g, Bd. 2.

165 Siehe etwa Schäffer an Auswärtiges Amt, Anlage: Memorandum zu Art. 5(a) des Teiles III der Abkommen Rückerstattungsrechtliche Verbindlichkeiten des Reichs, 10.1. 1952, PA/AA, II 241-27g, Bd. 2.

${ }^{166}$ Dehler an Adenauer, 20.12. 1951, Anlage: Memorandum, BA, B 136/1125. Vgl. dazu auch oben, Abschnitt I. 1.

167 Acheson an HICOG, Bonn, 8. 2. 1952, USNA, RG 59, 262.0041/1-2652.

168 Siehe dazu etwa Schäffer an Auswärtiges Amt, 10.1. 1952 (Anm. 165).

169 Stellungnahme der alliierten Sachverständigen zu dem deutschen Memorandum über Art. 5(a) des Teiles III des Abkommens, Anlage zu Debevoise an Trützschler, 11.2. 1952, PA/AA, II 241-27g, Bd. 2. 
argumentierte Adenauer nun vor allem damit, daß vor dem Hintergrund solcher Belastungen kein Bundestag bereit wäre, einem alliiert dominierten obersten Rückerstattungsgericht zuzustimmen. Geschickt verband er dieses Argument mit der Frage der Zustimmung der SPD zu einem deutschen Verteidigungsbeitrag. Zugleich lockte er aber damit, daß er sein Urteil noch einmal überdenken könnte, falls der Gesamtbetrag der Rückerstattungsverbindlichkeiten des Deutschen Reiches auf ein bis zwei Mrd. DM begrenzt würde ${ }^{170}$. Die Opposition spielte insofern eine nützliche Rolle für die Verhandlungstaktik Adenauers: Unter Hinweis auf erhebliche Widerstände im Bundestag gegen allzu hohe deutsche Konzessionen, konnte er die Alliierten unter einen gewissen Druck setzen, in manchen Einzelfragen Zugeständnisse zu machen, da diese primär daran interessiert waren, die politische und militärische Westintegration der Bundesrepublik voranzubringen. Im Verhältnis dazu waren die Fragen der Rückerstattung und Entschädigung für Verfolgte des Nationalsozialismus ohnedies nur ein Nebenthema, wenngleich kein unbedeutendes.

In beiden Fällen schufen schließlich alliierte Konzessionen die Voraussetzung für eine Einigung. Auf der Londoner Konferenz der drei Außenminister im Februar 1952 wurde beschlossen, daß die geldlichen Rückerstattungsforderungen gegen das Reich unter die Währungsreform fallen sollten und damit zehn zu eins abgewertet würden. Die Außenminister glaubten, die dadurch gegebene drastische Verringerung der rückerstattungsrechtlichen Geldverbindlichkeiten werde es Adenauer ermöglichen, dem Vorschlag einer alliierten Majorität in den Obersten Rückerstattungsgerichten zuzustimmen. Doch ermächtigten sie zugleich die Hohen Kommissare, der deutschen Forderung nach einem paritätisch besetzten Gericht mit neutralem Vorsitzenden zuzustimmen, falls die Deutschen den alliierten Vorschlag nicht akzeptieren sollten ${ }^{171}$. Am 1. März unterbreiteten die Alliierten diese Vorschläge im Koordinierungsausschuß, doch reagierte Hallstein weniger angetan als erhofft. Da das Argument der finanziellen Überforderung nun weitgehend entkräftet schien, brachte er wieder die angebliche Antisemitismus-Gefahr ins Spiel; einer alliierten Majorität in einem gemischten Obersten Rückerstattungsgericht wollte er deshalb nach wie vor nicht zustimmen ${ }^{172}$. Erst nach mehreren weiteren Besprechungen der Hohen Kommissare mit Adenauer gelang hier ein Durchbruch. Nachdem der Bundeskanzler zunächst erneut gefordert hatte, daß die rückerstattungsrechtlichen Geldverbindlichkeiten des Reiches nur im Zusammenhang der deutschen Gesamtverbindlichkeiten gesehen werden dürften ${ }^{173}$, akzeptierte er schließlich im April den alliierten Vorschlag, die Gesamtsumme dieser Forderungen auf 1,5 Mrd. DM zu begrenzen, wobei zugleich die RM-Forderungen eins zu zehn abgewertet werden sollten ${ }^{174}$. Da die Alliierten ohnehin mit einem Betrag rechneten, der unter einer Milliarde DM lag, fiel ihnen dieses Zugeständnis nicht allzu schwer.

In der Frage der Zusammensetzung der obersten Rückerstattungsgerichte war eine

170 Protokoll der Sitzung Adenauers mit den Hohen Kommissaren am 22. 1. 1952, in: Adenauer und die Hohen Kommissare 1952, S.9f; McCloy an Acheson, 23.1. 1952, USNA, RG 59, 262.0041/1-2352.

171 Memorandum von Slater an McCloy, Hays u.a., 10.3. 1952, WNRC, RG 466, McCloy Papers, Box 38.

172 Ebenda.

173 Bericht über Treffen der Hohen Kommissare mit Adenauer am 11. März in Schreiben McCloys an State Department, 12.3. 1952, WNRC, RG 466, McCloy Papers, Box 37; Aufzeichnung Brückner für Adenauer, 21.3. 1952, PA/AA, II 241-27g, Bd. 3.

174 Protokoll des Treffens Adenauers mit den Hohen Kommissaren am 4.4. und 9.4. 1952, in: Adenauer und die Hohen Kommissare 1952, S. 38f. u. 70f. Siehe auch HICOG an State Department, 5.4. 1952 und 10.4. 1952, WNRC, RG 466, McCloy Papers, Box 39 u. 40. 
Lösung bereits früher erreicht worden. Am 25. März hatten die Alliierten schließlich dem deutschen Wunsch nachgegeben und paritätisch besetzten Kammern mit einem neutralen Vorsitzenden zugestimmt ${ }^{175}$. Daß sie die Forderung nach einer alliierten Majorität überhaupt so lange aufrecht erhalten hatten, beruhte weniger auf eigener Überzeugung als auf dem Drängen jüdischer und anderer interessierter Organisationen. Das Zugeständnis paritätischer Kammern unter neutralem Vorsitz war bereits von Anbeginn der Verhandlungen als Option bereitgehalten worden, doch hatten die Alliierten zunächst die deutsche Schmerzgrenze ausgelotet und damit die eigenen innenpolitischen Verpflichtungen erfüllt.

Nach der Klärung dieser Grundfragen wurde im weiteren nur noch redaktionell an den Entwürfen gearbeitet ${ }^{176}$, und am 26. Mai 1952 unterzeichneten Adenauer, Schuman, Acheson und Eden schließlich den Überleitungsvertrag im Rahmen des Deutschlandvertrags. Durch das Scheitern dieses Vertragswerkes in der französischen Nationalversammlung an der Frage der Europäischen Verteidigungsgemeinschaft konnte das Gesamtvertragswerk zwar erst 1955 nach erneuten Verhandlungen endgültig in Kraft treten ${ }^{177}$, doch minderte dies nicht die Bedeutung der in Abschnitt III und IV des Überleitungsabkommens festgehaltenen alliierten Forderungen. Diese bezeichneten der deutschen Seite unmißverständlich den Preis, der für die Aufgabe der alliierten Vorbehaltsrechte im Bereich der Rückerstattung und Entschädigung zu entrichten war.

Offensichtlich lag dabei das Schwergewicht auf der Rückerstattung ${ }^{178}$ : Teil III des Vertrages bestimmte vor allem, daß die Bundesrepublik die alliierten Gesetze zur Regelung der Rückerstattung feststellbarer Vermögenswerte an Verfolgte des Nationalsozialismus sowie auch zur Rückerstattung und Übertragung von Vermögenswerten an Genossenschaften, Gewerkschaften, Wohltätigkeitsorganisationen und andere demokratische Organisationen gemäß Kontrollratsdirektive Nr. 50 und den entsprechenden zonalen Militärregierungsgesetzen in vollem Umfange und beschleunigt durchführen müsse. Außerdem sollte die Bundesrepublik alle geldlichen Rückerstattungsforderungen gegen das Deutsche Reich bis zu einem Gesamtbetrag von 1,5 Mrd. DM erfüllen, wobei sie hinsichtlich Zeit und Methode dieser Zahlungen ihre Zahlungsfähigkeit berücksichtigen durfte. Die nach den Rückerstattungsgesetzen bestimmten Nachfolgeorganisationen für erbenloses Eigentum und Treuhandkörperschaften sollten Gemeinnützigkeitstatus erhalten und von Steuern und Lastenausgleichsabgaben befreit sein - dies war ein Punkt gewesen, für den sich die jüdischen Organisationen sehr stark eingesetzt hatten ${ }^{179}$. Zuletzt war auch Aufbau und Zusammensetzung des künftigen paritätisch besetzten Obersten Rückerstattungsgerichtes bestimmt.

Demgegenüber verpflichtete sich die Bundesrepublik im Vierten Teil des Abkommens dazu, „Personen, die wegen ihrer politischen Überzeugung, ihrer Rasse, ihres Glaubens oder ihrer Weltanschauung verfolgt wurden und hierdurch Schaden an Le-

175 Niederschrift über die 9. Besprechung des Unterausschusses „Innere Rückerstattung und Innere Wiedergutmachung" am 25.3. 1952, PA/AA, II $241-27 \mathrm{~g}$, Bd. 3.

176 Siehe dazu PA/AA, II 241-27 g, Bd. 4 u. 5.

177 Vgl. dazu Féaux de la Croix, Internationalrechtliche Grundlagen, S. 136-139.

${ }^{178}$ Siche zum folg. Vertrag zur Regelung aus Krieg und Besatzung entstandener Fragen, Dritter Teil: Innerer Rückerstattung, in: Verträge der Bundesrepublik Deutschland, Serie A: Multilaterale Verträge, Nr.62-68, Bd. 7, hrsg. vom Auswärtigen Amt, Bonn usw. 1957, S. 251-279.

179 Siehe etwa Department of State, Memorandum of Conversation, 27.4. 1951, Webb und Lewis mit Leavitt, Robinson, Rock, Warburg und Rubin, USNA, RG 59, 262.0041/4-2751. 
ben, Körper, Gesundheit, Freiheit, Eigentum, Vermögen oder an ihrem wirtschaftlichen Fortkommen erlitten haben ..., eine angemessene Entschädigung ... sicherzustellen“. Außerdem sollten „Personen, die aus Gründen der Nationalität unter Mißachtung der Menschenrechte verfolgt wurden und gegenwärtig politische Flüchtlinge sind, die den Schutz ihres früheren Heimatlandes nicht mehr genießen, eine angemessene Entschädigung erhalten, soweit ihnen ein dauernder Gesundheitsschaden zugefügt worden ist" ${ }^{180}$. Zur Erfüllung dieser Verpflichtung durften die künftigen Rechtsvorschriften im Bereich der Entschädigung nicht ungünstiger ausfallen als bisher. Zudem verpflichtete sich die Bundesrepublik dazu, „beschleunigt Rechtsvorschriften zu erlassen, welche die gegenwärtig in den verschiedenen Ländern geltenden Rechtsvorschriften ergänzen und abändern und welche ... im gesamten Bundesgebiet eine nicht weniger günstige Grundlage für die Entschädigung bilden als die gegenwärtig in den Ländern der amerikanischen Zone geltenden Rechtsvorschriften “ ${ }^{181}$. Es folgten Bedingungen für eine gerechte Durchführung dieses Programms sowie die Verpflichtung der Bundesrepublik zur Mittelbereitstellung. Doch auch hier wurde ihr zugestanden, Zeit und Methode der Entschädigungszahlungen ihrer Zahlungsfähigkeit anzupassen.

Féaux de la Croix relativiert die Bedeutung des Überleitungsabkommens für die weitere Entwicklung der Wiedergutmachung mit dem Argument, daß viele der dort festgelegten Bestimmungen „Selbstgänger" gewesen seien, d. h. früher oder später auch ohne alliierte Nachhilfe gekommen wären. Er spekuliert weiter darüber, ob es nicht durch ein geschickteres Taktieren möglich gewesen wäre, gerade im Bereich der „Nicht-Selbstgänger" zu einigen wesentlich bescheideneren Wiedergutmachungsregelungen im Überleitungsabkommen zu gelangen ${ }^{182}$. Dies wirft ein bezeichnendes Licht auf die Problematik dieses Abkommens und der vorangegangenen Verhandlungen. Franz Böhm nannte es 1953 eine „Perversion des Denkens“, daß die Deutschen „in eifrigen Verhandlungen und unter Vergießung von viel diplomatischen VerhandlungsSchweißes" versucht hätten, die Forderung der Alliierten herunterzuhandeln, „daß wir Deutsche unsere deutschen Mitbürger, an denen Verbrechen begangen worden sind, ausreichend entschädigen“. Sarkastisch stellte Böhm fest: „Wir überließen nicht nur den siegreichen Mächten die Wahrnehmung der Interessen unserer Mitbürger gegen die eigene Regierung, sondern wir empfanden es als einen Verhandlungserfolg, als es uns gelang, die Interessen unserer deutschen Mitbürger zu schädigen. ${ }^{\text {" } 83}$ Allerdings verkannte Böhm, wenn er mit Penetranz auf die geschädigten deutschen Mitbürger hinwies, daß es den Alliierten zum Teil bei diesen Verhandlungen gerade auch um die nichtdeutschen Verfolgten des Nationalsozialismus ging!

Neben Carlo Schmid ${ }^{184}$ bezeichnete es vor allem Adolf Arndt wiederholt als beschämend, daß die Wiedergutmachung quasi als alliiertes Oktroi komme und nicht die Bundesregierung von sich aus eine eigene Initiative ergreife und selbst Maßstäbe für dieses Gebiet formuliere. So erklärte er am 11. September 1952 vor dem Bundestag: „Eine der peinlichsten Bestimmungen der umstrittenen Verträge mit den westlichen

180 Vertrag zur Regelung aus Krieg und Besatzung entstandener Fragen, Vierter Teil: Entschädigung für Opfer der nationalsozialistischen Verfolgung, S. 279-283, hier S. 279.

181 Ebenda, S. 281.

182 Vgl. Féaux de la Croix, Internationalrechtliche Grundlagen, S. 142-146, insbes. S. 146.

183 Franz Böhm, in: Otto Küster, Wiedergutmachung als elementare Rechtsaufgabe, Frankfurt a.M. 1953, S. 23.

184 Protokoll der 98. Sitzung des Bundestags-Ausschusses für Rechtswesen und Verfassungsrecht, 18.4. 1951, BA, B 126/12523. 
Besatzungsmächten ist die uns auferlegte Wiedergutmachung. Als ob es nicht unser ureigenstes Anliegen sein müßte, diese gesetzgeberische Aufgabe selbst zu lösen. " 185 Tatsächlich verdeutlicht die Entstehung des Überleitungsabkommens erneut, daß ein politisches Konzept der Bundesregierung im Bereich der Wiedergutmachung allenfalls ex negativo existierte, bestehende Chancen, eigene Vorstellungen einzubringen, blieben ungenutzt. Da durch diese politische Verhaltensweise, die die Wiedergutmachung offensichtlich als Hol- und nicht als Bringschuld auffaßte, jeweils nur auf entsprechend starken Druck reagiert wurde, ist es kein Wunder, daß die Strukturen der Wiedergutmachung in so hohem Maße die unterschiedliche Fähigkeit der Verfolgten des Nationalsozialismus, ihre Interessen wirkungsvoll zu organisieren bzw. Unterstützung zu mobilisieren, widerspiegeln.

\section{Das Luxemburger Abkommen mit Israel und der Claims Conference}

\section{Der steinige Weg zu direkten Gesprächen}

a) Die Formulierung der israelischen Globalforderung und die alliierten und jüdischen Reaktionen

Als ein weiterer Faktor in der Auseinandersetzung um die Wiedergutmachung trat gegen Anfang der fünfziger Jahre auch der neugegründete Staat Israel auf den Plan. Dies führte bei den jüdischen Organisationen, die sich bislang um die Ansprüche jüdischer Opfer des Nationalsozialismus gekümmert hatten, zu manchen Irritationen: Als etwa im Sommer 1949 die Nachricht kursierte, daß die israelische Regierung eine Liste von Schadensersatzforderungen gegen Deutschland und deutsche Staatsangehörige für zerstörtes, beschlagnahmtes oder erbenloses Eigentum aufgestellt hatte, die der künftigen Bundesregierung vorgelegt werden sollte, befürchtete man bei der United Restitution Organization (URO), daß es nun zu einem „Konkurrenzkampf der verschiedenen an dem Vermögen interessierten Stellen “ kommen werde ${ }^{186}$.

Diese israelischen Pläne beschränkten sich zunächst auf individuelle Ansprüche israelischer Staatsbürger bzw. auf den Transfer erbenlosen jüdischen Eigentums nach Israel. Bald wurde jedoch auch der kollektive jüdische Wiedergutmachungsanspruch wieder aufgegriffen, der seit der Pariser Reparationskonferenz nicht weiter verfolgt worden war. Schon im Januar 1950 fragte Schalom Adler-Rudel von der Jewish Agency, der bereits während des Krieges an solchen Plänen gearbeitet hatte ${ }^{187}$, die amerikanischen jüdischen Organisationen nach ihrer Meinung zu dem Gedanken, „wieder Verhandlungen mit den Alliierten über das Problem der Reparationen für das jüdische Volk als

${ }^{185}$ Deutscher Bundestag, 229. Sitzung, 11.9. 1952, Stenographische Berichte, Bd. 13, S. 10434 f. In der 163. Sitzung des Bundestags-Ausschusses für Rechtswesen und Verfassungsrecht am 21.2. 1952 hatte Arndt erklärt: „Die Wiedergutmachung ... sei ... eine deutsche Angelegenheit. Eine Abmachung des Inhalts, daß Deutschland sich durch internationalen Vertrag zur innerdeutschen Wiedergutmachung verpflichte, sei nicht einmal zu wünschen. “ (BA, B 141/409).

186 URO/Hannover an URO/London, 7.6. 1949, LBI-Archiv, AR 5890/16, Council of Jews from Germany. Zur URO vgl. auch Hans Günter Hockerts, Anwälte der Verfolgten. Die United Restitution Organization, in: Herbst/Goschler (Hrsg.), Wiedergutmachung, S. 249-272.

187 Vgl. Erstes Kapitel, Abschnitt II. 2. 
Ganzes aufzunehmen“ ${ }^{188}$. Dort reagierte man jedoch zurückhaltend: die Idee sei „zwar gerecht und wünschenswert, doch extrem schwierig, wenn nicht aussichtslos zu realisieren ${ }^{\text {189. }}$.

Auf der anderen Seite befand sich Israel in einem innenpolitischen Dilemma zwischen der gravierenden wirtschaftlichen Notlage, derentwegen Leistungen von Deutschland dringend erwünscht waren, und den politisch-psychologischen Hürden, die einer jeden Kontaktaufnahme mit den Deutschen im Weg standen ${ }^{190}$. Dennoch verhandelte im Verlaufe des Frühjahrs und Sommers 1950 Kurt Mendelsohn, der Direktor der israelischen Steuerbehörde, diskret mit offiziellen Vertretern von Bund und Ländern über den Transfer deutscher Sperrmark mittels deutscher Warenexporte nach Israel. Dabei war daran gedacht, Entschädigungsansprüche israelischer Staatsbürger im Rahmen eines Globalabkommens abzugelten, ähnlich wie es die JRSO für die ihr zustehenden erbenlosen Rückerstattungsansprüche versuchte. Der Bundesfinanzminister versuchte jedoch, derartige Vorschußzahlungen der Bundesrepublik zu verhindern ${ }^{191}$. Allenfalls wollte Schäffer zulassen, daß die Länder, aus deren Gesetzgebung die Ansprüche resultierten, ein solches Globalabkommen - Mendelsohn hatte die Größenordnung von 100 Mio. DM genannt - finanzieren würden ${ }^{192}$. Doch fürs erste befreite die Alliierte Hohe Kommission die deutsche Seite aus der Verlegenheit: Diese pochte auf die alliierte Devisenbewirtschaftung und hatte bereits in einem Schreiben vom 11. Mai 1950 unterstrichen, daß nach ihrer Auffassung die deutsche Wirtschaft zur Zeit noch nicht in der Lage sei, sich die Ausfuhr von Waren gegen Bezahlung in DM erlauben zu können ${ }^{193}$. Daß sich die deutsche Regierung in dieser Frage nun hinter dem Rücken der Hohen Kommissare versteckte, stieß auf jüdischer und israelischer Seite auf herbe Kritik. Bitter wurde dort bemerkt, „daß die Bonner Regierung es in vielen anderen Dingen verstanden hat, gegenüber der HICOG auf den Tisch zu schlagen und Dinge, die ihr am Herzen lagen, durchzusetzen. Diese Einstellung scheint bei den Fragen, die mit der Rückerstattung des jüdischen Besitzes und des Transfers verbunden sind, bei der Bonner Regierung nicht vorhanden zu sein. “ 194

So hielt man es Anfang 1951 in Israel für unergiebig, weiterhin direkte Gespräche mit Bonn zu suchen, solange von dort kein deutliches Zeichen des guten Willens komme. Deshalb richteten sich die nächsten Schritte an die vier Siegermächte. Im Mittelpunkt einer ersten Note vom 16. Januar 1951 standen Fragen der Rückerstattungs- und Entschädigungsgesetzgebung. Israel forderte die Beibehaltung der alliierten Vorbehaltsrechte und die Verbesserung der Entschädigungsgesetzgebung namentlich durch Ausweitung des US-Zonen-Gesetzes auf die ganze Bundesrepublik. Weitere Wünsche wa-

188 Adler-Rudel an Max Isenbergh (AJC), 30. 1. 1950, YIVO-Archiv, RG 347, AJC Records, GEN-10, Box 282.

$189 \mathrm{AJC} / \mathrm{New}$ York, an AJC/Paris, 28. 2. 1950, YIVO-Archiv, RG 347, AJC Records, GEN-10, Box 282.

190 Vgl. Nana Sagi, Wiedergutmachung für Israel. Die deutschen Zahlungen und Leistungen, Stuttgart 1981, S. 49-53; Yeshayahu A. Jelinek, Israel und die Anfänge der Shilumim, in: Herbst/Goschler (Hrsg.), Wiedergutmachung, S. 127-133.

191 Schäffer an Hartmann, betr. Kabinettssitzung am 9.6. 1950, BA, NL Schäffer, 168/33.

192 Kurzbericht über die 15. Sitzung des Bundesrats-Finanzausschusses am 9.6. 1950, BA, B 126/12523; Vormerkung von Ministerialdirektor K. Augustin (hess. Finanzministerium), 13.6. 1950, BA, B 126/12359; Schäffer an Hartmann, betr. Kabinettssitzung am 9.6. 1950 (Anm. 191); 72. Kabinettssitzung am 9.6. 1950, in: Kabinettsprotokolle der Bundesregierung, Bd. 2, S. 438.

193 Hays (AHK) an Adenauer, 11.5. 1950, PA/AA, II 244-10, Bd. 1; Vormerkung Kuschnitzky, 23. 2. 1951, BA, B 126/12360; Konrad Adenauer, Erinnerungen, Bd. 2: 1953-1955, Stuttgart 1966, S. 133 f.

194 Das Zitat stammt aus einem Briefwechsel von Karl Marx mit einem ungenannten Vertreter der israelischen Regierung. Siehe Dehler an Schäffer, 5.2. 1952, AdL, N 1/3151. 
ren die Beschleunigung der laufenden Rückerstattungs- und Entschädigungsverfahren sowie - besonders wichtig - die Lösung der Transferfrage. Zugleich kündigte die israelische Regierung eine eigene Reparationsforderung an ${ }^{195}$. Dies geschah schließlich durch eine zweite Note vom 12. März, die unter Berufung auf die Verluste des jüdischen Volkes durch deutsche Hand sowie die Eingliederungskosten für etwa 500.000 Einwanderer aus früher vom Deutschen Reich besetzten Ländern Reparationen für Israel als Entschädigung für das jüdische Volk forderte. Unter Bezug auf die Eingliederungskosten wurde die Forderung auf 1,5 Mrd. Dollar beziffert ${ }^{196}$.

Die Sowjetunion reagierte weder auf die erste noch auf die zweite Note. Anders die drei Westmächte: Vor allem auf Drängen der Briten ${ }^{197}$ wurden die Antworten der westlichen Alliierten im Rahmen der laufenden ISG-Beratungen in London koordiniert, da die israelischen Forderungen in engem Zusammenhang mit den dort besprochenen Fragen standen. Neu an der ersten Note war dabei eigentlich nur, daß nunmehr der Staat Israel als Statthalter der Interessen des jüdischen Volkes auftrat. Daran nahm jedoch die britische Delegation Anstoß. Sie bestritt, daß Israel befugt sei, für alle ehemaligen deutschen jüdischen Emigranten zu sprechen, hätten doch die meisten von ihnen Zuflucht in den USA, Großbritannien oder Frankreich gefunden ${ }^{198}$. Der Tenor der zwar abgestimmten, aber getrennt abgefaßten alliierten Antwortschreiben war dann schließlich freundlich, aber unverbindlich: Übereinstimmend hieß es dort, die westlichen Alliierten würden ihr Augenmerk weiterhin auf diese Fragen richten, wenngleich insbesondere der Forderung nach einer Aufhebung der einem Transfer von Wiedergutmachungsleistungen entgegenstehenden Bestimmungen im Augenblick nicht stattgegeben werden könne ${ }^{199}$.

Die zweite israelische Note war hingegen um einiges brisanter, denn hier wurde ein neuartiger Anspruch präsentiert: Reparationen für das jüdische Volk an Israel. Diese Forderung stellte die westlichen Alliierten vor schwierige völkerrechtliche Fragen, weshalb sich die Beratungen, die auch hier durch die ISG koordiniert wurden, geraume Zeit beanspruchten. Währenddessen lief die israelische Diplomatie auf vollen Touren, um die Auswärtigen Ämter der angesprochenen Länder zu einer positiven Haltung gegenüber der Forderung nach 1,5 Mrd. Dollar Reparationen für Israel zu bewegen. Der israelische Finanzstaatssekretär David Horowitz begab sich im April auf eine Rundreise durch die Hauptstädte der westlichen Alliierten, fand dabei jedoch abgesehen von aufmunternden Worten nirgends konkrete Unterstützung ${ }^{200}$.

195 Israelische Note vom 16.1. 1951, in: Documents Relating to the Agreement between the Government of Israel and the Government of the Federal Republik of Germany (Signed on 10 September 1952 at Luxemburg), hrsg. v. State of Israel, Ministry of Foreign Affairs, 1953, S.13-16, hier: S. 16. Die Note an die Sowjetunion unterschied sich wegen der unterschiedlichen Situation in der Sowjetischen Besatzungszone in den einzelnen Forderungen. Vgl. Note Israels vom 16.1. 1951, ebenda, S. 17-19.

196 Israelische Note vom 12.3. 1951 an die vier Besatzungsmächte, in: Documents Relating to the Agreement, S. 20-24, hier: S. 24.

197 Department of State, Memorandum of Conversation, Prud'homme u. Margolies (State Department) mit Penson (brit. Botschaft in Washington), 31.1. 1951, USNA, RG 59, 396.1-ISG/1-3151.

198 Gifford (London) an Acheson, 9.3. 1951, USNA, RG 59, 396.1-ISG/3-651.

199 Britische Note vom 20.3. 1951, in: Documents Relating to the Agreement, S. 28 f; Note der USA vom 21.3. 1951, ebenda, S. 30-32; französische Note 21.3. 1951, ebenda, S. $32 \mathrm{f}$.

200 Siehe dazu etwa Acheson an US-Botschaft in London, 12.4. 1951, USNA, RG 59, 396.1-1-ISG/4-1151; Department of State, Memorandum of Conversation, Abba Eban (israel. Botschafter in Washington), Horowitz, Byroade, Alexander Kiefer, 10.4. 1951, in: FRUS 1951, Bd. V: The Near East and Africa, Washington, D.C., 1982, S.630f. Vgl. auch Sagi, Wiedergutmachung, S.63-65; Michael Wolffsohn, Das deutsch-israelische Wiedergutmachungsabkommen von 1952 im internationalen Zusammenhang, in: VfZ 36 (1988), S. $697 \mathrm{f}$. 
Wie sich bei den Beratungen der ISG bald zeigte, stimmten die drei Westmächte darin überein, daß die Berechtigung der israelischen Regierung, Reparationen von Deutschland zu fordern, vom völkerrechtlichen Standpunkt her zweifelhaft sei. Doch sollte ihr freigestellt werden, ihre Forderung zum Zeitpunkt eines Friedensvertrages zu präsentieren. Kern der israelischen Forderung waren nach Auffassung der ISG die unzureichenden Leistungen, die aus Artikel 8 des Pariser Reparationsabkommens resultierten. Doch war man sich einig, daß alle beteiligten Staaten nur einen Bruchteil ihrer tatsächlichen Verluste ersetzt bekommen hätten. So bestimmten die Delegierten als Leitlinie ihrer Antwort, daß auf die umfangreichen alliierten Maßnahmen im Bereich der Rückerstattung, der Entschädigung und der Reparationen für nichtrepatriierbare Flüchtlinge hingewiesen werden sollte und daß weitere Schritte nur im Zusammenhang eines Friedensvertrages erfolgen könnten ${ }^{201}$.

Eine massive Erweiterung der deutschen Verpflichtungen, wie sie aus der israelischen Reparationsforderung resultierte, war also mit dem Generalzweck der ISG-Beratungen nicht vereinbar: Hier ging es darum, die durch das Besatzungsstatut bestehenden Beschränkungen der Bundesrepublik nach Möglichkeit auf dem Wege von Selbstverpflichtungen der deutschen Seite zu liquidieren. Bedenkt man, daß Großbritannien und Frankreich bei derselben Gelegenheit gezwungen waren, ihre eigenen Forderungen nach Ausweitung der deutschen Wiedergutmachungsleistungen erheblich zurückzustecken ${ }^{202}$, kann es nicht überraschen, daß die Alliierten keine Bereitschaft zeigten, sich hier zum Anwalt für Israels Sache zu machen. So erklärten sie sich in ihren drei Antwortnoten, die alle vom 5. Juli datierten, unter Berufung auf das Pariser Reparationsabkommen übereinstimmend für außerstande, Deutschland zum gegenwärtigen Zeitpunkt neue Reparationszahlungen aufzuerlegen ${ }^{203}$. Israel blieb also nichts anderes übrig, als selbst an Deutschland heranzutreten, wenn es solche Ansprüche realisieren wollte. Um einen „freiwilligen deutschen Hilfsbeitrag an Israel“ nicht zu behindern, wurden die alliierten Antwortnoten auf Wunsch der israelischen Regierung gegenüber der Bundesregierung geheimgehalten ${ }^{204}$.

Auch bei den jüdischen Organisationen in den USA hatten die israelischen Noten zunächst alles andere als einhellige Zustimmung ausgelöst. Wortführer der Kritiker war das American Jewish Committee, das in Fragen der Eigenständigkeit der jüdischen Diaspora traditionell sehr empfindlich war. Dort herrschte zunächst die Auffassung, der Staat Israel habe kein Recht, Forderungen auf Entschädigung und Rückerstattung für das jüdische Volk als Ganzes zu stellen. Besonders verärgert war man darüber, daß die erste israelische Note vom 16. Januar ohne Rücksprache mit einer der amerikanischen jüdischen Organisationen veröffentlicht worden war ${ }^{205}$. Die zweite israelische Note, die die Reparationsforderung enthielt, wurde vom American Jewish Committee sogar noch kritischer bewertet. Die Argumentation dieser Note sei äußerst konfus, und

201 Gifford an Acheson, 19.4. 1951, USNA, RG 59, 396.1-ISG/4-1951.

202 Vgl. oben, Abschnitt III.

203 Acheson an Eban, 5. 7. 1951, in: FRUS 1951 V, S. 748-752. Britische Antwortnote vom 5. 7. 1951, in: Documents Relating to the Agreement, S. 36f. Französische Antwortnote vom 5.7. 1951, ebenda, S. 39-41.

204 Acheson an US-Botschaft in London, 3. 7. 1951, in: FRUS 1951 V, S. 742. Der Verlauf einer Besprechung bei Adenauer mit Abs, Böhm und anderen am 5.4. 1952 bestätigt, daß sich jedenfalls die USA an diese Abmachung hielten. Siehe Aufzeichnung der Besprechung vom 5.4. 1952, BA, NL Blankenhorn, 351/17.

205 Eugen Hevesi (AJC) an Jacob Blaustein, 24. 1. 1951, YIVO-Archiv, RG 347, AJC Records, GEN-10, Box 291. 
schließlich: „The resulting document offers so many openings for critical attack which may seriously affect the issue itself." 206 Auch Simon Segal hieb namens des AJC bei einer Besprechung des Komitees der vier jüdischen Organisationen am 28. März in diese Kerbe. Überdies hielt er den Zeitpunkt der Veröffentlichung dieser Note für unglücklich, da hierdurch die laufenden Verhandlungen mit den US-Zonen-Ländern über Globalabkommen gefährdet würden ${ }^{207}$. In dieser Umgebung hätte man sich anfänglich lieber auf den Abschluß der bisherigen Wiedergutmachungsmaßnahmen konzentriert, als hier durch neuartige Forderungen unabsehbare Risiken zu schaffen.

Die beiden israelischen Noten wurden also zunächst weder bei den Alliierten noch bei den amerikanischen jüdischen Organisationen besonders freundlich aufgenommen. Erklärt sich dies im Falle der drei Westmächte aus der Unvereinbarkeit mit dem geplanten Abbau der Souveränitätsbeschränkungen Deutschlands und dem damit einhergehenden Rückzug aus der Verantwortung im Bereich der Wiedergutmachung, so hatte dies bei den jüdischen Organisationen andere Gründe: Die israelischen Forderungen gefährdeten ihren bislang aufrechterhaltenen Alleinvertretungsanspruch. Zudem bedeuteten die israelischen Reparationsforderungen eine gewisse Konkurrenz im Rahmen der bisher entwickelten Strukturen der Wiedergutmachung, die vor allem auf individuelle Entschädigung und Rückerstattung zielten.

Um hier zu vermitteln, diskutierte Nahum Goldmann, der Vorsitzende der Jewish Agency, bei Gesprächen mit der israelischen Regierung im März 1951 die künftige Aufgabenteilung zwischen dem Staat Israel und den amerikanischen jüdischen Organisationen. Dabei wurde festgelegt, daß sich die israelische Regierung auf das Problem der Reparationen beschränken solle. Demgegenüber oblägen den jüdischen Organisationen künftig - in enger Zusammenarbeit mit Israel - Fragen der Rückerstattung, des erbenlosen Eigentums, Forderungen gegen das Reich usw. Israel würde also nicht für alle Juden sprechen, sondern nur für die von ihm aufgenommenen jüdischen Überlebenden ${ }^{208}$. Unter dem ausdrücklichen Vorbehalt, daß der israelische Reparationsanspruch ausschließlich auf der Grundlage der Eingliederungskosten jüdischer Überlebender in Israel basiere, stellte sich so schließlich auch das Komitee der vier amerikanischen jüdischen Organisationen hinter die israelischen Forderungen ${ }^{209}$.

Der Verzicht auf die dort zunächst vorhandene reservierte Haltung gegenüber der israelischen Initiative trug bald erste Früchte. Eine Delegation des American Jewish Committee unter Leitung ihres Präsidenten Jacob Blaustein vereinbarte bei einem Gespräch mit dem amerikanischen Hohen Kommissar McCloy im Hause des Senators Averell Harriman im Juni 1951, daß Bundeskanzler Adenauer und die deutsche Regierung neben anderem zu einer Reihe von Schritten auf dem Gebiet der Wiedergutmachung bewegt werden sollten ${ }^{210}$. Dies hatte zur Folge, daß, verglichen mit den Skepti-

206 AJC, Comments on the Note Adressed on March 12, 1951, by the Government of Israel to the United States, Great Britain, France and the Soviet Union, (o.Dat.) ca. Ende März 1951, YIVO-Archiv, RG 347, AJC Records, GEN-10, Box 282.

207 Notes on the Meeting of the Four Organizations (Jewish Agency, AJDC, AJC, WJC), 28. 3. 1951, YIVOArchiv, RG 347, AJC Records, GEN-10, Box 291.

208 Ebenda.

209 Simon Segal (AJC) an John Slawson (AJC), 8. 5. 1951: Bericht über Treffen bei der Jewish Agency am 26. 4. , YIVO-Archiv, RG 347, AJC Records, GEN-10, Box 282; Jacob Blaustein an Acheson, 5.6. 1951, ebenda.

210 Blaustein an McCloy, 24. 8. 1965, AJC-Archiv, JSX, Subject Restitution 65-66. Vgl. auch Yeshayahu A. Jelinek, McCloy, Blaustein, and the Shilumim: A Chapter in American Foreign Affairs. (Erscheint voraussichtlich Anfang 1992 als Occasional Paper des Deutschen Historischen Instituts in Washington). 
kern im State Department, McCloy fortan eine erkennbar freundlichere Haltung gegenüber den israelisch-jüdischen Forderungen an den Tag legte; er war überdies in dieser Angelegenheit gewiß mehr als nur ein "Implementator" der Richtlinien aus Washington $^{211}$. Daß man bald darauf auf Wunsch des amerikanischen Hohen Kommissars auch davon abging, hier von Reparationen zu sprechen ${ }^{212}$, steht vermutlich gleichfalls damit in Verbindung: Die verbale Abgrenzung von der Reparationsthematik und damit auch die Betonung der Einzigartigkeit dieser Ansprüche waren wichtige Voraussetzungen zur Überwindung der Hindernisse, die sich aus der Befangenheit des Denkens in traditionellen völkerrechtlichen Kategorien ergaben.

\section{b) Adenauers Entschluß zu Verhandlungen}

Die israelischen Noten an die Alliierten waren, wie geschildert, durch die das Jahr 1950 hindurch an den Tag gelegte intransigente Haltung der Bundesregierung motiviert gewesen. Umso überraschender war es, daß die ersten deutschen Reaktionen auf die israelische Initiative verhältnismäßig positiv ausfielen. Offensichtlich hatten die israelischen Anstrengungen im Verein mit einer Anzahl von Bemühungen einzelner Persönlichkeiten wie Karl Marx, Jakob Altmaier und anderen die deutsche Haltung zu diesen Fragen wenigstens an manchen Stellen in Bewegung gebracht ${ }^{213}$. Wie Goldmann dem Komitee der amerikanischen jüdischen Organisationen bereits Ende März mitteilte, hatten hohe offizielle Kreise signalisiert, daß die deutsche Regierung die Angelegenheit diskutieren wolle. Vertrauenswürdig erschien jedoch vor allem die Mitteilung des jüdischen Bundestagsabgeordneten Jakob Altmaier, daß Adenauer bereit sei, mit einem autorisierten Vertreter der Juden zusammenzutreffen ${ }^{214}$. Tatsächlich kam es am 19. April in Paris unter größter Geheimhaltung zu einer Begegnung Adenauers, der von seinem außenpolitischen Ratgeber Herbert Blankenhorn begleitet wurde, mit Horowitz sowie dem israelischen Botschafter Maurice Fischer. Doch stand die Unterredung unter keinem glücklichen Stern: Horowitz forderte Adenauer dazu auf, eine Geste der Anerkennung gegenüber der israelischen Forderung zu unternehmen. Der Bundeskanzler zeigte sich gegenüber diesem Wunsch zwar persönlich aufgeschlossen, fürchtete aber angeblich die Reaktion der SPD. Vor allem aber erklärte er sich außerstande,

211 Saul Kagan am 15.3. 1991 bei einem Symposiums des Deutschen Historischen Instituts, Washington, in New York zum Thema „Holocaust und Shilumim“.

212 Blaustein an Eban, 23. 7. 1951, YIVO-Archiv, RG 347, AJC Records, GEN-10, Box 282. Zum Problem der Bezeichnung der israelischen Forderung vgl. auch Jelinek, Israel und die Anfänge der Shilumim, S. 120.

213 Yeshayahu A. Jelinek versucht diesen Knoten zu durchschlagen: Aufgrund einiger Inidizien sieht er die Möglichkeit, daß die Übermittlung der israelischen Noten an die Alliierten mit vorheriger Zustimmung Adenauers erfolgt sei. Vgl. ders., Political Acumen, Altruism, Foreign Pressure or Moral Debt - Konrad Adenauer and the "Shilumim", in: Tel Aviver Jahrbuch für deutsche Geschichte 19 (1990), S. 86. Dies erscheint jedoch angesichts der aus den von mir eingesehenen Quellen hervorgehenden deutschen Haltung in dieser Phase als gänzlich unwahrscheinlich, abgesehen vom Fehlen eines direkten Belegs für diese Annahme. Siehe dazu insbesondere die Dokumentation der Kontakte Dehlers und Karl Marx Ende 1950/Anfang 1951; AdL, N 1/3151. Zur Rolle Altmaiers vgl. Willy Albrecht, Ein Wegbereiter: Jakob Altmaier und das Luxemburger Abkommen, in: Herbst/Goschler (Hrsg.), Wiedergutmachung, S. $208 \mathrm{f}$.

214 Notes on the Meeting of the Four Organizations, 28.3. 1951, YIVO-Archiv, RG 347, AJC Records, GEN10, Box 291. Namentlich Dehler hatte seit Anfang 1951 Karl Marx wiederholt vorsichtige Signale in dieser Richtung gegeben, der dies wiederum der israelischen Regierung zur Kenntnis brachte. Siehe dazu etwa Karl Marx an Dehler, 18.4. 1951, AdL, N 1/3151. Auch das deutsche Konsulat in Washington bemühte sich in dieser Frage mehrfach um Kontakt zu den jüdischen Organisationen. Siehe Segal an Slawson, 8. 5. 1951 (Anm. 209). 
einen solchen Schritt ohne Zustimmung der USA zu unternehmen, sei er doch von amerikanischer finanzieller Beihilfe für Deutschland abhängig ${ }^{215}$.

Den Israelis war nicht entgangen, daß die SPD erst vor kurzem im Bundestag die Forderung nach Wiedergutmachungsleistungen an Israel eingebracht hatte ${ }^{216}$, so daß dieses Argument Adenauers offensichtlich vorgeschoben war. Deshalb hakten sie als nächstes, noch bevor die alliierten Antwortnoten eingetroffen waren, in Washington nach. Doch sowohl der israelische Premierminister David Ben-Gurion als auch der israelische Botschaftsrat Moshe Keren sahen sich bei ihren Gesprächen im State Department mit amerikanischen Bedenken über die wirtschaftlichen Auswirkungen dieses Plans konfrontiert. Ähnlich wie zuvor Außenminister Acheson beschied auch Henry Byroade, Leiter der Deutschlandabteilung, er stehe dem Gedanken einer deutschen Geste gegenüber Israel zwar wohlwollend gegenüber, doch müsse die israelische Reparationsforderung im Lichte der Auswirkungen auf die deutsche Wirtschaft untersucht werden. Er versprach aber, daß die in den nächsten Tagen eintreffende offizielle amerikanische Antwort die israelische Forderung oder die Möglichkeit, Deutschland zu einer Geste gegenüber Deutschland zu bewegen, nicht gefährden würde ${ }^{217}$.

Bereits vor dem Eintreffen der alliierten Antwortnoten war somit klar, daß für Israel der Weg zu der angestrebten Globalentschädigung nur über direkte Gespräche mit den Deutschen führen konnte. Als größte Hürde dafür erwies sich jedoch die geforderte Erklärung des Bundeskanzlers, in der er im Namen der Bundesrepublik die Verantwortung des neuen demokratischen Deutschlands „für die nationalsozialistischen Verbrechen anerkenne(n) und Israel und das Weltjudentum feierlich zu Verhandlungen über eine Entschädigung einlade(n)" sollte ${ }^{218}$. Eine solche Erklärung wurde bereits seit geraumer Zeit von verschiedener Seite dringend angemahnt: In dieser breit gefächerten Koalition trafen sich etwa der Vorsitzende der europäischen Sektion des Jüdischen Weltkongresses Noah Barou ${ }^{219}$, der einflußreiche Kolumnist der New York Times Jack Raymond ${ }^{220}$, der deutsch-jüdische Verleger Karl Marx, Rudolf Küstermaier und Erich Lüth mit ihrer Aktion „Friede mit Israel“ und nicht zuletzt auch McCloy, der Adenauer mehrfach auf die Notwendigkeit einer solchen Erklärung hinwies ${ }^{221}$. Wichtige

215 Vgl. Felix E. Shinnar, Bericht eines Beauftragten. Die deutsch-israelischen Beziehungen 1951-1966, Tübingen 1967, S. 14; Bericht von Moshe Keren bei einer Besprechung mit Byroade und Baker am 29.6. 1951, WNRC, RG 466, McCloy Papers, Box 28; Acheson an US-Botschaft in London, 3.7. 1952, in: FRUS 1951 V, S. 742. Michael Brecher (Decisions in Israel's Foreign Policy, London usw. 1974, S. 78) und Lily Gardner Feldman (The Special Relationship between West Germany and Israel, London und Sydney 1984, S. 55) führen das Zustandekommen dieses Treffens auf amerikanischen Druck zurück, wobei sie sich allein auf persönliche Aussagen von Horowitz stützen. Dem ist entgegenzuhalten, daß die überlieferten Aufzeichnungen der diesbezüglichen Besprechungen von Horowitz im State Department keinerlei Rückschluß auf eine derartige amerikanische Intervention zulassen. Siehe etwa Acheson an US-Botschaft in London, 12.4. 1951 (Anm. 200); Memorandum of Conversation, Eban, Horowitz, Byroade, Kiefer, 10.4. 1951 (Anm. 200).

216 Vgl. oben, Abschnitt I. 3.

217 Department of State, Memorandum of Conversation, Ben-Gurion, Acheson, Eban, Lewis, Jones, Waldo, 8.5. 1951, in: FRUS 1951 V, S.669; Department of State, Memorandum of Conversation, Keren, Byroade, Baker, 29.6. 1951, WNRC, RG 466, McCloy Papers, Box 28.

218 Vgl. Goldmann, Mein Leben als deutscher Jude, München u. Wien 1980, S.378f

${ }^{219}$ Herbert Blankenhorn, Verständnis und Verständigung. Blätter eines politischen Tagebuchs 1949-1979, Frankfurt a.M. usw. 1980, S. 139; Tagebuch-Blankenhorn, Eintrag vom 4.4. 1950, BA, NL Blankenhorn, $351 / 3$.

220 Tagebuch-Blankenhorn, Eintrag vom 6. 4. 1950, BA, NL Blankenhorn, 351/3. Daß Raymond auch für die spätere Berichterstattung über die Wassenaar-Verhandlungen in der amerikanischen Presse eine bedeutende Rolle spielte, zeigt Norbert Frei, Wiedergutmachungspolitik im Urteil der amerikanischen Öffentlichkeit, in: Herbst/Goschler (Hrsg.), Wiedergutmachung, S. 220-225, 228.

221 Vgl. Blaustein an McCloy, 24.8. 1965 (Anm. 210). 
Schrittmacherdienste leistete dabei immer wieder Blankenhorn, der zunächst als Leiter der Verbindungsstelle zur Alliierten Hohen Kommission und dann der Politischen Abteilung des Auswärtigen Amtes großen Einfluß darauf hatte, daß sich Adenauer aus seiner anfänglichen Lethargie in dieser Frage löste. Der Bundeskanzler war schließlich überzeugt von der „Bedeutung einer Erklärung zur Judenfrage für (die) öffentliche Weltmeinung “222, über deren Text Blankenhorn und Barou seit Frühjahr 1951 monatelang verhandelten. An der Redaktion der Erklärung beteiligten sich neben der israelischen Regierung und den amerikanischen jüdischen Organisationen auch der Stab des amerikanischen Hohen Kommissars ${ }^{223}$. Hauptstreitpunkt bildete die von jüdischer Seite geforderte Anerkennnung einer Kollektivschuld des deutschen Volkes, wobei sich Adenauer durchsetzte, der dies strikt ablehnte ${ }^{224}$. Am 27. September 1951 gab er

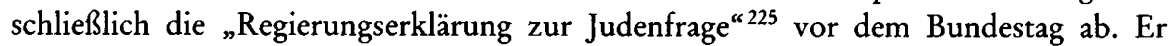
erklärte unter anderem die Bereitschaft der Bundesregierung, "gemeinsam mit Vertretern des Judentums und des Staates Israel ... eine Lösung des materiellen Wiedergutmachungsproblems herbeizuführen“. Allerdings betonte er auch die "Grenzen, die der deutschen Leistungsfähigkeit durch die bittere Notwendigkeit der Versorgung der zahllosen Kriegsopfer und der Fürsorge für die Flüchtlinge und Vertriebenen gezogen" seien ${ }^{226}$.

Adenauers Rede war ein Markstein in dieser Angelegenheit, doch, wie McCloy an Blaustein schrieb, bestand das Problem nun darin, die Bundesregierung dazu zu bewegen, die in der vom Bundestag feierlich angenommenen Erklärung enthaltenen Grundsätze in die Tat umzusetzen ${ }^{227}$. Zu diesem Zweck erfolgte einige Wochen später in New York die Gründung der Claims Conference, was Goldmann auf israelischen Wunsch hin bereits seit Sommer 1951 vorbereitet hatte ${ }^{228}$. Am 26. Oktober wurde dort eine Resolution angenommen, worin der Anspruch des Staates Israel unter Bezug auf die Eingliederung von Verfolgten des Nationalsozialismus in Israel unterstützt wurde. Daneben stand aber als gleichberechtigte Forderung, daß auch die bislang von den jüdischen Organisationen gegen Deutschland erhobenen Rückerstattungs- und Entschädigungsansprüche befriedigt werden müßten ${ }^{229}$. Damit hatte sich die Claims Conference dagegen verwahrt, als reines Akklamationsorgan für die israelischen Forderungen $\mathrm{zu}$ fungieren ${ }^{230}$.

Diese Erklärung überreichte Goldmann, der zum Präsidenten der Claims Conference gewählt worden war, am 8. November förmlich dem State Department. In der Erwartung eines Unterstützungsgesuchs hatte Geoffrey W. Lewis, stellvertretender Leiter der

222 Vgl. Adenauer bei Tee-Empfang am 6.9. 1951, BA, NL Blankenhorn, 351/7a.

223 Oral Memoir of Benjamin J. Buttenwieser, 1. 6. 1977, William E. Wiener OHL of the AJC, Jacob Blaustein Oral History Project.

224 Vgl. Kai von Jena, Versöhnung mit Israel? Die deutsch-israelischen Verhandlungen bis zum Wiedergutmachungsabkommen von 1952, in: VfZ 34 (1986), S. 463 f.; Yeshayahu A. Jelinek, Political Acumen, S. $87 \mathrm{f}$.

225 So Adenauer in der 175. Kabinettssitzung am 26.9. 1951, in: Kabinettsprotokolle der Bundesregierung, Bd. 4, S. 662.

226 Deutscher Bundestag, 165. Sitzung am 27.9. 1951, Stenographische Berichte, Bd. 9, S. $6697 \mathrm{f}$.

227 McCloy an Secretary of State for Blaustein, 2. 10. 1951, WNRC, RG 466, McCloy Papers, Box 32.

${ }^{228}$ Vgl. Nahum Goldmann, Staatsmann ohne Staat. Autobiographie, Köln u. Berlin 1970, S.313f.; Fünftes Kapitel, Abschnitt II. 3.

229 Resolution der Conference on Jewish Material Claims against Germany, New York, 26. 10. 1951, in: Documents Relating to the Agreement, S. 46.

$230 \mathrm{Vgl}$. auch Zweig, German Reparations and the Jewish World: A History of the Claims Conference, Boulder and London 1987, S. 15-18. 
Deutschlandabteilung, Goldmanns Gesprächspartner, Staatssekretär James Webb, vor dem Gespräch ausführlich präpariert: Webb solle Goldmann die Hoffnung des State Departments auf ein großzügiges deutsches Angebot mitteilen, zugleich aber darauf hinweisen, daß jede Lösung „die andauernde Notwendigkeit finanzieller Hilfen durch diese Regierung und die zusätzlichen Verteidigungslasten, die die deutsche Regierung vermutlich bald übernehmen" werde, in Rechnung stellen müsse. Auch komme nicht in Frage, McCloy damit zu beauftragen, auf die Höhe der Zahlungen einzuwirken und Adenauer zu schleunigen Verhandlungen mit den jüdischen Organisationen zu drängen. Überhaupt dürften Adenauer und McCloy angesichts der momentan wichtigen Fragen - Grotewohl-Vorschläge; Deutschlandvertrag; Europäische Verteidigungsgemeinschaft - nicht allzusehr mit diesen Problemen belastet werden ${ }^{231}$. Vom State Department konnten sich also die Claims Conference und Israel zu diesem Zeitpunkt zwar ein gewisses $\mathrm{Maß}$ an Wohlwollen, aber keine konkrete Unterstützung erhoffen.

Doch auch ohne solchen Rückhalt wurde die erste Begegnung Goldmanns mit Adenauer am 6. Dezember 1951, die nach der Ansprache des Bundeskanzlers vor dem Bundestag am 27. September nunmehr möglich geworden war, zu einem Erfolg. Unter größter Geheimhaltung trafen sich die beiden nur in Begleitung Barous und Blankenhorns in einem Londoner Hotel. Bei dieser Gelegenheit erklärte sich Adenauer zu Verhandlungen mit der Claims Conference und Israel bereit und stellte Wiedergutmachungsleistungen für Israel in Form von Warenlieferungen in Aussicht. Zugleich akzeptierte er die israelische Note vom 12. März als Verhandlungsgrundlage und bekräftigte dies, indem er einen von Goldmann entworfenen Brief ausfertigte ${ }^{232}$. Zur Überraschung Blankenhorns, der hierfür bei einem Gespräch mit Goldmann am Vortag keine Chance gesehen hatte ${ }^{233}$, war Adenauer somit auf die israelische Forderung nach einer Mrd. Dollar - das war der auf die Bundesrepublik entfallende 2/3-Anteil der Gesamtforderung - eingegangen.

Man kann diesen Schritt nicht auf unmittelbare Zwänge zurückführen; vielmehr war dies eine der berühmten „einsamen Entscheidungen“ Adenauers, die ohne vorherige Absprache mit seinem Kabinett erfolgte. Nachdem er mittlerweile dazu entschlossen war, eine Lösung in der Frage der israelischen Wiedergutmachungsforderungen aktiv anzustreben - wozu vielfältige in- und ausländische Anstöße kräftig beigetragen hatten -, und er sich in seiner Erklärung vor dem Bundestag auch feierlich dazu verpflichtet hatte, bewegte ihn offenbar die bewegende Gesprächssituation in London zu der folgenreichen Zusicherung an Goldmann. Allerdings zeigte die weitere Entwicklung, daß der Bundeskanzler die finanzielle Komponente dieser Verpflichtung zunächst nur als sehr unverbindlich beurteilte, d. h. nach Maßgabe dessen, was er als tatsächliche deutsche Leistungsfähigkeit betrachtete. Hieraus resultierten im wesentlichen auch die späteren Schwierigkeiten während der Verhandlungen ${ }^{234}$.

${ }^{231}$ Lewis an Webb, 6. 11. 1951, USNA, RG 59, 262.0041/11-651.

232 Siehe Goldmann, Leben als deutscher Jude, S. 382-387; ders., Adenauer und das jüdische Volk, in: Konrad Adenauer und seine Zeit. Politik und Persönlichkeit des ersten Bundeskanzlers. Bd. 1: Beiträge von Wegund Zeitgenossen, hrsg. v. Dieter Blumenwitz u. a., Stuttgart 1976, S. 431 f.; Adenauer, Erinnerungen, Bd. 2: 1953-1955, S. 137-139. Text des Briefes u. a. abgedruckt in Adenauer, Rhöndorfer Ausgabe, Briefe, hrsg. v. Rudolf Morsey u. Hans-Peter Schwarz, bearb. v. Hans-Peter Mensing, Bd. 4: 1951-1953, Berlin 1987, S. 150.

233 Siehe Goldmann, Adenauer und das jüdische Volk, S.431.

${ }^{234}$ Dafür spricht auch die Art, in der Adenauer das Kabinett erstmals über diese Begegnung informierte. Siehe Aufzeichnung Schäffers über Kabinettssitzung am 18.12. 1951, BA, NL Schäffer, 168/33; Im Zentrum der 
c) Erwartungen und Strategien im Vorfeld der Gespräche

In einer dramatischen Sitzung, der tagelange gewalttätige Protestdemonstrationen vorausgegangen waren, beschloß die Knesseth am 9. Januar 1952, Adenauers Verhandlungsangebot anzunehmen ${ }^{235}$. Auch die Claims Conference beriet in der folgenden Zeit ihre Verhandlungsziele. Während Israel einen Globalanspruch in Höhe von einer Mrd. Dollar, d. h. 4,2 Mrd. DM, stellte, setzte die Claims Conference einen eigenen Globalanspruch in Höhe von 500 Mio. Dollar fest und forderte daneben eine Reihe von Verbesserungen der bundesdeutschen Wiedergutmachungsgesetzgebung ${ }^{236}$. Zur Vermeidung von Überschneidungen stützte sich der israelische Globalanspruch auf die Eingliederungskosten für jüdische Opfer des Nationalsozialismus, während die Claims Conference ihre Forderung mit Ansprüchen auf erbenloses Eigentum begründete ${ }^{237}$. Bei einem erneuten Treffen in London am 17. Februar legten schließlich Goldmann und Adenauer Ort und Zeitpunkt der geplanten Konferenz fest: Sie sollte in einem Monat auf neutralem Boden im niederländischen Wassenaar beginnen ${ }^{238}$.

Seine Berater hatten Adenauer dazu geraten, die Kontakte zu den Juden nur über Goldmann laufen zu lassen, um nicht in innerjüdische Auseinandersetzungen verwikkelt zu werden ${ }^{239}$. Darüber war inbesondere dessen Stellvertreter in der Claims Conference, Jacob Blaustein, ziemlich erbost ${ }^{240}$ : Er stand in dieser Angelegenheit stets etwas im Schatten des weltmännischen und auch ein wenig eitlen Goldmann und versuchte dies unter anderem durch eigene Kontakte zu Adenauer, die ihm McCloy mehrfach vermittelte, zu kompensieren ${ }^{241}$. Der persönliche Gegensatz zwischen Goldmann und Blaustein besaß auch eine Entsprechung in der angestrebten Verhandlungstaktik: Blaustein vertraute primär auf seine ausgezeichneten Kontakte zur Truman-Administration, die bis zum Präsidenten persönlich reichten. Er favorisierte eine Lösung, wonach die amerikanische Regierung den Umfang der von Deutschland zu erbringenden Leistungen festsetzen sollte. Dem widersetzte sich Goldmann vehement: „Over my dead body. I'll get much more than the State Department would ever suggest." Dabei hielt er sich einiges auf seine Fähigkeit zugute, gegenüber Adenauer den richtigen Gesprächston zu treffen. Blaustein hingegen, so Goldmann, hätte niemals eine derartige persönliche Beziehung zu Adenauer aufbauen können, „speaking German, on Goethe and on Bach, and God knows“242. Von amerikanischer Seite hingegen erwartete Goldmann nicht allzu viel. Deshalb sah er auch davon ab - so etwa bei einem Treffen am Tage nach der

Macht. Das Tagebuch von Staatssekretär Lenz 1951-1953, bearb. v. Klaus Gotto, Hans-Otto Kleinmann und Reinhard Schreiber, Düsseldorf 1989, Eintrag vom 18.12. 1951, S. 200.

$235 \mathrm{Vgl}$. Sagi, Wiedergutmachung für Israel, S. 86.

236 Vgl. ebenda, S. 88-98; Zweig, German Reparations, S. $57 \mathrm{f}$.

237 Siehe dazu die Eröffnungsansprachen der Delegationen Israels und der Claims Conference in Wassenaar am 21.3. 1952, in BA, B 141/418, abgedruckt in: Documents Relating to the Agreement, S. 71-74 und 75-79.

238 Aufzeichnung Alexander Bökers aus London vom 17.2. 1952, PA/AA, II-244-13, Bd. 1.

239 Dies hatte McCloy zufolge der Bundeskanzler berichtet. Siehe dazu Schreiben von Segal an Blaustein u. Slawson, 25.2. 1952, anbei Bericht über Treffen mit McCloy am 15. und 16.2 und mit Byroade am 16.2. 1952, YIVO-Archiv, RG 347, AJC Records, GEN-10, Box 291; sowie Blankenhorn an Heinz D. Krekeler (deutscher Botschafter in USA), 10.1. 1952, IfZ-Archiv, ED 135, NL Krekeler, Bd. 43.

240 Siehe Goldmann, Leben als deutscher Jude, S. 389.

241 McCloy bezeichnete Blaustein als „pretty horn-handed, vigorous oil merchant who had a sense of public reponsibility as his career went on and wished to do something with the wealth and the power and the influence that he exerted", Interview mit McCloy, 23.2. 1972, William E. Wiener Oral History Library of the AJC, Jacob Blaustein Oral History Project.

242 Interview mit Nahum Goldmann, 24.11. 1971, William E. Wiener OHL of the AJC, Jacob Blaustein Oral History Project. 
ersten Begegnung mit Adenauer in London - McCloy als Vermittler anzurufen und zur Unterstützung bestimmter jüdischer Forderungen oder gar konkreter Beträge zu drängen; vielmehr bat er ihn nur, seinen Einfluß zur Durchsetzung der allgemeinen Prinzipien, die diesen Verhandlungen zugrundelagen, geltend $\mathrm{zu}$ machen ${ }^{243}$.

Daß der Einsatz von amerikanischer Seite bzw. seitens der Westalliierten zugunsten der jüdischen Sache begrenzt sein werde, machten sie auch der israelischen Regierung noch einmal deutlich. Diese waren in einer israelischen Note vom 30. November 1951 erneut gebeten worden, auf die Bundesrepublik Druck zur Erfüllung der in der Regierungserklärung vom 27. September in Aussicht gestellten Maßnahmen auszuüben ${ }^{244}$. Der britische Außenminister Anthony Eden antwortete am 10. Januar 1952, die britische Regierung erwarte das Ergebnis deutsch-israelischer Gespräche mit „sympathetic interest", wolle aber keinesfalls selbst in diese eingreifen ${ }^{245}$. Ähnlich die Antwort seines amerikanischen Kollegen Acheson vom 24. Januar: „The United States will await with sympathetic interest the outcome of the negotiations. “246 Die französische Regierung antwortete gar nicht, was das zukünftige Ausmaß ihres Interesses am Schicksal dieser Verhandlungen ziemlich exakt ausdrückte. Die anglo-amerikanische Formel des „sympathetic interest“ machte hingegen zwar deutlich, daß es kein direktes Engagement in den Verhandlungen geben werde, war aber andererseits auch elastisch genug, um Spielraum für mehr oder weniger massiven moralischen Druck auf die Deutschen offen zu lassen.

$\mathrm{Zu}$ einem ersten Test der alliierten Haltung kam es bereits vor Verhandlungsbeginn, und zwar durch die innerdeutsche Opposition gegen die Verhandlungen mit Israel und der Claims Conference. Schäffer lehnte diese grundsätzlich ab und hatte bereits in der Kabinettssitzung am 18. Dezember 1951, in der die Minister erstmalig über Adenauers Besprechung mit Goldmann informiert wurden, erklärt, daß „der Bundeshaushalt nicht in der Lage sei, vor Entscheidung über den Verteidigungsbeitrag und über die Frage der Auslandsschulden irgendwelche Beträge nach dieser Richtung hin aufzubringen " 247. Bei den Vorbesprechungen der zuständigen Bundesressorts, denen das Bundesfinanzministerium ostentativ fern blieb, stießen die geplanten Verhandlungen gleichfalls auf Bedenken. Im Mittelpunkt stand das Verhältnis zu der am 28. Februar beginnenden Londoner Schuldenkonferenz, bei der mit 65 Gläubigerstaaten über die Regelung der deutschen Vor- und Nachkriegsschulden verhandelt werden sollte ${ }^{248}$. Ähnliche Vorbehalte existierten auch in deutschen Industrie- und Wirtschaftskreisen. Hermann Josef Abs, der Leiter der deutschen Delegation in London, versuchte Adenauer, bei dem sein Wort beträchtliches Gewicht besaß, wiederholt von seinen heftigen Bedenken gegen die

243 Zachariah Shuster (AJC) an Slawson, 10.12. 1951, Anlage: Bericht über Treffen von Goldmann und Ferencz mit McCloy am 7. 12. 1952, YIVO-Archiv, RG 347, AJC Records, GEN-10, Box 275.

244 Israelische Note an die USA vom 30.11. 1951, in: Documents Relating to the Agreement, S. 47-50; entsprechende Noten an Großbritannien und Frankreich siehe ebenda, S. 50-53; S. 53-56.

245 Britische Note an Israel vom 10.1. 1952, ebenda, S.62.

246 Note der USA an Israel vom 24.1. 1952, ebenda, S. 63.

247 Aufzeichnung Schäffers zur Kabinettssitzung am 18.12. 1951, BA, NL Schäffer, 168/33. Siehe auch Hartmann an Hallstein, 18.2. 1952, PA/AA, II 244-13, Bd. 1. Zur Opposition Schäffers vgl. Michael Wolffsohn, Globalentschädigung für Israel und die Juden? Adenauer und die Opposition in der Bundesregierung, in: Herbst/Goschler (Hrsg.), Wiedergutmachung in der Bundesrepublik Deutschland, S. 161-190.

248 Aufzeichnungen über interministerielle Besprechungen am 6., 8. und 21.2. 1952, BA, B 136/1127 sowie PA/ AA, II 244-13, Bd. 1. Vgl. auch v. Jena, Versöhnung mit Israel, S. 467; Huhn, Die Wiedergutmachungsverhandlungen in Wassenaar, in: Herbst/Goschler (Hrsg.), Wiedergutmachung in der Bundesrepublik Deutschland, S. $142 \mathrm{f}$. 
Aufnahme von Verhandlungen mit Israel zu überzeugen, „da diese eine Regelung der deutschen Auslandsschulden bei der Londoner Konferenz in Frage stellen würden“ ${ }^{249}$.

Aus diesem Grund warb Abs in London Anfang März bei dem US-Delegierten, Botschafter Warren Lee Pierson, für den Gedanken, die Wassenaar-Konferenz bis nach dem Ende der Londoner Verhandlungen zu verschieben bzw. sie wenigstens nach London zu verlegen, um so mehr Kontrolle über die deutsch-israelisch-jüdischen Verhandlungen zu gewinnen. Doch auch wenn die amerikanische Seite großes Verständnis für die wirtschaftlichen Bedenken von Abs zeigte, lehnte sie doch eine Verschiebung oder eine Verlegung strikt ab, um den Erfolg der Wiedergutmachungsverhandlungen nicht zu gefährden ${ }^{250}$. Diese Haltung wurde von Acheson ausdrücklich bestätigt und schließlich durch McCloy auch Adenauer persönlich nahegebracht ${ }^{251}$. Hier zeichnete sich nun deutlich ein Wandel der amerikanischen Taktik ab: Nachdem die Angelegenheit mittlerweile zum Gegenstand direkter deutsch-israelisch-jüdischer Verhandlungen geworden war, setzten sich die USA in zunehmendem Maße für einen erfolgreichen und für beide Seiten tragbaren Ausgang ein, ohne selbst dafür in die direkte Verantwortung eintreten $\mathrm{zu}$ wollen.

Zwar wurde der Beginn der Verhandlungen nicht verschoben, doch einen Teilerfolg erzielten die innerdeutschen Gegner der Gespräche in Wassenaar gleichwohl. Als der zum Leiter der deutschen Delegation bestimmte Franz Böhm, Frankfurter Professor für Bürgerliches, Handels- und Wirtschaftsrecht, am 21. Februar dem Bundeskanzler vorgestellt wurde, erfuhr er zu seinem Erstaunen, daß offenbar noch keine Entscheidung über den Inhalt der deutschen Verhandlungsangebote getroffen war. Vielmehr sollte er die Gespräche in Wassenaar hinhaltend führen, damit man abwarten könne, wie sich die Dinge in London entwickeln. Auf Böhms verwunderte Frage, was im Haag eigentlich verhandelt werden sollte, meinte Adenauer: „Stellen Sie doch einmal fest, was die Herren eigentlich wollen." Dies war, wie Böhm bemerkte, zu diesem Zeitpunkt eigentlich schon recht genau bekannt ${ }^{252}$. Der Bundeskanzler war hingegen der Auffassung, daß er die Forderung Israels zwar mündlich und schriftlich „dem Grunde nach anerkannt habe, über die Höhe und Modalitäten der Abwicklung habe man (sci. aber)

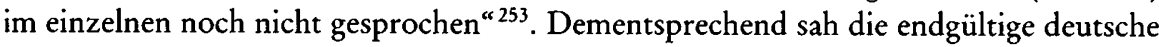
Verhandlungsstrategie vor, daß sich die Konferenz in zwei Abschnitten vollziehen sollte: In einer ersten Phase müsse sich die deutsche Delegation darauf beschränken, „die Forderungen der Gegenseite anzuhören“254. Erst sobald die Größenordnung der aus den Londoner Verhandlungen resultierenden Verpflichtungen bekannt sein würde, könnten dann schließlich in einer zweiten Phase die tatsächliche Höhe und die Modalitäten der deutschen Leistungen bestimmt werden ${ }^{255}$.

${ }^{249}$ Vgl. Hermann J. Abs, Konrad Adenauer und die Wirtschaftspolitik der fünziger Jahre, in: Konrad Adenauer und seine Zeit, Bd. 1, S. 240.

${ }^{250}$ Gifford an State Departement, 3.3. 1952, WNRC, RG 466, McCloy Papers, Box 37.

251 Acheson an Gifford, 7.3. 1952, WNRC, RG 466, McCloy Papers, Box 37; McCloy an State Department, 10.3. 1952, ebenda, Box 38 .

252 Vgl. Franz Böhm, Das deutsch-israelische Abkommen 1952, in: Konrad Adenauer und seine Zeit, Bd. 1, S. 449.

253 Vorlage von Rust an Adenauer, 22. 2. 1952, BA, B 136/1127.

254 Aufzeichnung v. Trützschlers für Blankenhorn über eine Besprechung im Auswärtigen Amt am 8.3. 1952, BA, NL Blankenhorn, 351/17.

255 Besprechung über die Vorbereitung der Konferenz mit Vertretern des Staates Israel und des Auswärtigen Amts am 8. 3. 1952, BA, NL Blankenhorn, 351/17. 


\section{Brennpunkt Wassenaar}

a) Verhandlungen unter Vorbehalt

Als am 21. März 1952 die Gespräche in Wassenaar begannen, sahen sich also die Vertreter des Staates Israel und der Claims Conference einer deutschen Delegation gegenüber, die zwar in personeller Hinsicht ihren Wünschen sehr entgegenkam, der aber die Hände weitgehend gebunden waren. So unterstrich Böhm in seiner Eröffnungsansprache erneut, daß zunächst nur die israelischen und jüdischen Ansprüche, ihre Höhe und Begründung im einzelnen geklärt werden sollten, um dann von der Bundesregierung im Lichte der deutschen Zahlungsfähigkeit geprüft zu werden ${ }^{256}$. Diese Taktik war nicht eben dazu angetan, die auf jüdischer Seite bestehende große Nervosität zu mildern ${ }^{257}$.

Die deutsche Delegation verhandelte parallel mit den Delegationen Israels und der Claims Conference. Letztere sprach in der ersten Phase nur über ihre Forderungen auf dem Gebiet der Gesetzgebung, die sie in einer Liste mit 24 Punkten unterbreitete ${ }^{258}$. Die Claims Conference-Delegation unter Leitung Moses Leavitts war angewiesen, dieser Frage Priorität vor ihrer Globalforderung einzuräumen ${ }^{259}$. Im Bereich der Rückerstattung begehrte sie in erster Linie die Aufrechterhaltung der geltenden Rückerstattungsgesetze sowie die Regelung der rückerstattungsrechtlichen Reichsverbindlichkeiten. Umfangreiche Wünsche bestanden vor allem im Bereich der Entschädigung: Das Entschädigungsrecht der US-Zone sollte auf die ganze Bundesrepublik einschließlich Westberlins ausgedehnt werden. Eine ganze Reihe von Forderungen zielte auf die Beschleunigung und erleichterte Durchführung der Verfahren. Daneben stand aber auch der Wunsch, den Berechtigtenkreis erheblich auszudehnen. Dies bezog sich einmal auf die Emigranten, Untergetauchten, vor 1947 ausgewanderten DP's sowie die jüdischen Gemeindebediensteten. Gravierender war jedoch die gewünschte Erweiterung der territorialen Voraussetzungen der Anspruchsberechtigung. So forderte die Claims Conference die Einbeziehung von Verfolgten aus der Ostzone, aus den Gebieten des Deutschen Reiches östlich der Oder-Neisse-Linie sowie aus den zeitweise eingegliederten Gebieten - letzteres zielte vor allem auf Österreich. Der Einbeziehung dieser Gebiete in eine Regelung maß die Claims Conference auch deshalb entscheidende Bedeutung zu, weil ihr eigener Globalanspruch in Höhe von 500 Mio. Dollar auf dem Anspruch auf erbenloses Vermögen ebendort beruhte ${ }^{260}$.

Die gewünschte Aufweichung des Territorialitätsprinzips erwies sich als der brisanteste Punkt der Forderungen. Die Beschränkung auf Verfolgte, die zu Beginn ihrer Verfolgung auf dem Gebiet der späteren Bundesrepublik gelebt hatten, war ein Erbe der Entstehung der Entschädigungsgesetze auf Länderebene und bedeutete den Ausschluß eines erheblichen Teils der Verfolgten. Nach zähen Verhandlungen war die deutsche Delegation hier zu einem Kompromiß bereit, an dessen Zustandekommen

\footnotetext{
256 Siehe dazu auch die Erklärung der deutschen Delegation bei Beginn der Verhandlungen in Wassenaar am 21.3. 1952, BA, B 141/418, abgedruckt in: Documents on the Agreement, S. $79 \mathrm{f}$.

257 Siehe dazu etwa Benjamin B. Ferencz an Saul Kagan, 3.3. 1952, WNRC, RG 466, McCloy Papers, Box 38.

258 Katalog der Forderungen der Conference Delegation auf dem Gebiet der Gesetzgebung, Anlage 1 zur Kabinettsvorlage Schäffers vom 9.5. 1952, BA, B 126/12524.

259 Vgl. Zweig, German Reparations, S. 23.

260 Moses Leavitt, Report No. 4 to the Presidium, 31.3. 1952, YIVO-Archiv, RG 347, AJC Records, GEN-10, Box 290.
} 
hauptsächlich Otto Küster beteiligt war ${ }^{261}$. Demnach sollten Emigranten aus dem Reichsgebiet vom 31. Dezember 1937 östlich der Oder-Neisse-Linie, aus Danzig, dem Memel- sowie dem Sudetenland zwei Drittel der Entschädigung im Rahmen der im Bundesgebiet geltenden Entschädigungsgesetzgebung erhalten. Emigranten aus Österreich sollten hingegen nur die Hälfte der dort vorgesehenen Entschädigung für Sonderabgaben einschließlich der Reichsfluchtsteuer bekommen - auch diese eingeschränkte Regelung war nur unter großen Vorbehalten konzediert worden. Bezeichnend für die Einstellung der deutschen Delegation war die Spitze Böhms in der Sitzung vom 26. März gegen Österreich, „das, statt seine Mithaftung anzuerkennen, sich als überfallenes Kind hätscheln" lasse $^{262}$.

Mit der Forderung nach Entschädigung der Verfolgten, die aus dem Gebiet der DDR stammten, war die Claims Conference hingegen gänzlich erfolglos geblieben, während eine ganze Reihe der übrigen Wünsche berücksichtigt worden $\operatorname{war}^{263}$. Doch stellte die deutsche Delegation die "Gemeinsamen Empfehlungen für die deutsche Gesetzgebung auf den Gebieten der Entschädigung und Rückerstattung“ vom 8. April 1952 am Ende noch einmal ausdrücklich unter Vorbehalt: Ihre Regierung müsse die Angelegenheit unter dem Gesichtspunkt der Leistungsfähigkeit der Bundesrepublik erst noch prüfen ${ }^{264}$. Dennoch war die Claims Conference zu diesem Zeitpunkt mit den bislang erreichten Fortschritten im großen und ganzen zufrieden ${ }^{265}$.

Erheblich stärker litten dagegen von Anfang an die Beratungen der von Giora Josephthal und Felix E. Shinnar geleiteten Israel-Delegation unter den Auswirkungen der deutschen Verhandlungstaktik. Sie stand unter doppeltem Druck der innerisraelischen Verhandlungsgegner und der heimischen wirtschaftlichen Notlage und akzeptierte das von deutscher Seite eingeschlagene Verfahren deshalb nur widerwillig. Die Gespräche drehten sich zunächst vor allem um die israelischen Berechnungen über die Eingliederungskosten für etwa $\mathbf{5 0 0 . 0 0 0 ~ j u ̈ d i s c h e ~ O p f e r ~ d e s ~ N a t i o n a l s o - ~}$ zialismus. Mit Hilfe des Bundesvertriebenenministeriums errechnete die deutsche Delegation einen Gesamtbetrag von etwa 4,5 Mrd. DM, wovon zwei Drittel, d.h. drei Mrd. DM, auf die Bundesrepublik entfielen ${ }^{266}$. Josephthal drängte heftig auf ein konkretes deutsches Angebot noch vor Beginn der Verhandlungspause, und Küster und Böhm waren schließlich geneigt, diesem Wunsch zu folgen ${ }^{267}$. Doch vor allem Schäffer und Abs protestierten vehement gegen eine solche $\mathrm{Absicht}^{268}$,

261 Siehe dazu die Berichte von Moses Leavitt an das Präsidium der Claims Conference, Report No. 1 (26.3. 1952) bis Report No. 7 (9.4. 1952), YIVO-Archiv, RG 347, AJC Records, GEN-10, Box 290; Bericht Böhms über den Stand der Verhandlungen mit der Claims Conference, 2.4. 1952, BA, NL Blankenhorn, 351/17.

262 Tagebuch Küster, Eintrag vom 26.3. 1952, ACDP, NL Küster (I-084-001A).

263 Ebenda; Gemeinsame Empfehlungen für die deutsche Gesetzgebung auf den Gebieten der Entschädigung und Rückerstattung, 8. 4. 1952, BA, B 141/415; Tagebuch Küster, Eintrag vom 8. 4. 1952, ACDP, NL Küster (I-084-001A).

264 Leavitt, Report No. 6 to the Presidium, 8.4. 1952, u. Report No. 7, 9. 4. 1952, YIVO-Archiv, RG 347, AJC Records, GEN-10, Box 290; Böhm an Leavitt, 8.4. 1952, BA, B 141/415.

${ }^{265}$ Department of State, Memorandum of Conversation, Goldmann, Rubin, Lewis, Reinstein u. Moores, 7.4. 1952, USNA, RG 59, 262.0041/4-752.

266 Vgl. Böhm, Das deutsch-israelische Abkommen 1952, S. 452.

267 Tagebuch Küster, Eintrag vom 27. und 28.3. sowie 3.4. 1952, ACDP, NL Küster (I-084-001 A); Bericht Böhms über den Stand der Verhandlungen mit Israel, 1.4. 1952, BA, NL Blankenhorn, 351/17.

${ }^{268}$ Ebenda, Eintrag vom 1.4. 1952; Bericht Böhms vom 1.4. 1952, BA, NL Blankenhorn, 351/17; Abs an Adenauer, 31.3. 1952, BA, NL Blankenhorn, 351/17; Gifford an State Department, 31. 3. 1952, WNRC, RG 466, McCloy Papers, Box 39. 
weshalb Adenauer schließlich zur Klärung dieser Differenzen für den 5. April eine Krisensitzung mit den Leitern der deutschen Delegationen in Wassenaar und London anberaumte.

Im Vorfeld dieser Sitzung meldete sich auch McCloy wieder zu Wort. Während einer Besprechung der Hohen Kommissare mit Adenauer am Vortag hatte ihn ein Telefonanruf erreicht, der ihn von Besorgnissen des State Departments über ein mögliches Scheitern der Verhandlungen unterrichtete ${ }^{269}$. Ein Schreiben Achesons, das McCloy tags darauf erhielt, bestätigte dies. Demnach hatte der israelische Botschafter unter Hinweis auf die kritische innenpolitische Situation in Israel dringend um eine Intervention zur Rettung der vom Scheitern bedrohten Wassenaar-Gespräche gebeten. Acheson betonte hier erneut sein Verständnis für die deutschen finanziellen Bedenken, die zum Teil auch seine eigenen waren. Doch wünschte er auf der Grundlage eines für beide Seiten tragbaren Kompromisses einen Erfolg der Verhandlungen und wies McCloy deshalb an: „Ger(man)s sh(ou)ld recognize unfortunate repercussions which w(ou)ld ensue if they now appear to have been insincere in their offer to negotiate. U(nited) $\mathrm{S}$ (tates) sh(ou)ld not of course attempt (to) tell (the) Ger(man)s what sh(ou)ld be magnitude or type of their offer to Israeli and Jewish org(anisation)s. " 270 Wiederum sind beide Elemente der gewandelten amerikanischen Taktik erkennbar: Hier wünschte man nunmehr den Erfolg der Verhandlungen, doch wurde die Lösung des Dilemmas zwischen wirtschaftlichen und moralischen Erfordernissen den Deutschen überlassen - vor allem, um nicht am Ende in die finanzielle Verantwortung für ein Abkommen hineingezogen zu werden. Noch vor der Sitzung vom 5. April informierte McCloy Adenauer über die in Washington aufgekommenen Befürchtungen ${ }^{271}$.

Die Sitzung selbst verlief turbulent: Adenauer teilte zunächst mit, die USA seien offensichtlich über einen möglichen Sturz der israelischen Regierung beunruhigt und folgerte, „wenn USA so starkes Interesse an dem Zustandekommen eines Abkommens zwischen der Bundesrepublik und Israel haben, so sollten sie uns helfen, damit wir wirklich leisten können “272. Hier offenbart sich die Zweischneidigkeit amerikanischer Interventionen: Stellungnahmen zugunsten eines Abkommens wurden auf deutscher Seite notorisch als Zahlungsbereitschaft aufgefaßt, zumal die entscheidende Frage, so der Bundeskanzler, lautete: „Wie sollen wir es bezahlen. ${ }^{273}$ Die deutsche Delegation solle vorläufig lieber die Stiftung eines Krankenhauses anbieten und die Festsetzung einer Summe bis zur Klärung der Leistungsfähigkeit vertagen ${ }^{274}$, meinte Adenauer weiter. Doch vor allem der Beredsamkeit Küsters gelang es schließlich, den Bundeskanzler auch gegen den Widerstand von $\mathrm{Abs}^{275}$ davon zu überzeugen, daß die deutsche

269 Adenauer und die Hohen Kommissare 1952, Verlaufsprotokoll der Sitzung vom 4.4. 1952, Anm. 5, S. 37. Dort ist irrigerweise von einem Anruf Achesons die Rede, während tatsächlich Staatssekretär David Bruce der Anrufer war.

270 Acheson an McCloy, 4.4. 1952, in: FRUS 1952-1954,Bd. IX/1: The Near and Middle East, Washington, D.C., 1986, S. $913 \mathrm{f}$. Israel hatte ähnliche Interventionen auch in Frankreich und Großbritannien unternommen, damit jedoch keinen Erfolg gehabt. Vgl. Huhn, Die Wiedergutmachungsverhandlungen in Wassenaar, S. 147.

271 Sagi (Wiedergutmachung für Israel, S. 139) hält diese Intervention für „praktisch nutzlos“. Huhn (Wiedergutmachungsverhandlungen in Wassenaar, S. 148) macht sie dagegen verantwortlich für die Sinnesänderung Adenauers.

272 Protokoll der Sitzung im Palais Schaumburg am 5. 4. 1952, BA, NL Blankenhorn, 351/17.

273 Tagebuch Küster, Eintrag vom 5.4. 1952, ACDP, NL Küster (I-084-001 A).

274 Ebenda. Vgl. auch Böhm, Das deutsch-israelische Abkommen 1952, S. 453.

275 Protokoll der Sitzung im Palais Schaumburg am 5.4. 1952, BA, NL Blankenhorn, 351/17. 
Delegation ermächtigt werde, in Wassenaar eine Summe von drei Mrd. DM als israelischen Anspruch anzuerkennen. Die effektive Höhe der deutschen Leistungen und der Zahlungsmodus sollten allerdings weiterhin offen bleiben.

Als McCloy anschließend von diesem Ergebnis informiert wurde, zeigte er zunächst deutliche Sympathie für die von Abs vorgebrachten Bedenken gegen das geplante Angebot $^{276}$. Die Erfüllung der israelischen Forderungen war für ihn offensichtlich niemals Selbstzweck, sondern vor allem ein Mittel, um die Belastungen der internationalen Stellung der Bundesrepublik zu verringern. In der ganzen Angelegenheit verlor McCloy nie sein Gesamtinteresse aus den Augen - innen- und außenpolitische Stabilisierung der Bundesrepublik bei gleichzeitiger Einbindung in den Westen -, und dies hieß eben auch, daß er die neuen Verpflichtungen in Grenzen halten wollte. McCloy stimmte dem deutschen Vorschlag schließlich $\mathrm{zu}$, doch was Bonn für ein deutliches Entgegenkommen hielt, erschien der israelischen Delegation am 7. April nur als ein erneutes Hinhalten ${ }^{277}$ : Aufgebracht über den Vorschlag, „Feststellung der Schuld und effektive Leistung zu trennen“, forderte sie nun ultimativ Höhe, Zeitraum und Konditionen des deutschen Angebots zu erfahren. Statt dessen wurde ihr tags darauf beschieden, die deutsche Delegation könne erst einen Monat nach Wiederbeginn der Londoner Verhandlungen, d.h. am 19. Juni, eine Erklärung dieser Art an Israel abgeben ${ }^{278}$. Dies bedeutete das vorläufige Aus für die Wassenaar-Gespräche.

\section{b) Die Krise und ihre Überwindung}

Während die Verhandlungen mit den Delegationen Israels und der Claims Conference ruhten, suchten diese nach Unterstützung ihrer Position. Jacob Blaustein setzte auf seine guten Beziehungen zum Weißen Haus und schlug bei einem persönlichen Treffen mit US-Präsident Truman am 7. April vor, dieser möge bei seiner nächsten Pressekonferenz sein Interesse an einem baldigen Erfolg dieser Verhandlungen erklären und damit Adenauer, der guten Willens sei, einen kleinen Stoß geben. Wenige Tage später versprach ihm Truman telefonisch eine derartige öffentliche Stellungnahme. Doch vergewisserte sich dieser anschließend bei seinem Außenminister, ob eine solche Erklärung opportun sei ${ }^{279}$. Acheson riet Truman jedoch davon ab, sah er doch die Gefahr, daß die Verhandlungsparteien aus einer solchen öffentlichen Erklärung des amerikanischen Präsidenten die Hoffnung zögen, daß die USA zur Finanzierung eines derartigen Abkommens bereit seien - wie gezeigt, waren derartige Befürchtungen wohlberechtigt. Daher sei es besser, so Acheson, der Bundesregierung die amerikanischen Hoffnungen auf ein erfolgreiches Ergebnis sowie die Empfehlung, daß die Haager Gespräche zum frühest möglichen Zeitpunkt wieder beginnen sollten, auf privatem Wege mitzutei-

276 Vgl. Abs, Adenauer und die Wirtschaftspolitik der fünfziger Jahre, S. 241; Böhm, Das deutsch-israelische Abkommen, S. 454. Siehe auch Tagebuch-Küster, Eintrag vom 5.4. 1952, ACDP, NL Küster (I-084-001 A); Aufzeichnung von Wolff (Bundesfinanzministerium) über Sitzung vom 5.4. 1952, BA, B 126/54544.

277 Tagebuch Küster, Eintrag vom 7.4. 1952, ACDP, NL Küster (I-084-001 A); Erklärung der deutschen Delegation, 5.4. 1952, in: Documents on the Agreement, S.82; Aufzeichnung Böhms, 7.4. 1952, BA, NL Blankenhorn, 351/17.

278 Tagebuch Küster, Eintrag vom 8.4. 1952, ACDP, NL Küster (I-084-001 A); Note der israelischen Delegation vom 8. 4. 1952, in: Documents on the Agreement, S. $82 \mathrm{ff}$; Erklärung der deutschen Delegation vom 9.4. 1952, in: ebenda, S. 85.

279 Blaustein an Truman, 11. u. 18.4. 1952, YIVO-Archiv, RG 347, AJC Records, GEN-10, Box 276; Truman an Blaustein, 30.4. 1952, ebenda. Wolffsohn datiert das Gespräch Blausteins mit Truman irrtümlicherweise auf den 21. April. Vgl. ders., Das deutsch-israelische Wiedergutmachungsabkommen, S. 702. 
$\operatorname{len}^{280}$. Noch am selben Tag instruierte er McCloy in diesem Sinne, nicht ohne erneut darauf hinzuweisen, daß er sich der deutschen Zwangslage, die Verpflichtungen aus London und Wassenaar erfüllen zu müssen, bewußt sei. Wichtig war aber sein Zusatz: "We are anxious, however, that this dilemma is resolved by Germans" ${ }^{281}$.

Goldmann, der sich bislang bewußt aus den Verhandlungen herausgehalten hatte ${ }^{282}$, setzte dagegen vor allem auf den direkten Kontakt zu Adenauer. Am 20. April trafen die beiden im Rhöndorfer Haus des Bundeskanzlers zusammen, und hier vertrat der Gastgeber den Standpunkt, daß die „Regelung des Schuldenkomplexes der Londoner Konferenz vordringlich sei, um die Kreditwürdigkeit Deutschlands wiederherzustellen und damit auch in die Lage versetzt zu werden, eine Wiedergutmachung an Israel zu leisten“283. Umgekehrt hatte er zuvor bei Abs um Verständnis für die Bedeutung Wassenaars für die wirtschaftliche Zukunft Deutschlands geworben: „Ich glaube, daß wenn es uns gelingt, das Judentum wenigstens in seinen führenden Männern zu versöhnen, wir dann doch auf wirtschaftliche Hilfe in stärkerem Maße rechnen können, als wenn dieser schroffe Gegensatz weiterbesteht. " ${ }^{284}$ Wohlwissend, wie sehr dies miteinander verknüpft war, wollte Adenauer beides: den Erfolg in London und in Wassenaar. Nur war er sich noch nicht darüber klar geworden, wie sich beides zugleich finanzieren ließ. Dagegen forderte Goldmann am 20. April den Vorrang der jüdischen vor den kommerziellen Forderungen in London, da diese moralischer Natur seien ${ }^{285}$. Deshalb drängte er Adenauer, bis spätestens Anfang Mai ein deutsches Angebot vorzulegen, was ihm der Bundeskanzler zunächst auch in Aussicht stellte.

Die klärenden Gespräche auf deutscher Seite ließen jedoch bis Mitte Mai auf sich warten. In der Zwischenzeit mußte Goldmann dem israelischen Ministerpräsidenten Ben-Gurion, der angesichts der verzweifelten wirtschaftlichen Situation seines Landes nunmehr bereit gewesen wäre, auch mit einer deutlich niedrigeren deutschen Offerte vorlieb zu nehmen, gut zureden, die Nerven zu behalten und an der bisherigen Forderung festzuhalten ${ }^{286}$. Es zeigte sich jedoch, daß die israelische Notlage auch auf deutscher Seite nicht unbemerkt geblieben war. Abs wollte die Gelegenheit beim Schopf packen und plädierte nun für jährliche Warenlieferungen an Israel in Höhe von 100 Mio. DM. Selbst dies ging jedoch Schäffer noch zu weit. Er sah für die nächsten Jahre keine Möglichkeit, diese Summe im Inland aufzubringen und regte statt dessen die Finanzierung durch eine amerikanische Anleihe an, die die amerikanischen Juden tunlichst selbst finanzieren sollten ${ }^{287}$.

${ }^{280}$ Acheson an Truman, 22.4. 1952, in: FRUS 1952-1954 IX/1, S. 917-919, hier: S. 919.

281 Acheson an McCloy, 22.4. 1952, ebenda, S. $919 \mathrm{f}$.

282 Goldmann, Leben als deutscher Jude, S. 390.

283 Besprechung Wiedergutmachung Adenauer-Goldmann, 19.4. 1952, BA, NL Blankenhorn, 351/11.

284 Adenauer an Abs, 8.4. 1952, in: Adenauer, Briefe, Bd. 4, S. $198 \mathrm{f}$.

285 Besprechung Wiedergutmachung Adenauer-Goldmann, 19.4. 1952 (Anm. 283); Goldmann, Leben als deutscher Jude, S. 392. Wie sich dieses Argument umdrehen ließ, zeigte Dehler: Er stellte sich am 20. Mai im Bundeskabinett auf den Standpunkt, daß Israel keinen finanziellen Anspruch habe, denn: „Moralische Forderungen seien eben nur moralisch." Tagebuch Lenz, Eintrag vom 20.5. 1952, S. 340.

286 Goldmann, Adenauer und das jüdische Volk, S. 428; ders., Leben als deutscher Jude, S. 394f. Vgl. auch Yeshayahu A. Jelinek, Die Krise der Shilumim/Wiedergutmachungsverhandlungen im Sommer 1952, VfZ 38 (1990), S. 128.

287 Aufzeichnung Blankenhorns über eine Besprechung mit Adenauer, Abs, Böhm, Küster, Schäffer, Erhard, Blücher, Dehler, Hallstein u. a. im Palais Schaumburg am 14.5. 1952, BA, NL Blankenhorn, 351/16; Tagebuch Küster, Aufzeichnung vom 14.5. 1952, ACDP, NL Küster (I-084-001 A); Aufzeichnung Böhm, 15.5. 1952, BA, NL Blankenhorn, 351/12. Vgl. dazu auch Jena, Versöhnung mit Israel?, S. 472f; Wolffsohn, Globalentschädigung für Israel und die Juden?, S. $173 \mathrm{f}$. 
Ähnlich entwickelte sich die Diskussion auch im Bundeskabinett. Als Böhm dort am 16. Mai erneut warnte, daß ein deutsches Angebot von 100 Mio. DM jährlich an Israel sofort abgelehnt werden würde, beharrten Abs und Schäffer auf ihren Standpunkten, wogegen Erhard wie schon früher für ein großzügigeres Angebot $e^{e i n t r a t}{ }^{288}$. Adenauer war darum bemüht, „einen Ausweg zu finden, der das Scheitern der Verhandlungen verhindere“ ${ }^{\text {(289 }}$ und führte dafür an: „Wiederherstellung unseres Kredits in der Welt hängt von dem Erfolg beider Verhandlungen ab. Das aber ist der Zweck des Ganzen. “290 Die Frage für Adenauer war nur, wieviel man dafür in Wassenaar zu geben bereit sein mußte. Im Konflikt zwischen dem Wunsch nach einem Erfolg der Verhandlungen und der Sorge um die Finanzierung eines Abkommens täuschte auch er sich über die Schmerzgrenze der Israelis und stimmte schließlich dem Vorschlag von Abs zu: Dieser wollte bei einem wenige Tage später stattfindenden Gespräch mit Shinnar und Keren, den Leitern der israelischen Delegationen in Wassenaar und London, die Reaktion auf ein inoffizielles 100-Millionen-DM-Angebot, das unter der Voraussetzung amerikanischer Hilfeleistung vielleicht noch aufgestockt werden könnte, sondieren ${ }^{291}$. In der Sicht von Abs war eine für Israel befriedigende Offerte ohnehin nicht möglich, vielmehr käme es "lediglich darauf an, ein Angebot zu machen, das in der Weltöffentlichkeit als eine vernünftige Basis betrachtet werde“ ${ }^{\text {292 }}$. Doch als er am 19. Mai in London den Israelis seinen Vorschlag unterbreitete, handelte er sich, wie von Böhm vorhergesagt, eine schroffe Abfuhr ein ${ }^{293}$.

Zwei Tage vor dieser mißglückten Aktion waren die Leiter der deutschen Wassenaar-Delegation, Böhm und Küster, aus Protest gegen die deutsche Verhandlungstaktik demonstrativ zurückgetreten. Küster hatte dies bereits seit einem heftigen Zusammenstoß mit Schäffer am 7. Mai geplant ${ }^{294}$. Bewußt gingen die beiden mit diesem Schritt an die Öffentlichkeit, um damit Druck auf die politische Führung auszuüben. Küster kritisierte, daß hinter dem ihm erteilten Auftrag "kein ernster und durchdachter Entschluß der Bundesregierung " gestanden habe ${ }^{295}$ - dem zweiten Teil seines Arguments wird man zustimmen können. Im Bundeskabinett wertete man den Rücktritt der deutschen Delegationsführer mehrheitlich als eine Art Dolchstoß in den Rücken der deutschen Sache, durch den man den unerfüllbaren Forderungen Israels ausgeliefert werde ${ }^{296}$, und auch Adenauer schien zunächst einer solchen Deutung anzuhängen ${ }^{297}$. Als er am 19. Mai Böhm zu einem Gespräch zitierte, begann er mit Vorwürfen, suchte aber zugleich nach einem Ausweg aus der verfahrenen Situation. So hörte er sich schließlich den Vorschlag Böhms an, wo-

\footnotetext{
288 Protokoll der 220. Kabinettssitzung, 16. 5. 1952, in: Die Kabinettsprotokolle der Bundesregierung, hrsg. f. d. Bundesarchiv v. Hans Booms, Bd. 5: 1952, bearb. v. Kai von Jena, Boppard a. Rh. 1989, S. $327 \mathrm{ff}$.

${ }^{289}$ Ebenda, S. 329.

290 Aufzeichnung Seebohms über Kabinettssitzung vom 16.5. 1952, BA, NL Seebohm, 178/7b.

${ }^{291}$ Protokoll der 220. Kabinettssitzung, 16.5. 1952, in: Kabinettsprotokolle der Bundesregierung, Bd. 5, S. $328 \mathrm{f}$.

292 Tagebuch Lenz, Eintrag vom 22.5. 1952, S. 342.

293 Notiz von Abs und Wolff über die Unterhaltung mit Keren und Shinnar am 19.4. 1952, BA, NL Blankenhorn, 351/16; Shinnar, Bericht eines Beauftragten, S. 40f.

294 Tagebuch Küster, Einträge vom 7.5.-20.5. 1952, ACDP, NL Küster (I-084-001 A); Böhm, Das deutschisraelische Abkommen, S. 459.

295 Vgl. etwa Frankfurter Rundschau, 21.5. 1952, „Leiter der deutschen Delegation bietet Rücktritt an“.

296 221. Kabinettssitzung vom 20.5. 1952, in: Kabinettsprotokolle der Bundesregierung, Bd. 5, S. 342; Tagebuch Lenz, Eintrag vom 20.5. 1952, S. 337 u. 340.

297 Sondersitzung des Kabinetts am 20.5. 1952, in: Kabinettsprotokolle der Bundesregierung, Bd. 5, S. 348.
} 
nach der israelischen Delegation eine Zahlung von drei Mrd. DM angeboten werden sollte, die während einer Dauer von acht bis zehn Jahren in Warenleistungen zu erfüllen wäre ${ }^{298}$.

In den folgenden zwei Tagen reifte bei Adenauer die Auffassung, daß sich die Verhandlungen nur durch einen solchen Schritt retten ließen - woran ihm im Gegensatz zu manchem seiner Minister sehr gelegen war. Zu dieser Entscheidung hatte neben der ungünstigen Publicity infolge des Rücktritts Böhms und Küsters ${ }^{299}$ auch ein am 21. Mai eingegangener Brief Goldmanns, der auf den mißlungenen Vorstoß von Abs in London reagierte, wesentlich beigetragen ${ }^{300}$. Er enthielt einen dringenden Appell an den Bundeskanzler, die Verhandlungen durch ein akzeptables Angebot zu retten. Die Vorschläge, die Abs in London unterbreitet hatte, seien hingegen beleidigend und ließen keine Bereitschaft der Bundesrepublik, „irgendwelche wirklichen Opfer für die Wiedergutmachung zu leisten“, erkennen ${ }^{301}$.

Im nachhinein war Adenauer die Sache peinlich: Als ihn am 21. Mai auch noch General Julius Klein, der Vorsitzende der jüdischen Kriegsveteranenorganisation in den USA, aufsuchte, um ihn gleichfalls zu einem befriedigenden deutschen Angebot zu drängen, erklärte er, Abs habe sich in London taktlos verhalten und sei bereits zurückbeordert worden ${ }^{302}$. Direkt im Anschluß an dieses Gespräch erschien der Gescholtene zu einer Unterredung mit dem Bundeskanzler. Abs Bericht über den völligen Mißerfolg seiner Mission brachte das Faß schließlich zum Überlaufen: Nachdem Adenauer so klar geworden war, daß ohne ein substantielles deutsches Angebot keine Aussicht auf einen Fortgang der Gespräche bestand, bat er nunmehr Böhm, sein zwei Tage zuvor skizziertes Angebot Goldmann privat zu unterbreiten, um damit die Gespräche wieder in Gang zu bringen ${ }^{303}$.

Böhm traf Goldmann sowie mehrere Vertreter der israelischen Delegation zwei Tage später in Paris und fand dabei weitgehende Zustimmung für seinen Vorschlag, der auf drei Mrd. DM Gesamtsumme für Israel, einer Erfüllungszeit von acht bis zwölf Jahren und der Beschränkung auf Warenlieferungen basierte. „Dies“, so Goldmann später, "waren Angebote, über die sich reden ließ.“ ${ }^{304}$ Zwar blieben einige Kritikpunkte auf israelisch-jüdischer Seite bestehen - so die in ihren Augen zu geringen Anfangsannuitäten, die Beschränkung auf Warenlieferungen und die lange Laufzeit. Doch unternahm Goldmann sogar von sich aus einen wichtigen Schritt, um die weiteren Verhandlungen zu erleichtern: Eigenmächtig reduzierte er den Globalanspruch der Claims Conference auf weniger als ein Viertel der ursprünglichen Forderung von 500 Mio. Dollar auf 400500 Mio. DM. Zugleich sollte dieser Betrag der an Israel zu leistenden Summe zuge-

${ }^{298}$ Böhm, Das deutsch-israelische Abkommen, S. 459 f.

${ }^{299}$ Siehe dazu Adenauer in der Sondersitzung des Kabinetts am 20.5. 1952, in: Kabinettsprotokolle der Bundesregierung, Bd. 5, S. 348 .

300 Adenauer, Erinnerungen, Bd. 2, S. 145.

301 Goldmann an Adenauer, 19.5. 1952, in: Der deutsch-israelische Dialog. Dokumentation eines erregenden Kapitels deutscher Außenpolitik, hrsg. v. Rolf Vogel, Teil I: Politik, Bd. 1, München usw. 1989, S. 65 f.

302 Tagebuch Klein, Eintrag vom 21. 5. 1952, Maj. Gen. Julius Klein Collection, Diary 1952, JWV-Archiv; Shepard Stone an McCloy, 21.5. 1951, WNRC, RG 466, McCloy Papers, Box 42. Auch in seinen Erinnerungen gab Adenauer vor, von dem Vorschlag von Abs nichts gewußt zu haben (Adenauer, Erinnerungen, Bd. 2, S. 147). Vgl. dazu auch v. Jena, Versöhnung mit Israel?, S. $473 \mathrm{f}$.

303 Bericht Adenauers in der Sondersitzung der Bundesregierung am 23.5. 1952, in: Kabinettsprotokolle der Bundesregierung, Bd. 5, S. 353f; Böhm, Das deutsch-israelische Abkommen, S. $460 \mathrm{f}$.

304 Goldmann, Leben als deutscher Jude, S. 397. 
schlagen werden, wobei sich dann Israel und die Claims Conference über die Aufteilung einigen könnten ${ }^{305}$.

Wie Shinnar schrieb, hatte Böhm bei diesen Gesprächen vom 23. Mai immer wieder darauf hingewiesen, daß er keine autorisierten Vorschläge machen könne, „sondern mit uns klären wolle, auf welche Regelung wir eingehen könnten“" ${ }^{306}$. Dies war nun erreicht, doch lag noch immer kein verbindliches Angebot der deutschen Regierung vor. An diesem Punkt erfolgte die bislang massivste Intervention von amerikanischer Seite: Wie McCloy gegenüber Julius Klein angekündigt hatte, sollte bei der bevorstehenden Unterzeichnung des Deutschland- und des EVG-Vertrages eine deutliche Stellungnahme zur gewünschten Wiederbelebung der Verhandlungen mit Israel und der Claims Conference erfolgen ${ }^{307}$. So geschah es dann auch: Als US-Außenminister Acheson am 25. Mai in Bonn mit Adenauer zusammentraf, hielt er ihm in dringender Form das amerikanische Interesse an einer für beide Seiten befriedigenden Lösung in den Verhandlungen mit Israel vor Augen. Heftig kritisierte er Berichte, wonach die Bundesrepublik auf amerikanische Hilfe zur Finanzierung eines derartigen Abkommens hoffe, da sich die Deutschen auf diese Weise der moralischen Verantwortung entzögen. Für diesen Zweck könne Deutschland keine US-Hilfe erwarten. Adenauer versuchte ihn unter Hinweis auf die erfolgreiche Böhm-Mission damit zu beschwichtigen, daß die Verhandlungen bereits wieder in Gang gekommen seien ${ }^{308}$.

Ähnlich relativiert auch Michael Wolffsohn die Bedeutung der Demarche Achesons, indem er sich darauf beruft, daß der Durchbruch ja bereits zwei Tage zuvor, bei dem Gespräch Böhms mit Goldmann, erfolgt sei ${ }^{309}$. Doch tatsächlich war die Angelegenheit zu diesem Zeitpunkt immer noch in der Schwebe, weshalb man den Wert dieser Intervention ruhig etwas höher bewerten darf, als Wolffsohn dies tut. Als nämlich Adenauer am 28. Mai Goldmann zu einem Gespräch einlud, konnte er noch immer keine Entscheidung über ein verbindliches deutsches Angebot präsentieren. Doch gab er sich bei dieser Gelegenheit entschlossen, zu einer Lösung auf Grundlage der Vorschläge Böhms zu gelangen ${ }^{310}$. Erneute Vorstöße McCloys bei Adenauer und Heuss dienten gleichfalls diesem Zweck ${ }^{311}$.

Am 10. Juni trafen Adenauer und seine Berater in Bonn mit Goldmann und Shinnar zusammen und fixierten nun endlich die Bedingungen eines verbindlichen deutschen Angebots, das auf den Ergebnissen der Besprechungen Böhms in Paris beruhte. Schwierigkeiten gab es allerdings vor allem in der Frage des Globalanspruchs der Claims Conference, dem die deutsche Seite sehr ablehnend gegenüberstand. Man einigte sich schließlich darauf, die Globalansprüche der Claims Conference und Israels gemeinsam zu behandeln, wobei ein Gesamtbetrag von 3,4 bis 3,5 Mrd. DM bestimmt wurde ${ }^{312}$.

305 Bericht Böhms über die Besprechung mit Goldmann und den israelischen Delegationsmitgliedern vom 23.5. 1952 in Paris, in: Vogel, Der deutsch-israelische Dialog, Teil I, Bd. 1, S. 67-72.

306 Shinnar, Bericht eines Beauftragten, S. 43.

307 Tagebuch Klein, Eintrag vom 21.5. 1952 (Anm. 302)

308 McCloy an State Department, 25.5. 1952, in: FRUS 1952-1954 IX/1, S. 938.

$309 \mathrm{Vgl}$. Wolffsohn, Das deutsch-israelische Wiedergutmachungsabkommen, S. 704.

310 Goldmann, Leben als deutscher Jude, S. 398; Adenauer, Erinnerungen, Bd. 2, S. 151 f.

311 AJC-Contributions to Postwar Economic Rehabilitation of Jewish Victims of Nazi Persecution, September 1965, AJC-Archiv, JSX, Subject Restitution 65-66.

312 Niederschrift über die Besprechung zwischen Goldmann, Shinnar, Hallstein, Böhm, Frowein und Abs am 10.6. 1952 (in Ggw. Adenauers), PA/AA, II 244-13, Bd. 2; Goldmann, Mein Leben als deutscher Jude, S. 398-403; Böhm, Das deutsch-israelische Abkommen 1952, S. 462-464; Shinnar, Bericht eines Beauftragten, S. 46-48. 
Hans-Peter Schwarz spricht von der „unverfrorene(n) Chuzpe“ Goldmanns, mit der er am 10. Juni 500 Mio. Dollar für die Claims Conference beim Bundeskanzler „herausgeschlagen" habe ${ }^{313}$. Dabei übersieht er, daß Goldmann diese Forderung bereits früher freiwillig auf ein knappes Viertel dieser Summe reduziert hatte. Drastischer hatte den hier verborgenen Vorwurf einst Schäffer formuliert, der Goldmann später, wann immer er in sein Büro kam, mit den Worten zu begrüßen pflegte: „Hier kommt ja der Mann, der uns einige hundert Millionen Mark gestohlen hat. Aber trotzdem gebe ich ihm eine gute Zigarre." 314

Doch bis dahin war es noch ein weiter Weg. Als am 17. Juni die Ergebnisse dieses Treffens im Kabinett besprochen wurden, zürnte Schäffer, daß er bei dem Gespräch übergangen worden war und bezeichnete die Resultate als unannehmbar. Die Globalansprüche Israels und der Claims Conference stellte er sachlich in Frage, in jedem Falle aber würden sie die Finanzierung der Individualansprüche gefährden. Die Quintessenz seiner Ausführungen war, daß kein Geld für diese Zwecke da sei ${ }^{315}$. Doch endete die Sitzung mit einer Schlappe für Schäffer. Adenauer unterstrich die „überragende Bedeutung der Angelegenheit im Verhältnis zur gesamten westlichen Welt und insbesondere zu den USA. Der ergebnislose Abbruch von Verhandlungen mit Israel würde die schwersten politischen und wirtschaftspolitischen Gefahren für die Bundesrepublik heraufbeschwören; deshalb müßten selbst erhebliche finanzielle Opfer in Kauf genommen werden, um mit Israel zu einer Einigung zu gelangen. “ 316 Nach den letztgenannten Interventionen Achesons und McCloys kann es nicht überraschen, daß er zu dieser Auffassung gelangt war. Auch auf das Kabinett wirkte dies überzeugend: Es stimmte „in überwältigender Mehrheit für die Fortsetzung der Verhandlungen “ 317 und billigte die Beschlüsse vom 10. Juni. Damit war der Weg zur Fortsetzung der Verhandlungen frei.

c) Von der Wiederaufnahme der Gespräche zur Ratifizierung

Am 24. Juni wurden die Gespräche in Wassenaar wieder aufgenommen. Die deutsche Delegation, diesmal mit Böhm, aber ohne Küster, dessen Stelle von Trützschler aus dem Auswärtigen Amt eingenommen hatte, war nun durch Vertreter des Finanz- und Justizministeriums verstärkt worden. Fortan wehte der Wind aus einer anderen Richtung, wie Frederick Goldschmidt von der Claims Conference-Delegation beschrieb: „Während im ersten Teil der Verhandlungen die maßgebende Persönlichkeit auf deutscher Seite Rechtsanwalt Küster gewesen war, hatten wir nunmehr den Eindruck, daß der Lauf der Verhandlungen durch eine im Haag nicht anwesende Persönlichkeit bestimmt wurde, nämlich durch Bundesfinanzminister Schäffer. “ ${ }^{318}$ Trotz der vorherigen Ankündigung war die Claims Conference-Delegation schwer enttäuscht, daß ein Teil der „Gemeinsamen Empfehlungen“ vom April 1952, auf die sich beide Delegationen in der ersten Verhandlungsphase geeinigt hatten, aus finanziellen und politischen Grün-

\footnotetext{
313 Vgl. Hans-Peter Schwarz, Adenauer. Der Aufstieg: 1876-1952, Stuttgart 1986, S. 903.

314 Goldmann, Leben als deutscher Jude, S. 387.

315 228. Kabinettssitzung vom 17.6. 1952, in: Kabinettsprotokolle der Bundesregierung, Bd. 5, S. 395-398. Siehe dazu auch Schäffer an Ministerialrat Spieler (Bundeskanzleramt), 18.6. 1952, Nachtrag zum Protokoll der Sitzung vom 17.6. 1952, BA, NL Schäffer, 168/33.

316 228. Kabinettssitzung vom 17.6. 1952, in: Kabinettsprotokolle der Bundesregierung, Bd. 5, S. 398.

317 Tagebuch Blankenhorn, Eintrag vom 17.6. 1952, BA, NL Blankenhorn, 351/10.

318 Bericht von F. Goldschmidt (Council for the Protection of the Rights and Interests of Jews from Germany) über die Gespräche in Wassenaar, 1. 9. 1952, LBI-Archiv, Council of Jews from Germany, Folder 19.
} 
den gestrichen worden war. Die neue Linie der deutschen Delegation stellte zunächst jede Regelung, die über die vertraglichen Abmachungen im Dritten und Vierten Teil des Überleitungsabkommens mit den Alliierten hinausging, in Frage ${ }^{319}$.

Insbesondere betraf das die zunächst konzedierten Ausweitungen des Kreises der Anspruchsberechtigten auf Verfolgte aus den vom Deutschen Reich besetzten und annektierten Gebieten. Nun wurden die Ansprüche von Österreich-Emigranten auch vom Bonner Kabinett endgültig abgelehnt ${ }^{320}$. Ähnlich verhielt es sich mit den Auswanderern aus den Gebieten des Deutschen Reiches östlich der Oder-Neiße-Linie, aus Danzig, dem Memel- und dem Sudetenland, denen in der ersten Verhandlungsphase eine 2/3-Entschädigung in Aussicht gestellt worden war. Doch entstand hier schließlich ein eigenartiger Kompromiß: Verfolgte aus den sogenannten Vertreibungsgebieten im Sinne des Lastenausgleichsgesetzes, von denen man annehmen konnte, daß sie den Vertreibungsmaßnahmen gegen Deutsche ausgesetzt gewesen wären, erhielten Entschädigungsansprüche, die im wesentlichen denen glichen, die Vertriebene nach dem Lastenausgleich beanspruchen konnten - Verfolgte wurden so zu fiktiven Vertriebenen ernannt ${ }^{321}$. Wieder einmal erwiesen sich Hilfsmaßnahmen für Kriegsgeschädigte als Motor für Verbesserungen zugunsten der Opfer des Nationalsozialismus.

Auch mit einigen anderen Forderungen gelang es der Claims Conference, über den durch Artikel III und IV des Überleitungsabkommens gesteckten Rahmen hinauszugelangen. Hatten sich die Deutschen gegenüber den Alliierten noch erfolgreich geweigert, sich auf einen Zeitraum zur Erfüllung der individuellen Entschädigungsansprüche festzulegen, so verpflichteten sie sich nunmehr zur Durchführung in maximal zehn Jahren. Aber auch etwa die Entschädigung für jüdische Gemeindebedienstete, für Leben in der Illegalität, für Ausbildungsschäden und für die sog. „Doppelverfolgten“, d.h. Verfolgte, die als politische Flüchtlinge aus der SBZ bzw. DDR in die Bundesrepublik gelangten, sowie die Gleichstellung von Zwangsarbeit mit Freiheitsentziehung waren derartige Erfolge der Claims Conference. Wichtig war auch, daß nunmehr Staatenlose und politische Flüchtlinge unter den Verfolgten wenigstens eine Entschädigung für Freiheitsentzug bzw. für Schaden an Gesundheit und Leben erhalten sollten. Am 8. August wurden schließlich diese und andere Punkte als "Vorgesehene Regelungen über den Ausbau der Wiedergutmachungsgesetzgebung" von beiden Delegationen beschlossen ${ }^{322}$. Darüber hinaus erhielt die

319 Ebenda; Report No. 8 to the Presidium by Moses A. Leavitt, 26.7. 1952, YIVO-Archiv, RG 347, AJC Records, GEN-10, Box 282; Tagebuch Küster, Eintrag vom 2.5. 1952, ACDP, NL Küster (1-084-001 A); Kabinettsvorlage Schäffers vom 5.9. 1952, BA, B 126/12524; Frowein, Entwurf II, Instruktion an die Delegation für die Wiedergutmachungsverhandlungen im Haag, o.Dat., BA, B 126/51544.

320 245. Kabinettssitzung am 8. September 1952, in: Kabinettsprotokolle der Bundesregierung, Bd. 5, S. 550 f. u. $557 f$.

321 Goldschmidt, 1. 9. 1952, Bericht über die im Juni, Juli und August geführten Verhandlungen zwischen der Delegation der Deutschen Bundesrepublik und der Delegation der Claims Conference, LBI-Archiv, Council of Jews from Germany, Folder 19. In der späteren Praxis wirkte sich diese Regelung vielfach höchst unglücklich aus, wurden doch ehemalige jüdische NS-Verfolgte aus den Vertreibungsgebieten dazu gezwungen, ihr „Bekenntnis zum deutschen Sprach- und Kulturkreis“ zu dokumentieren. Vgl. Walter Schwarz, Die Wiedergutmachung nationalsozialistischen Unrechts durch die Bundesrepublik Deutschland. Ein Überblick, in: Herbst/Goschler (Hrsg.), Wiedergutmachung in der Bundesrepublik Deutschland, S. 47.

322 Vorgesehene Regelungen über den Ausbau der Wiedergutmachungsgesetzgebung, 8. 8. 1952, Anlage 3 zur Kabinettsvorlage Schäffers vom 5. 9. 1952, BA, B 126/12524. Vgl. auch Sagi, Wiedergutmachung für Israel, S. 166-168 (mit einigen Ungenauigkeiten!). 
Claims Conference die Zusicherung, bei der künftigen Umsetzung der Vereinbarungen beteiligt $\mathrm{zu}$ werden ${ }^{323}$.

Schwieriger gestaltete sich die Frage des Globalanspruchs der Claims Conference. Böhm forderte nun weisungsgemäß einen Nachweis über die Zusammensetzung dieser Forderung ${ }^{324}$. Die Claims Conference-Delegation rechnete daraufhin vor, daß sich das Deutsche Reich durch Raubzüge im Reichsgebiet und in den besetzten Gebieten jüdisches Vermögen in Höhe von etwa 1,9 Mrd. Dollar einverleibt habe ${ }^{325}$. Überdies verwies sie darauf, daß die der Claims Conference angeschlossenen Organisationen bereits etwa 1,1 Mrd. Dollar für die Rehabilitierung jüdischer Opfer des Nationalsozialismus ausgegeben hätten ${ }^{326}$. Demgegenüber wollte Böhm auf der Grundlage der erbenlosen Ansprüche nur 95 Mio. DM als berechtigt anerkennen. Jedoch schlug er vor, der Claims Conference zusätzlich einen Härtefonds in Höhe von 305 Mio. DM zur Verfügung zu stellen. Dahinter steckte die Überlegung, daß sich die Ablehnung einiger in der ersten Verhandlungsphase in Aussicht gestellter Verbesserungen der Entschädigungsgesetzgebung auf diese Weise leichter vertreten ließe. Dies bedeutete also eine Verlagerung von Individualansprüchen auf kollektive Leistungen zugunsten der Claims Conference. Überdies forderte Böhm auch, daß zehn Prozent dieser Summe zugunsten der sogenannten Nicht-Glaubensjuden abgezogen werden sollten, da die Claims Conference die Zuständigkeit für diese Gruppe ablehnte ${ }^{327}$. Den Vertretern des Finanzministeriums in der deutschen Delegation ging das alles viel zu weit. Ministerialdirektor Wolff beschwerte sich am 4. Juli bei Schäffer über die Delegationsleitung, die „sich nur schwer und selten gegenüber Forderungen und Wünschen der Gegenseite zu einem klaren Nein zu entschließen" vermöge und selbst bei eigentlich unmöglichen Forderungen „immer noch die Neigung“ hätte, „nach Kompromißformeln zu suchen“ ${ }^{328}$.

Auch der Bundesfinanzminister selbst stellte am 11. Juli im Kabinett die Ansprüche der Claims Conference erneut grundsätzlich in Frage ${ }^{329}$. Goldmann protestierte gegen diesen Vorstoß, der im Widerspruch zu den Absprachen mit Adenauer vom 10. Juni stand. Hintersinnig erinnerte er den Bundeskanzler daran, „daß in unserer letzten Besprechung, als von einem der Beteiligten die Frage nach der detaillierten Begründung dieses Globalanspruches gestellt wurde, Sie es gerade waren, der sehr weise und mit voller Berechtigung darauf hinwies, daß die detaillierte Diskussion dieses Fragenkomplexes, die natürlich in die Öffentlichkeit dringen würde, und der detaillierte Nachweis des schrecklichen Charakters dieser Sonderaktionen gegen die Juden, denkbar unerwünscht wäre vom Standpunkt unserer gemeinsamen Zielsetzung “330. Auch McCloy warnte Adenauer kurz vor seiner endgültigen Rückkehr nach den USA, eine Vertagung oder gar Ablehnung der jüdischen Forderung durch das Kabinett „könnte nicht nur die

${ }^{323}$ Leavitt, Report No. 8 to the Presidium, 26.7. 1952, (Anm. 319); Leavitt an Böhm, 8. 9. 1952, in: Documents on the Agreement, S. 159; Böhm an Leavitt, 8.9. 1952, ebenda, S. 160.

324 Protokoll über die Sitzung im Palais Schaumburg, 23.6. 1952, Hallstein, Böhm, Blankenhorn u. a., PA/AA, II 244-13, Bd. 3.

325 Dokument der Claims Conference vom 30.6. 1952 zur Begründung des Globalanspruchs, PA/AA, II 24413, Bd. 2.

326 Siehe zusammenfassende Aufzeichnung Ludwigs über die Sitzung mit der Claims Conference am 27.6. 1952, nachmittags, PA/AA, II 244-13, Bd. 2.

327 Berichte Böhms vom 2.7. und 14.7. 1952 an Bundesregierung, BA, B 149/419 und PA/AA, II 244-13, Bd. 3. Vgl. auch Huhn, Wiedergutmachungsverhandlungen in Wassenaar, S. 156.

328 Wolff an Schäffer, 4. 7. 1952, BA, B 126/51544.

329 234. Kabinettsitzung am 11. Juli 1952, Kabinettsprotokolle der Bundesregierung, Bd. 5, S. 452.

330 Goldmann an Adenauer, 11.7. 1952, BA, B 141/415. 
gesamten Arbeiten der Haager Konferenz gefährden, sondern vor allem hinsichtlich der Aussöhnung Deutschlands mit dem jüdischen Volk, die für Deutschlands Zukunft und internationale Stellung so bedeutsam ist, schwerwiegende Folgen haben " ${ }^{331}$.

Diese Interventionen waren zu diesem Zeitpunkt weniger ausschlaggebend für die Haltung Adenauers, der ja den Globalanspruch der Claims Conference bereits explizit anerkannt hatte ${ }^{332}$, als dazu wichtig, einige widerstrebende Mitglieder seiner Regierung zu beeindrucken. So schlug Staatssekretär Hallstein der Ministerrunde am 15. Juli vor, der Claims Conference eine Globalentschädigung von 450 Mio. DM anzubieten. Daneben sollten weitere, von der Bundesrepublik zu verteilende 50 Mio. DM als Härtefonds für Nicht-Glaubensjuden zur Verfügung gestellt werden. Dafür machte Hallstein weniger rechtliche als politische Erwägungen geltend: Insbesondere würde hierdurch „voraussichtlich eine günstige Atmosphäre für die Aufbringung einer äußeren Anleihe geschaffen, die die vorgesehenen Leistungen an Israel sehr erleichtern würden “333. In einem vorangegangenen Brief an Adenauer hatte er dagegen die Nachteile eines Scheiterns der Verhandlungen betont: Neben einer verstärkten politischen Agitation inbesondere der amerikanischen Juden seien auch wirtschaftliche Nachteile etwa durch „Boykotthetze“ zu erwarten ${ }^{334}$. Auch der Bundeskanzler wies dann vor dem Kabinett „auf die große wirtschaftliche Macht des Judentums in der Welt“, zugleich aber auch „auf das ungeheuerliche Ausmaß des deutscherseits den Juden in ganz Europa angetanen Unrechts" hin ${ }^{335}$. Moralische Begründung und pragmatisches Kalkül gingen hier Hand in Hand, auffällig dabei besonders die Dramatisierung des jüdischen Einflusses.

Schäffer beharrte jedoch auf seiner Ablehnung und drohte dabei insbesondere damit, daß die Finanzierung der Individualentschädigung durch die zusätzliche Globalentschädigung an die Claims Conference gefährdet sei. Dem hielt Adenauer entgegen, daß gerade die Globalentschädigung für die Claims Conference „die Bundesrepublik praktisch sehr entlasten würde, weil sie ja jeden Hilfsbedürftigen, der sich an sie wende, an die CC verweisen könne und müsse “ ${ }^{336}$. Tatsächlich übte die deutsche Delegation in den Verhandlungen großen Druck aus, daß die Globalentschädigung der Claims Conference zur Rehabilitierung und Fürsorge bedürftiger Verfolgter, die keine Entschädigung im Rahmen der deutschen Gesetzgebung erhalten konnten, verwendet würde ${ }^{337}$. Adenauer setzte sich schließlich erneut durch, auch wenn die Schlußabstimmung im Kabinett nur eine Stimme Mehrheit gegen Schäffer, Hellwege, Dehler und Kaiser zugunsten des Antrags Hallsteins ergab ${ }^{338}$.

Weniger Schwierigkeiten machten in der zweiten Phase die Gespräche mit der IsraelDelegation, die sich hauptsächlich um technische Fragen drehten. Probleme bereitete dabei in erster Linie der israelische Wunsch nach einer Wertsicherungsklausel, mit der sie sich gegen eventuelle Risiken einer inflationären Entwicklung absichern wollten, während umgekehrt die deutsche Seite auf einer Katastrophenklausel bestand, die eine

331 McCloy an Adenauer, vorgelegt am 15. 7. 1952, BA, NL Blankenhorn, 351/16.

332 Siehe dazu auch Aufzeichnung Hallsteins für Adenauer, 7.7. 1952, PA/AA, II 244-13, Bd. 2; Hallstein an Böhm, 7.7. 1952, ebenda.

333 235. Kabinettssitzung am 15.7. 1952, in: Kabinettsprotokolle der Bundesregierung, Bd. 5, S. $456 \mathrm{f}$.

334 Aufzeichnung Hallsteins für Adenauer, 7.7. 1952 (Anm. 332).

335 235. Kabinettssitzung am 15.7. 1952, in: Kabinettsprotokolle der Bundesregierung, Bd. 5, S. 457.

336 Ebenda.

337 Vgl. dazu auch Zweig, German Reparations, S.24f. u. $60 \mathrm{f}$.

338 235. Kabinettssitzung am 15.7. 1952, in: Kabinettsprotokolle der Bundesregierung, Bd. 5, S. 458; TagebuchBlankenhorn, Eintrag vom 15. 7. 1952, BA, NL Blankenhorn, 351/13. 
Handhabe im Falle einer dramatischen Verschlechterung der deutschen Zahlungsfähigkeit geben sollte ${ }^{339}$.

Bedrohlich waren jedoch Einflüsse von außen: Die arabischen Nachbarstaaten Israels reagierten auf die Nachrichten von den geplanten deutschen Leistungen an ihren Gegner mit heftigen Protesten, da sie hierdurch die wirtschaftliche und militärische Lage im Nahen Osten zu ihren Ungunsten verändert sahen ${ }^{340}$. Sowohl die Schalmeienklänge der deutsch-arabischen Freundschaft als auch die dumpfen Trommelwirbel eines Handelsboykotts, die aus dem Nahen Osten drangen, waren willkommene Verstärkung im Orchester der innerdeutschen Gegner des Abkommens mit Israel. Besonders Finanzminister Schäffer und der aufstrebende Bundestagsabgeordnete Franz-Josef Strauß ${ }^{341}$ waren dort tonangebend. Angesichts dieser Wirkung der arabischen Proteste wandte sich Adenauer drei Tage vor der entscheidenden Kabinettsabstimmung über die in Wassenaar ausgehandelten Abkommen hilfesuchend an McCloys Amtsnachfolger Walter Donelly. Wie dieser dem State Department berichtete, war der Bundeskanzler entschlossen, die Angelegenheit zum Erfolg zu führen. Adenauer zweifelte nicht daran, die Opposition überstimmen zu können, doch hätte er es als Stärkung seiner Politik begrüßt, darauf verweisen zu können, daß die Vereinigten Staaten bereit seien, sich für die Beschwichtigung der arabischen Drohungen einzusetzen ${ }^{342}$. Am selben Tag noch gab Acheson Donelly positiven Bescheid: „You may authorize Chancellor to make statement to effect US is willing to use its good offices to try to abate Arab pressure and to endeavor to persuade at least some of the Arab states to abandon their threats. “ ${ }^{343}$ Überdies wurde Adenauer über die Anstrengungen, die die USA in dieser Hinsicht bereits unternommen hatten, informiert. So hatte Byroade, der inzwischen vom Leiter der Deutschlandabteilung zum Staatssekretär für Nahost-, südasiatische und afrikanische Angelegenheiten aufgestiegen war, gegenüber dem syrischen Botschafter die deutschen Leistungen an Israel verteidigt: Das State Department habe sich niemals in die deutsch-israelischen Verhandlungen eingemischt, aber gegenüber der deutschen politischen Führung die Haltung eingenommen, daß das deutsche Volk Israel aus moralischen Gründen Reparationen schulde ${ }^{344}$. Mit diesen Erklärungen gewappnet stellten sich Adenauer und Hallstein in der Kabinettssitzung am 8. September dem Argument der Gefährdung der deutsch-arabischen Beziehungen entgegen ${ }^{345}$. So handelte es sich hier also keineswegs um einen Bluff ${ }^{346}$, vielmehr bestand auf amerikanischer Seite tatsächlich die Absicht, den Bundeskanzler in dieser Sache zu stützen.

339 236. Kabinettssitzung am 18. 7. 1952, in: Kabinettsprotokolle der Bundesregierung, Bd. 5, S. 468 ; 237. Kabinettssitzung am 25.7. 1952, ebenda, S. 479; Sondersitzung des Kabinetts am 12.8. 1952, ebenda, S. 505507; 245. Kabinettssitzung am 8.9. 1952, ebenda, S. 552 ff. Vgl. auch Huhn, Wiedergutmachungsverhandlungen in Wassenaar, S. $158 \mathrm{f}$.

340 245. Kabinettssitzung am 8.9. 1952, Kabinettsprotokolle der Bundesregierung, Bd. 5, S. 549; PA/AA, II 24413, Bd. 4 u. 5; Memorandum der Delegation der arabischen Staaten Ägypten, Irak, Jemen, Jordanien, Libanon, Saudi-Arabien und Syrien an die Regierung der Bundesrepublik Deutschland, 31. 10. 1952, BA, B 126/51545.

341 Siehe dazu BA, B 126/51545; Tagebuch-Blankenhorn, Eintrag vom 16. 10. 1952, BA, NL Blankenhorn, 351/ 14; Tagebuch Lenz, Eintrag vom 18.8. 1952, S. 412.

342 Walter J. Donelly an State Department, 6.9. 1952, in: FRUS 1952-1954 IX/1, S. 991.

343 Acheson an Donelly, 6.9. 1952, ebenda, S. 992.

344 State Department an US-Botschaft/Damaskus, 22. 8. 1952, ebenda.

345 245. Kabinettssitzung am 8.9. 1952, in: Kabinettsprotokolle der Bundesregierung, Bd. 5, S. 549 u. $551 \mathrm{f}$.

346 Diese Auffassung vertritt hingegen Michael Wolffsohn, dessen Argumentation jedoch auch grobe faktische Irrtümer, so z.B eine falsche Zuordnung Byroades, enthält. Vgl. ders. Globalentschädigung für Israel und die Juden? in: Herbst/Goschler (Hrsg.), Wiedergutmachung, S. 183. 
Neben außenpolitischen bestanden aber auch finanzpolitische Einwände fort. Vor allem Finanzminister Schäffer beharrte darauf, daß eine Ratifizierung der Abmachungen mit Israel und der Claims Conference unmöglich sei, „wenn nicht gleichzeitig die Deckung für die Ausgaben beschlossen werde“ ${ }^{\text {347 }}$. Adenauer, der Schäffer zuvor unter Hinweis auf außenpolitische Gründe vergeblich beschworen hatte, der Unterzeichnung des Abkommens zuzustimmen ${ }^{348}$, gelang es jedoch, den Bundesfinanzminister zu überspielen. Am 8. September erwirkte er so einen Kabinettsbeschluß, wonach den Abmachungen mit Israel und der Claims Conference zugestimmt würde, allerdings mit der Maßgabe, „daß die Weiterleitung an den Bundesrat nur unter gleichzeitiger Vorlage eines Deckungsvorschlages, über den das Kabinett noch im einzelnen nach Vortrag des Bundesfinanzministers zu beschließen ha-

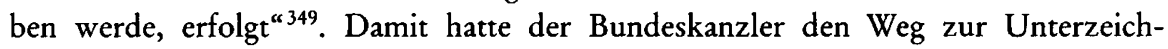
nung der Abkommen geebnet, wenngleich die endgültige Klärung der Finanzierungsfrage vertagt war. So konnten Adenauer, der israelische Außenminister Sharett und Goldmann am 10. September in Luxemburg ihre Unterschriften unter das mühsam ausgehandelte Paket setzen. Dem Vertrag mit Israel über eine Globalentschädigung in Höhe von drei Mrd. DM standen zwei Protokolle mit der Claims Conference zur Seite. Protokoll Nr.1 enthielt die ausgehandelten Grundsätze für die Verbesserung der bestehenden Wiedergutmachungsgesetzgebung, Protokoll Nr. 2 regelte die Globalentschädigung für die Claims Conference in Höhe von 450 Mio. $\mathrm{DM}^{350}$.

Bis zur endgültigen Ratifizierung sorgten aber vor allem die arabischen Proteste weiterhin für Aufregung, wie Adenauer Donelly fünf Tage nach der Unterzeichnung des Abkommens in Luxemburg mitteilte. Erneut bat er um die Hilfe der USA, einen eventuellen arabischen Boykott deutscher Waren, der Wasser auf die Mühlen der innerdeutschen Gegener des Abkommens wäre, abzuwenden ${ }^{351}$. Die USA selbst bekamen den Zorn der arabischen Staaten zu spüren, denn dort herrschte die Auffassung vor, daß diese die Deutschen zu dem Abkommen gezwungen hätten - eine Meinung, die durch private Äußerungen deutscher Kabinettsmitglieder und Politiker bewußt genährt wurde ${ }^{352}$. Die US-Diplomatie bestritt dies und verwies statt dessen auf die moralische Berechtigung dieser Forderungen. Um dies den arabischen Staaten schmackhaft zu machen, verwies sie auch auf die präjudizierende Wirkung des Abkommens im Hinblick auf die Ansprüche arabischer Flüchtlinge aus Palästina an Israel ${ }^{353}$. Gleichwohl bestanden keine Illusionen darüber, daß Schweigen wie Reden in jedem Falle als Eingeständnis der amerikanischen Verantwortung für dieses Abkommen gewertet werden würde ${ }^{354}$. Doch wurde bereits hellsichtig das Resultat der arabischen Drohgebärden prognostiziert: „While threat of boycott may be carried out even if only on a token or temporary basis, Embassy's opinion is that there is so much latent pro-German sympathy in

347 245. Kabinettssitzung am 8.9. 1952, in: Kabinettsprotokolle der Bundesregierung, Bd. 5, S. 554.

348 Adenauer an Schäffer, 28.8. 1952, BA, B 136/1130.

349 Ebenda, S. 554-558, hier: S. 557. Vgl. auch Wolffsohn, Globalentschädigung für Israel und die Juden?, S. $182 \mathrm{f}$.; Huhn, Die Wiedergutmachungsverhandlungen in Wassenaar, S. 159.

350 Siehe Documents to the Agreement, S. 125-168.

351 Donelly an State Department, 16.9. 1952, in: FRUS 1952-1954 IX/1, S. 999.

352 So z.B. auch von Dehler. Vgl. Tagebuch Lenz, Eintrag vom 22. 2. 1953, S. 564.

353 Lobenstine (US-Chargé im Libanon) an State Department, 30.9. 1952, in: FRUS 1952-1954 IX/1, S. $1013 \mathrm{f}$.

354 Bruce (Acting Secretary of State) an US-Botschaft im Libanon, 22. 10. 1952, ebenda, S. 1037. 
Arab world (on basis enemy of their enemy is their friend) that German interest will not in long run suffer irreparably because of agreement particularly while US is such a convenient whipping boy. "355

Tatsächlich sorgten die arabischen Proteste zwar für eine gewisse Verzögerung der Ratifizierung, da erst das Ergebnis deutscher Beschwichtigungsversuche in Ägypten abgewartet wurde ${ }^{356}$, eine ernstliche Gefährdung stellten sie aber nicht mehr dar. Auch die Versuche Schäffers, dem der Vertrag „um zwei Milliarden zu teuer“ ${ }^{357}$ war, die Finanzierungsfrage noch einmal als Stolperstein in die Debatte zu werfen, endeten letztlich in einem lauten Grummeln des Finanzministers. Bei der Sitzung am 13. Februar 1953, in der es um die Weiterleitung an den Bundesrat ging, stimmte er zwar dagegen, verzichtete aber darauf, formell Widerspruch einzulegen ${ }^{358}$.

Zuvor hatte Hallstein im Auftrag des Bundeskanzlers noch einmal die außen- und innenpolitischen Gründe für eine baldige Ratifizierung des Abkommens genannt: Sowohl der neue amerikanische Außenminister Dulles als auch der neue amerikanische Hohe Kommissar hatten sich dafür eingesetzt ${ }^{359}$. Auch sei die Ratifizierung des IsraelVertrages eine wichtige atmosphärische Vorbedingung für Adenauers bevorstehenden USA-Besuch. Überdies habe die SPD ihre Unterstützung zugesagt ${ }^{360}$. Letztere war bei der Abstimmung im Bundestag auch dringend erforderlich: Lediglich die Fraktion der SPD stimmte am 18. März 1953 einstimmig für das Abkommen, während aus den Reihen der Regierungskoalition eine beträchtliche Anzahl von Stimmenthaltungen, darunter, sehr zum Ärger des Bundeskanzlers ${ }^{361}$, auch Finanzminister Schäffer, kamen $^{362}$. Adenauer war also in dieser Angelegenheit bis zuletzt dem Grundsatz treu geblieben, sich seine Unterstützung zur Durchführung dieses Vorhabens dort zu holen, wo sie zu finden war.

Anders als in den übrigen Bereichen der Wiedergutmachung, so läßt sich summieren, war das Luxemburger Abkommen mit Israel und der Claims Conference ganz wesentlich vom persönlichen Einsatz Adenauers geprägt, der, nachdem er einmal zu der Auffassung gelangt war, daß hier etwas getan werden müsse, erhebliche innenpolitische Widerstände überwand, um ans Ziel zu gelangen. Zahlreiche Anstöße von inner- und außerhalb Deutschlands hatten ihn von der Wichtigkeit eines deutlichen Zeichens an die Adresse Israels und der Juden in aller Welt für die internationale Reputation der Bundesrepublik überzeugt und so seine Entscheidung, ihnen direkte Gespräche über ihre Wiedergutmachungsforderungen anzubieten und dabei schließlich die israelische

355 Lobenstine an State Department, 30.9. 1952, ebenda, S. 1014.

356 273. Kabinettssitzung am 3.2. 1953, in: Die Kabinettsprotokolle der Bundesregierung, hrsg. f.d. Bundesarchiv v. Hans Booms, Bd. 6: 1953, bearbeitet von Ulrich Enders und Konrad Reiser, Boppard a.Rh. 1989, S. 153.

357 Aufzeichnung Schäffers über die Kabinettssitzung am 3.2. 1953, BA, NL Schäffer, 168/33.

358 273. Kabinettssitzung am 3. 2. 1953, in: Kabinettsprotokolle der Bundesregierung, Bd. 6, S. 153; 275. Kabinettssitzung am 13.2. 1953, ebenda, S.172f.; Schäffer an Hartmann, 13.2. 1953, BA, NL Schäffer, 168/33. Vgl. dazu auch Wolffsohn, Globalentschädigung für Israel und die Juden?, S. 186.

359 Siehe auch Adenauer an Schäffer am 12. 2. 1953 (in: Adenauer, Briefe, Bd. 3, S. 342): „Es ist aber aus allgemein politischen Gründen unbedingt notwendig, den Vertrag mit Israel in den Bundesrat zu bringen. Herr Conant, der mir heute seinen Antrittsbesuch machte, fing selbst davon an und machte mich darauf aufmerksam, wie wichtig die baldige Ratifizierung sei."

360 275. Kabinettssitzung am 13.2. 1953, in: Kabinettsprotokolle der Bundesregierung, Bd. 6, S. $171 \mathrm{f}$.

361 Tagebuch Lenz, Eintrag vom 18. 3. 1953, S. $591 \mathrm{f}$.

362 Deutscher Bundestag, 255. Sitzung vom 18.3. 1953, Stenographische Berichte, Bd. 15, S. 12362-12366. 
Note vom 12. März 1951 als Verhandlungsgrundlage zu akzeptieren, vorbereitet. Wesentlichen Anteil daran, daß diese Einflüsse kanalisiert wurden und den Bundeskanzler schließlich dazu bewegten, von prinzipiell bekundeter Bereitschaft zu konkretem Handeln zu wechseln, hatte Blankenhorn besessen, was ihm später nicht nur Dank ein$\operatorname{trug}^{363}$.

Doch muß zugleich betont werden, daß in der ersten Phase der Angelegenheit - bis zum Beginn der Verhandlungen - keineswegs amerikanischer Druck den Ausschlag gab, auch wenn McCloy ein wichtiges Glied in der Kette der Interventen war. Wie gezeigt, bestanden vor allem im State Department zunächst erhebliche Bedenken gegen die israelische Reparationsforderung. Dies verwandelte sich aber in ein aktives Eintreten für den Erfolg dieser Verhandlungen, nachdem durch Adenauers Erklärung vor dem Bundestag und das Ergebnis seiner Londoner Besprechung mit Goldmann Ende 1951 klargestellt war, daß es sich hierbei um eine deutsch-jüdisch-israelische Angelegenheit handelte und somit keine direkte amerikanische Verantwortung bestand.

Der moralische Druck seitens der USA während der Verhandlungen diente überwiegend dazu, Adenauer gegenüber den Opponenten im Kabinett den Rücken zu stärken bzw. ihn gelegentlich an seine eigenen Prinzipien zu erinnern, sofern die Sache aus dem Ruder zu laufen drohte: Der Bundeskanzler wünschte zwar prinzipiell, sehr im Gegensatz zu großen Teilen seiner Regierung und der deutschen Bevölkerung, ein Abkommen mit Israel und der Claims Conference, doch geriet er angesichts der von ihm nicht von vornherein klar bedachten finanziellen Konsequenzen mehrfach gefährlich ins Schwanken und so in das Fahrwasser einer Argumentation, in die sich gelegentlich neben deutsch-nationalen auch antisemitische Töne mischten ${ }^{364}$. Vereinfacht gesagt bestand die Problematik darin, daß Adenauer zwar ein Abkommen dringend anstrebte, zugleich aber so wenig wie möglich dafür bezahlen wollte, während andererseits McCloy und das State Department gleichfalls den Verhandlungserfolg wünschten, aber in keinem Fall hinnehmen wollten, daß dies zu irgendwelchen finanziellen Belastungen der USA führte. Daraus ergab sich um die Frage, wer eigentlich für das Abkommen verantwortlich sei, teilweise eine Art von Katz-und-Maus-Spiel, das bis heute in der Historiographie nachwirkt.

McCloy beschrieb seine eigene Rolle für das Zustandekommen der Luxemburger Abkommen später damit, daß sein Einfluß und sein Druck bzw. Einwirken „auf Adenauer, um ihn dazu zu bewegen, an dem breiten, großzügigen Grundkonzept festzuhalten, ein wichtiger Faktor" für den Erfolg der Verhandlungen gewesen sei (das war genau das, was Goldmann von ihm erwartet hatte ${ }^{365}$ ). Ohne seinen Einfluß, so McCloy, wäre das Abkommen zwar nicht gescheitert, aber vermutlich bescheidener ausgefallen: „I think that Adenauer was quite prepared to lead his country into an acknowledgement of the indebtness, but I think the extent and the character and the spirit of it was something to which I may immodestly say I contributed. “366 Um die Details des Abkommens oder gar um bestimmte Beträge kümmerten sich die USA dagegen nicht, und insbesondere Goldmann war daran wohlweislich keineswegs interessiert. Wie er

363 Siehe dazu die aufschlußreichen Bemerkungen im Tagebuch Lenz, Eintrag vom 2.3. 1953, S. $571 \mathrm{f}$.

364 So bemerkte Adenauer am 6. 9. 1952 zum Israel-Abkommen, „daß leider in Deutschland antisemitische Tendenzen wieder festzustellen wären und leider auch innerhalb der CDU." Siehe Tagebuch-Lenz, Eintrag vom 6.9. 1952, S. 429.

$365 \mathrm{Vgl}$. oben, S. 267.

366 Interview mit McCloy am 23.2. 1972 (Anm. 241). 
später berichtete, besuchte er, nachdem die Deutschen seine Forderungen akzeptiert hatten, Byroade im State Department und fragte ihn: „'Now that I got it signed, eight hundred twenty-three million, suppose I would have come to you, what would you have suggested?' ... He says, '... I would have said two hundred, two hundred fifty million dollars is enough. '“ ${ }^{367}$ So läßt sich mit einigem Recht vermuten, daß eine von den Alliierten bzw. den USA oktroyierte Regelung eine erheblich bescheidenere Summe beinhaltet hätte als die deutsche Seite - zwar nicht kampflos, aber letztlich aus eigener Verantwortung - am Ende zu geben bereit war.

Die finanziellen Bedenken der deutschen Gegner des Abkommens darf man nicht ohne weiteres auf die leichte Schulter nehmen. Annuitäten an Israel in Höhe von 200 Mio. DM waren angesichts eines damaligen Bundeshaushalts von etwa $20 \mathrm{Mrd}$. DM keine Lappalie. Doch standen sich auf deutscher Seite zwei verschiedene Betrachtungsweisen gegenüber. Fritz Schäffer war dabei Prototyp einer "statischen“ Betrachtungsweise: Er setzte Einnahmen und Ausgaben in ein direktes Verhältnis und versuchte hier eine Übereinstimmung herzustellen. Demgegenüber schrieb Ludwig Erhard auf dem Höhepunkt der Auseinandersetzungen mit Schäffer im April 1952 an Adenauer, „daß wir uns selbst preisgeben würden, wenn wir nicht auf wirtschaftliche Expansion setzen ... In einer mehr dynamischen Beurteilung der Entwicklung und vor allem unter politischem Aspekt könnte es aber durchaus sein, daß eine höhere Schuldanerkenntnis im Endeffekt den deutschen Interessen besser dient, dann nämlich, wenn wir die deutsche Kreditwürdigkeit stärken und schließlich vielleicht sogar die Juden der Welt mit der deutschen Vergangenheit versöhnen. “ 368

Innere finanzielle Erwägungen standen so im Konflikt mit außenpolitischen Erfordernissen: Das Luxemburger Wiedergutmachungsabkommen war zwar keine Eintrittskarte der Bundesrepublik für die Westintegration, doch wäre ein Scheitern der Verhandlungen kontraproduktiv für diesen Prozeß gewesen. Nachdem Adenauer bei seiner Rede vor dem Bundestag und gegenüber Goldmann bestimmte Hoffnungen geweckt hatte, wäre ein solcher Mißerfolg als erneute deutsche Wortbrüchigkeit ausgelegt worden. Das aber hätte die Eingliederung der Bundesrepublik in den Kreis der freien Völker und ihren Anspruch, ein neues, demokratisch geläutertes Deutschland zu verkörpern, mit einer schwerwiegenden moralischen Hypothek belastet.

Die moralische war von der finanziellen Seite des deutschen Kredits nicht zu trennen, das zeigte sich in dieser Angelegenheit deutlich. Vor allem Adenauer realisierte dies sehr genau. Doch geriet sein eigener politischer Kompaß wiederholt unter den Einfluß mächtiger Magnetberge, namentlich Schäffer und Abs. Zudem besaß auch der Bundeskanzler für sein entschlossenes Handeln in dieser Frage eine ganze Reihe gewichtiger realpolitischer Motive, die vor allem mit dem deutschen Ansehen in der Welt und ganz besonders in den USA zusammenhingen. Dies wird auch dadurch bestätigt, daß sich Adenauer in anderen, für die internationale Reputation der Bundesrepublik weniger brisanten Aspekten der Wiedergutmachung keineswegs mit vergleichbarer Intensität einsetzte. So bleibt das Luxemburger Abkommen in vielerlei Hinsicht ein Sonderfall in der Geschichte der Wiedergutmachung, der stärker unter außen- als unter innenpolitischen Vorzeichen steht.

367 Interview mit Goldmann am 24.11. 1971 (Anm. 242).

368 Erhard an Adenauer, 16.4. 1952, BA, NL Blankenhorn, 351/11. 


\section{Das erste Bundesentschädigungsgesetz 1953}

\section{Umschwung durch Junktim?}

Die Vereinbarungen von Mehlem und Wassenaar besaßen erhebliches Gewicht für die weitere Entwicklung der innerdeutschen Wiedergutmachung. Doch bereits vor Abschluß dieser Verhandlungen hatte sich, wie zuvor geschildert, die Stimmung allmählich zugunsten bundeseinheitlicher Regelungen verschoben. Wie schon bei der Regelung der Wiedergutmachung für den öffentlichen Dienst spielte auch hierbei ein - allerdings etwas anders gelagertes Junktim - eine wichtige Rolle: Die Zustimmung zu einem Bundesrahmen- bzw. Bundesergänzungsgesetz im Bereich der Entschädigung wurde nun insbesondere von großen Teilen der Regierungskoalition von einer Regelung der rückerstattungsrechtlichen Reichsansprüche der Verfolgten des Nationalsozialismus, aber auch der sogenannten „loyalen Rückerstattungspflichtigen“ abhängig gemacht. Der Sinn dieses aus heterogenen Elementen zusammengeschnürten Gesamtpakets bestand dabei vor allem darin, auf diesem Wege den massiven Protesten der deutschen Rückerstattungsgeschädigten die Spitze abzubrechen. Nicht nur die Meinung des Bundestags-Rechtsausschusses hatte sich seit Ende 1951 in diese Richtung bewegt ${ }^{369}$, sondern auch Justizminister Dehler machte sich nun für eine baldige Regelung stark und fand dabei Unterstützung beim Bundeskanzler$\mathrm{amt}^{370}$.

Aber auch hier stellte sich der Bundesfinanzminister quer. Schäffer schloß eine Vorabregelung der Rückerstattungsansprüche gegenüber den gesamten Reichsverbindlichkeiten kategorisch aus und erklärte zugleich, daß die Finanzlage des Bundes einstweilen kein Einspringen im Bereich der Entschädigung zulasse ${ }^{371}$. Auch im Bundestags-Rechtsausschuß sträubte sich der Vertreter des Finanzressorts, Ministerialrat Kuschnitzky, auftragsgemäß, vor „Abschluß der großen internationalen Verhandlungen ... konkrete Erklärungen zur finanziellen Seite der Frage abzugeben " ${ }^{372}$. Hier ist daran zu erinnern, daß umgekehrt bei den Vorbesprechungen mit den Alliierten über die Ablösung des Besatzungsstatuts es der deutsche Vertreter abgelehnt hatte, eine Stellungnahme abzugeben, bevor der Bundestags-Rechtsauschuß eine Meinung gefaßt hätte ${ }^{373}$. Das wirft ein bezeichnendes Licht auf die hinhaltende Politik der Bundesregierung, die offensichtlich darauf abzielte, durch ein solches doppeltes Spiel Wiedergutmachungsleistungen des Bundes auf die lange Bank zu schieben.

Der Rechtsausschuß überging jedoch die Einwände des Bundesfinanzministeriums und beauftragte am 18. Januar 1952 einen Unterausschuß damit, Vorschläge für eine Regelung der Entschädigung sowie einen Härteausgleich in der Rückerstattung auszuarbeiten ${ }^{374}$ - das Junktim dieser konträren Fragen war hier also erneut ausdrücklich festgehalten. Gleichfalls gegen den Widerstand des Bundesfinanzmini-

369 Vgl. oben, Abschnitt I. 3.

370 Dehler an Adenauer, 20.12. 1951, BA, B 136/1125; Vorlage Gumbels für Adenauer, 9.1. 1952, ebenda.

371 Vorlage Gumbcls für Adenauer, 9.1. 1952 (Anm. 370).

372 Vermerk von Kuschnitzky, 18.1. 1952; Protokoll der 148. Sitzung des Bundestags-Ausschusses für Rechtswesen und Verfassungsrecht am 18. 1. 1952, BA, B 126/12523.

${ }^{373}$ Vgl. oben, Abschnitt III. 1.

${ }^{374}$ Protokoll der 148. Sitzung des Bundestags-Ausschusses für Rechtswesen und Verfassungsrecht am 18.1. 1952, BA, B 126/12523. 
steriums wurde auf Betreiben von Bundesjustizministerium und Bundeskanzleramt Anfang Februar ein Bundesrahmengesetz für die Entschädigung auch unter die vordringlichen Gesetzesvorhaben der Bundesregierung aufgenommen ${ }^{375}$.

Konkurrierend dazu hatte der Bundesrat eine eigene Initiative entfaltet und am 7. Dezember 1951 einen ständigen Ausschuß für Wiedergutmachungsfragen eingesetzt ${ }^{376}$. Dieser Ausschuß unter Leitung des Bremer Senators Gerhard van Heukelum strebte eine bundesgesetzliche Entschädigungsregelung an, nachdem inzwischen auch in den Ländern die ursprüngliche Mehrheit gegen ein Bundesentschädigungsgesetz abgebrökkelt war. Hauptmotiv war hier der Wunsch, den Bund an den finanziellen Lasten der Länder, die aus der Schließung der bestehenden entschädigungsrechtlichen Lücken, aber auch aus der Erfüllung bestehender Verpflichtungen entstanden, zu beteiligen. Wiederum versuchte Kuschnitzky namens des Bundesfinanzministeriums abzuwiegeln und erklärte, „daß der Entwurf eines Bundesrahmengesetzes schon längst vorgelegt worden wäre, wenn nicht die Frage der finanziellen Deckung noch völlig ungeklärt wäre". Statt dessen warb er dafür, daß die Länder die fehlenden Regelungen von sich aus ergänzen sollten ${ }^{377}$.

Unbeeindruckt beauftragte der Wiedergutmachungs-Ausschuß des Bundesrats am 27. März 1952 einen Unterausschuß, den Entwurf eines umfassenden Bundesentschädigungsgesetzes auszuarbeiten. Damit waren die Einwände des Bundesjustizministeriums und des Vertreters Württemberg-Badens, die lediglich ein Rahmen- oder Richtliniengesetz für angebracht gehalten hatten, überstimmt worden ${ }^{378}$. Unter Federführung Otto Küsters begann der Unterausschuß im April mit der Arbeit am Entwurf eines Initiativgesetzes des Bundesrats. Das Bundesfinanzministerium, aber auch das Bundesjustizministerium registrierten diese Aktivitäten von Anfang an mit unverhohlener Abneigung. Vor allem im Hause Schäffers konnte man sich mit dem Vorhaben, finanzielle Lasten auf den Bund abzuwälzen, in keiner Weise anfreunden. Nach anfänglicher Beteiligung zogen sich deshalb beide Ressorts aus den Beratungen zurück, um später jede Mitverantwortung für diesen Entwurf zurückweisen zu können ${ }^{379}$.

Das ohnehin schon komplizierte Bild wurde aber bald darauf noch unübersichtlicher: Am 18. Juni 1952 legte die SPD-Fraktion im Bundestag einen eigenen Entwurf für ein „Gesetz zur Anerkennung des deutschen Widerstandes und zur Wiedergutmachung nationalsozialistischen Unrechts" vor. Dieser löste sich stark von den Strukturen der bisherigen Entschädigungsgesetzgebung und nahm auch bewußt keine Rücksicht auf die Verpflichtungen aus dem Überleitungsabkommen. Er folgte vielmehr der von der SPD vertretenen Devise, daß die Entschädigung eine deutsche Angelegenheit sei und man deshalb nicht, wie von Regierungsseite befürwortet, erst das Ergebnis der internationalen Verhandlungen abwarten solle ${ }^{380}$. Bemerkenswert an dem Entwurf war, daß er

375 Ministerialrat Belau an Schäffer, 12.2. 1952, BA, B 126/12523.

376 Sitzungsberichte des Deutschen Bundesrats, 74. Sitzung am 7. 12. 1951, S. 832.

377 Kurzprotokoll über die 1. Sitzung des Bundesrats-Sonderausschusses für Wiedergutmachungsfragen am 8.2. 1952, BayMF, Az. IV N-403-33, Bd. 1.

378 Kurzprotokoll über die 2. Sitzung des Bundesrats-Sonderausschusses für Wiedergutmachungsfragen am 27. 3. 1952, BayMF, Az. IV N-403-33, Bd. 1.

379 Kurzprotokolle des Unterausschusses des Bundesrats-Sonderausschusses für Wiedergutmachungsfragen, Sitzungen am 7. u. 21.5. 1952, BayMF, Az. IV-N-403-33, Bd. 1.; Kuschnitzky an Hartmann, 5.6. 1952, BA, B 126/12524.

380 Arndt, Protokoll der 163. Sitzung des Bundestags-Ausschusses für Rechtswesen- und Verfassungsrecht am 21.2. 1952, BA, B 141/409. 
in einem ersten Teil ausdrücklich die Anerkennung des Widerstandes gegen das NSRegime formulierte ${ }^{381}$, um damit ein Zeichen gegen die zunehmende gesellschaftliche Stigmatisierung dieser Menschen zu setzen. Zugleich versuchte der SPD-Entwurf, von der Formel der rassisch, religiös und politisch Verfolgten abzukehren, die auch etwa Kuschnitzky als „eine Art Verewigung der Nazi-Terminologie“ ${ }^{382}$ kritisierte. Einen Anspruch auf Wiedergutmachung sollte derjenige haben, der „durch nationalsozialistische Verfolgungs- oder Unterdrückungsmaßnahmen, die sich gegen die Menschen- und Bürgerrechte ... richteten“, Unrecht erlitten hatte ${ }^{383}$. Dies implizierte natürlich eine erhebliche Ausweitung des Verfolgungsbegriffes. Hinzu kam, daß der Entwurf im Vergleich zu bisher bestehenden Entschädigungsregelungen stärker auf die Interessen der politisch Verfolgten zugeschnitten war.

Wie nicht anders zu erwarten, war die SPD-Vorlage, die die ganze Wiedergutmachungslast ausschließlich dem Bund zuwies und die Frage der Finanzierung durch die Ausgabe von Bundesschuldverschreibungen lösen wollte, „für das Bundesfinanzministerium ganz unannehmbar ${ }^{3384}$. Féaux de la Croix blieb der in seinem Hause herrschenden Einschätzung auch später treu und bezeichnet den Entwurf in seiner Darstellung als „offensichtlich grob gesagt hingehauen ${ }^{4385}$. Doch auch das Bundesjustizministerium reagierte frostig, vor allem deshalb, weil die SPD hier ein Vollgesetz forderte, während die Bundesregierung nur ein Rahmen- und Ergänzungsgesetz auf der Grundlage des US-Zonen-Entschädigungsgesetzes für angebracht hielt ${ }^{386}$.

Auch im Bundestags-Rechtsausschuß hielt die Koalitionsmehrheit daran fest, „daß die Initiative für die in Aussicht genommene Gesetzgebung bei der Bundesregierung zu liegen habe ${ }^{\alpha 387}$. Dort legte Berichterstatter Karl Weber (CDU) am 26. Juni zwei Anträge vor, die stark von einer „Formulierungshilfe“ geprägt waren, die Landgerichtsrätin Becker vom Bundesjustizministerium erstellt hatte ${ }^{388}$. Der erste Antrag schlug vor, die Bundesregierung zur Vorlage eines Entwurfes für ein Gesetz, „das die Entschädigung der Opfer des Nationalsozialismus durch ein Bundesergänzungs- und Rahmengesetz regelt", aufzufordern. Dabei sollten die in den Ländern bereits bestehenden Rechtsvorschriften in einer Weise ergänzt werden, daß insgesamt das gegenwärtige Niveau der US-Zone erreicht würde ${ }^{389}$. Der Entwurf stieß auf breite Zustimmung, doch ergänzte der Ausschuß als Zugeständnis an die SPD einen Passus, in dem der Widerstand gegen

381 Siehe $\$ 1$, Entwurf der SPD-Fraktion für ein Gesetz zur Anerkennung des deutschen Widerstandes und zur Wiedergutmachung nationalsozialistischen Unrechts, Deutscher Bundestag, 1. Wp. 1949-1953, Drucksache Nr. 3472, 18.6. 1952, Anlagen-Bd. 18.: „Wer aus Überzeugung oder um seines Glaubens oder Gewissens willen der nationalsozialistischen Gewaltherrschaft Widerstand leistete, um die Menschenrechte zu verteidigen oder einem Verfolgten beizustehen oder der Zerstörung Deutschlands Einhalt zu gebieten oder sich gegen die Unterdrückung aufzulehnen, hat sich um das Wohl des deutschen Volkes und Staates verdient gemacht. Sein Verhalten war rechtmäßig."

382 Protokoll der 255. Sitzung des Bundestags-Ausschusses für Rechtswesen und Verfassungsrecht, 7.5. 1953, BA, B 141/618.

${ }^{383} \$ 1$, Entwurf der SPD-Fraktion für ein Gesetz zur Anerkennung des deutschen Widerstandes und zur Wiedergutmachung nationalsozialistischen Unrechts (Anm. 381).

384 Vermerk Kuschnitzky, 27.6. 1952, (mit zustimmenden Anstreichungen durch Hartmann und Schäffer), BA, B $126 / 12524$.

385 Vgl. Féaux de la Croix, Vom Unrecht zur Entschädigung, S. 66.

386 Vermerk (Autor unleserlich) für Staatssekretär Walter Strauß (Bundesjustizministerium), 10. 9. 1952, BA, B 141/409.

387 Vermerk Kuschnitzkys vom 27.6. 1952, BA, B 126/12524.

${ }^{388}$ Becker an Weber, 14.6. 1952, BA, B 126/12524; Vermerk Kuschnitzkys, 27.6. 1952, BA, B 126/12524.

389 Antrag Webers betr. Entschädigung, (Ausschuß-Drucksache Nr. 67 des Bundestags-Ausschusses für Rechtswesen und Verfassungsrecht), 18.6. 1952, BA, B 126/12524. 
den Nationalsozialismus als rechtmäßig anerkannt wurde. Dies führte allerdings zu anhaltenden Kontroversen, die sich teils an der „Kriminellenproblematik“ entzündeten, aber auch daran, daß ein Teil der Abgeordneten ausdrücklich die Einbeziehung von Sabotageakten als Widerstandshandlungen ablehnte ${ }^{390}$.- Der zweite Antrag Webers enthielt dagegen quasi den Preis für die Bereitschaft der Unions-Vertreter, nunmehr eine Bundesentschädigungsregelung zu unterstützen: Darin wurde nicht nur die Regelung der rückerstattungsrechtlichen Ansprüche von Verfolgten des Nationalsozialismus, sondern auch die Entschädigung der sogenannten loyalen Rückerstattungspflichtigen angeregt ${ }^{391}$.

Als dann der Rechtsausschuß schließlich am 3. Juli seine Ergebnisse in einem mündlichen Bericht vorlegte, wurde so die Bundesregierung sowohl zur Vorlage eines Bundesgesetzes im Bereich der Entschädigung als auch der Rückerstattung aufgefordert ${ }^{392}$. Ein solches Junktim kam insbesondere den Wünschen des Justizministeriums sowie der CDU-Bundestagsfraktion und ihrer konservativen Partner entgegen, die großes Interesse daran hatten, in diesem Zusammenhang zugleich auch die Härten der besatzungsrechtlich angeordneten Rückerstattung auf seiten der Pflichtigen zu bereinigen. Hingegen lehnte es das Bundesfinanzministerium weiterhin ab, den Rückerstattungsgeschädigten Rechtsansprüche zu eröffnen ${ }^{393}$ - der Rotstift des Finanzressorts setzte also nicht allein bei den Verfolgten des Nationalsozialismus an.

Der Bericht des Rechtsausschusses formulierte eine Reihe von Richtlinien für das geforderte Bundesergänzungsgesetz, mit denen die Ergebnisse der Verhandlungen mit den Alliierten und der Claims Conference berücksichtigt wurden. Wie im Bundesjustizministerium bemerkt wurde, blieben diese allerdings „im ganzen erheblich hinter diesem Programm zurück, da die Bundesregierung im Rechtsausschuß bewußt nur die ganz unstrittigen Punkte angeregt hat ${ }^{\star 394}$. Die Koalitionsmehrheit im Ausschuß hatte also tunlichst vermieden, mehr zu fordern, als die Bundesregierung in den internationalen Verhandlungen bereits zugesagt hatte, wozu neben der "Formulierungshilfe“ des Bundesjustizministeriums auch einschüchternde Kostenberechnungen des Bundesfinanzministeriums beigetragen hatten ${ }^{395}$. Ganz anders der rückerstattungsrechtliche Teil des Berichtes: Dieser enthielt neuartige, innenpolitisch motivierte Forderungen, vor allem auch nach Entschädigung der Rückerstattungsgeschädigten, die nun von einer solchen „Huckepacklösung“ profitieren sollten. In der Sitzung vom 11. September einen Tag nach der Unterzeichnung der Abkommen mit Israel und der Claims Conference in Luxemburg - nahm der Bundestag die Ausschußvorlage an ${ }^{396}$.

390 Deutscher Bundestag, 229. Sitzung am 11.9. 1952, Stenographische Berichte, Bd. 13, S. 10431, 10436f. u. 10444; Vermerk von Regierungspräsident Schmidt, 7.7. 1952, BA, B 126/12524.

391 Antrag Webers betr. Rückerstattung (Ausschußdrs. Nr.68 des Bundestags-Ausschusses für Rechtswesen und Verfassungsrecht), 18.6. 1952, BA, B 126/12524; Vermerk Kuschnitzkys vom 27.6. 1952, ebenda.

392 Deutscher Bundestag, 1. Wp. 1949-1953, Mündlicher Bericht des Ausschusses für Rechtswesen und Verfassungsrecht, Drucksache Nr. 3583, Drucksachen-Bd. 19.

393 Siehe etwa Vorlage Koppe an Schäffer, 16.7. 1952, BA, B 126/12524.

394 Vermerk für W. Strauß, 10.9. 1952 (Anm. 386).

395 Siehe dazu den Aktenvermerk von Regierungsrat Ludwig (Bundesfinanzministerium) vom 25.6. 1952 über die Sitzung des Rechtsausschusses am 13.6. 1952, BA, B 126/12524.

396 Deutscher Bundestag, 229. Sitzung am 11.9. 1952, Stenographische Berichte, Bd. 13, S. 10445. 


\section{Die defensive Initiative des Bundesfinanzministeriums}

Spätestens seit Herbst 1952 war ein bundeseinheitliches Entschädigungsgesetz nicht mehr aufzuhalten: Sowohl der Vierte Teil des Überleitungsabkommens als auch das Haager Protokoll Nr. 1 enthielten die Verpflichtung, schleunigst eine Entschädigungsregelung auf dem Mindeststandard des US-Zonen-Gesetzes für das Bundesgebiet zu schaffen. Auch der Bundestag hatte, wie gesagt, die Bundesregierung aufgefordert, in dieser Beziehung tätig zu werden. Am 22. September drängte schließlich Dehler den Bundesfinanzminister, unverzüglich mit den Vorarbeiten zu einem Bundesentschädigungsgesetz zu beginnen ${ }^{397}$. Zu Recht befürchtete er, das Bundesfinanzministerium werde versuchen, die Arbeiten so lange hinauszuzögern, bis eine Verabschiedung in der laufenden Legislaturperiode nicht mehr möglich sei ${ }^{398}$. Prompt antwortete Schäffer, eine bundesgesetzliche Entschädigungsregelung noch in dieser Legislaturperiode führe zu einem beträchtlichen Haushaltsdefizit, und dies könne er in einem Wahljahr nicht verantworten $^{399}$.

Doch bald darauf sprang das Bundesfinanzministerium, das bis dahin eine ausgesprochene „Verzögerungs- und Sabotagetaktik“ ${ }^{400}$ verfolgt hatte, auf den abfahrenden Zug auf. Ausschlaggebend war vor allem, daß der Bundesrats-Sonderausschuß für Wiedergutmachungsfragen am 15 . Oktober seinen Entwurf eines Initiativgesetzes vorgelegt hatte ${ }^{401}$, so daß im Hause Schäffers nunmehr die Furcht aufstieg, gegenüber dem Bundesrat ins Hintertreffen zu geraten ${ }^{402}$. Dem zuständigen Referenten Kuschnitzky erschien dies insbesondere deshalb als mißlich, weil der Bundesrats-Entwurf „fast die ganze Last der Wiedergutmachung dem Bunde aufbürdet und auch in materiell-rechtlicher Hinsicht unseren Intentionen nicht entspricht ... Diesem Gesetzentwurf“, so Kuschnitzky, „wird wirksam nur durch eine eigene Vorlage begegnet werden können. “ 403

$\mathrm{Zu}$ diesem $\mathrm{Zwecke} \mathrm{lud} \mathrm{das} \mathrm{Bundesfinanzministerium} \mathrm{nunmehr} \mathrm{die} \mathrm{zuständigen} \mathrm{Refe-}$ renten des Bundesjustiz- und Bundesinnenministeriums in ein am 24. November beginnendes Konklave in der Bundesfinanzschule in Siegburg ein, um dort einen eigenen Entwurf eines Bundesergänzungsgesetzes auszuarbeiten. Dieser sollte den in Mehlem und Wassenaar eingegangenen Verpflichtungen Rechnung tragen und zugleich auf den geltenden Ländergesetzen aufbauen. Das war insofern wesentlich, als, so Kuschnitzky, bei der „Regelung der Wiedergutmachungslast ... grundsätzlich davon auszugehen sein (dürfte), daß die Länder mindestens in dem bisherigen Umfang Wiedergutmachungsschuldner bleiben." Ziel dieser Arbeiten war also, „dem Bundesratsentwurf möglichst mit einer eigenen Vorlage zu begegnen “ ${ }^{404}$. Die Halbherzigkeit dieses Unternehmens offenbarte sich auch darin, daß das Bundesfinanzministerium „mit Rücksicht auf die angespannte Haushaltslage“ zunächst vorgesehene Mittel für die Entschädigung wieder

397 Dehler an Schäffer, 22. 9. 1952, BA, B 141/417.

398 Vermerk von Becker für W. Strauß und Dehler, 18.4. 1952, BA, B 141/417.

399 Schäffer an Dehler, 25.9. 1952, BA, B 141/417.

400 Goldmann an Hallstein, 10. 10. 1952, PA/AA, II 244-13, Bd. 4. Siehe auch Böhm, Aktennotiz über Besprechung mit Dehler am 29. 10. 1952, PA/AA, II 244-13, Bd. 5.

401 Niederschrift über die 5. Sitzung des Bundesrats-Sonderausschusses für Wiedergutmachungsfragen, 15. 10. 1952, BayMF, Az. IV-N 403-33, Bd. 2; Entwurf eines Bundesentschädigungsgesetzes, BR-Drucksache Nr. 413/52.

402 Böhm, Aktennotiz über Besprechung mit Wolff und Kuschnitzky am 29. 10. 1952, PA/AA, II 244-13, Bd. 5.

403 Kuschnitzky an Schäffer, 5. 11. 1952, BA, B 126/12522.

${ }^{404}$ Kuschnitzky an Schäffer, 21.11. 1952, ebenda. 
aus dem Bundeshaushalt 1953/54 herausgestrichen hatte ${ }^{405}$. Die Beratungen des Siegburger Konklaves zogen sich bis Ende Januar hin ${ }^{406}$. Aus dem ursprünglich angestrebten „Ergänzungsgesetz“ war bei dieser Gelegenheit ein „Vollgesetz“ geworden, hatte sich doch jede andere Lösung als unpraktikabel erwiesen. Dabei waren die Autoren nahe am Vorbild des Entschädigungsgesetzes der US-Zone geblieben, das ja sowohl im Überleitungsabkommen als auch im Haager Protokoll Nr. 1 als Mindeststandard definiert worden war, und hatten dieses um Einzelparagraphen ergänzt, mit denen den dort aufgestellten zusätzlichen Forderungen Genüge geleistet werden sollte ${ }^{407}$.

Damit trat das Bundesfinanzministerium nun dem Bundesrats-Entwurf entgegen. Schon am 18. Dezember war es Finanzstaatssekretär Hartmann, indem er die Vorlage des Regierungsentwurfs bis Januar in Aussicht stellte, gelungen, im Bundesrat eine knappe Mehrheit dafür zu gewinnen, dessen eigenes Initiativgesetz bis Ende Januar 1953 zurückzustellen - nicht ohne bei dieser Gelegenheit deutlich zu machen, daß die Bundesregierung in keinem Fall bereit sein würde, dem Vorschlag des Bundesrates zu folgen. Dies begründete er hauptsächlich damit, daß die Abmachungen von Mehlem und Wassenaar dort nicht ausreichend berücksichtigt worden seien ${ }^{408}$. Tatsächlich war der Bundesrats-Entwurf - anders als der Entwurf des Bundesfinanzministeriums - von der strikten Fortentwicklung des US-Zonen-Gesetzes abgegangen, um bei dieser Gelegenheit Schwächen, die bei seiner Durchführung mittlerweile deutlich geworden waren, beseitigen zu können. Hiermit stand er in einem gewissen Gegensatz zu der Forderung des Überleitungsabkommens sowie dem Haager Protokoll Nr. 1. Am schwersten wog jedoch, daß die DP's, deren Ansprüche der Bundesrat in einem eigenen Gesetz regeln wollte, hier nicht berücksichtigt wurden. $\mathrm{Zu}$ dieser Entwicklung hatte aber auch nicht zuletzt der bewußte Boykott der vorangegangenen Beratungen durch die zuständigen Bundesressorts beigetragen.

$\mathrm{Da}$, anders als vom Bundesfinanzministerium zugesagt, Ende Januar 1953 erst der in Siegburg erstellte Referentenentwurf vorlag, nahm der Bundesrat im Februar die Beratungen an seinem eigenen Entwurf wieder auf ${ }^{409}$. Am 20. Februar verabschiedete er schließlich den Initiativgesetzentwurf eines Bundesentschädigungsgesetzes an den Bundestag. Dabei hatte er an der Fassung, die der Rechts- und Innenausschuß am 13. November empfohlen hatten - dem sogenannten Novemberentwurf -, eine ganze Reihe von Änderungen vorgenommen, die auf die Empfehlungen des Finanzausschusses zurückgingen und denen der Sonderausschuß für Wiedergutmachungsfragen weitgehend gefolgt war. Vergeblich protestierte der baden-württembergische Justizminister Renner, daß bei diesen Vorschlägen fiskalische Interessen dominierten: „Diese Bestimmungen sind nicht in der noblen Gesinnung getroffen worden, wie man sie hätte erwarten können. In unserem staatlichen Leben haben wir bisher für andere Dinge Geld gehabt und haben dabei nicht so eng gerechnet. " ${ }^{410}$ Der Vorsitzende des Sonderausschusses für Wiedergutmachung, Senator Heukelum, wies diese Vorwürfe empört zurück. Aller-

405 Kuschnitzky an Schäffer, 5.11. 1952 (Anm. 403).

406 Erster Referentenentwurf eines Bundesentschädigungsgesetzes, 27.1. 1952, BA, B 141/617. Vgl. dazu auch Féaux de la Croix, Vom Unrecht zur Entschädigung, S. 74-77.

407 Siehe dazu Kuschnitzky im Protokoll der 252. Sitzung des Bundestags-Ausschusses für Rechtswesen und Verfassungsrecht, 17.4. 1952, BA, B 141/618.

408 Sitzungsberichte des Deutschen Bundesrats, 98. Sitzung am 18.12. 1952, S. 619-623.

409 Sitzungsberichte des Deutschen Bundesrats, 100. Sitzung am 6. 2. 1953, S. 57-63, 74.

410 Ebenda, S. 62. 
dings hätte es der Sonderausschuß, so Heukelum, für erforderlich gehalten, auch auf die finanzielle Leistungsfähigkeit des Bundes Rücksicht zu nehmen. Zugleich stand hier aber auch eine prinzipielle Frage zur Debatte: Heukelum vertrat die Auffassung, man sollte „sich nicht allzusehr gesetzesrestaurativ benehmen als vielmehr sozial“, und das hieß für ihn, „Not zu lindern ... wo es am allernotwendigsten ist“. Deshalb habe der Sonderausschuß ähnlich wie beim Lastenausgleich "soziale und in beschränkten Umfang quotale Gesichtspunkte zugrundegelegt "411. Dies bedeutete vor allem eine $\mathrm{Be}$ schränkung des Ausgleichs der hohen Eigentums- und Vermögensschäden.

Dagegen lehnte es Otto Küster $a b$, bei der Entschädigung für Verfolgte des Nationalsozialismus eine Analogie zum Lastenausgleich herzustellen: Dort gehe es um „Volksgenossen, die ins Unglück“ geraten seien, denen man „mit den Mitteln der Gesamtheit einen Teil des Schadens abnehmen“ wolle. Doch habe es, so Küster, keinen Sinn, „soziale oder quotale Erwägungen anzustellen, wenn man Unrecht wiedergutmachen will, das im Namen der Volksgesamtheit begangen worden ist. Ebenso gut könnte man die Wiedergutmachung überhaupt verweigern. " ${ }^{412}$ Für ihn war diese ein unbedingter rechtlicher Anspruch, keinesfalls dürfe sie, wie unmittelbar nach dem Krieg, als staatliche Fürsorge-Aufgabe behandelt werden; ihm ging es um ein „Gesetz, das in der Welt des Rechts heilende Wirkung haben soll“. Nach seiner Berechnung würden die vorgesehenen Kürzungen allenfalls zehn Prozent der Kosten einsparen, doch zugleich die moralische Wirkung der restlichen 90 Prozent vernichten ${ }^{413}$. Bei späterer Gelegenheit bemühte Küster die Aristotelische Unterscheidung zwischen der wiederherstellenden und der austeilenden Gerechtigkeit zur Verdeutlichung seiner Auffassung: Wiedergutmachung gehörte ihm zufolge notwendigerweise in den Bereich der wiederherstellenden Gerechtigkeit ${ }^{414}$. Was den „verschlimmbesserten“ Länderratsentwurfs betraf, so teilte auch Küster die Auffassung des Bundesfinanzministeriums, daß er den Anforderungen der internationalen Vereinbarungen nicht Genüge leisten würde ${ }^{415}$. BadenWürttemberg lehnte so im Bundesrat als einziges Bundesland den revidierten Initiativgesetzentwurf $a b$ und favorisierte weiter die Novemberfassung, die Küsters Handschrift trug ${ }^{416}$. So konkurrierten nun zwei Versionen des Bundesrats-Entwurfs mit dem der Bundesregierung sowie dem SPD-Entwurf.

Das Bundesfinanzministerium setzte jedoch alle Hebel in Bewegung, um den Initiativgesetzentwurf des Bundesrats zu blockieren - der Entwurf der SPD war aufgrund der politischen Kräfteverhältnisse ohnehin chancenlos. So begann nun ein Spiel auf Zeit - immer mit Blick auf das Ende der laufenden Legislaturperiode. Zum einen wurde deshalb auf Antrag Schäffers der Initiativgesetzentwurf der Länderkammer vier Monate lang nicht an den Bundestag weitergeleitet, mit der Begründung, daß in naher Zukunft ein Regierungsentwurf vorgelegt würde und der Bundesrats-Entwurf nicht vor diesem

411 Van Heukelum in Sitzungsberichte des Deutschen Bundesrats, 101. Sitzung am 20.2. 1953, S. 105. Siehe auch ders. an Bundestagspräsident Reinhold Maier, 18.2. 1953, in: Unterlagen zum Bundesentschädigungsgesetz, hrsg. v. d. Landesregierung Baden-Württemberg (Schwarzbuch), Stuttgart, März 1953, S. $87 \mathrm{f}$.

412 Küster, ebenda.

413 Ebenda.

414 Otto Küster, Wiedergutmachung als elementare Rechtsaufgabe, Frankfurt a.M. 1953, S. $10 f$.

415 Küster an van Heukelum, 17. 1. 1953, BayMF, Az. IV-N 403-35, Bd. 4.

116 Sitzungsberichte des Deutschen Bundesrats, 101. Sitzung am 20.2. 1953, S. 107. Siehe dazu auch R. Maier an den Deutschen Bundestag, März 1953, in: Unterlagen zum Bundesentschädigungsgesetz (Schwarzbuch), S. $3 f$. 
behandelt werden sollte ${ }^{417}$. Die verfassungsrechtlichen Bedenken des Bundesinnenministeriums verhallten ungehört ${ }^{418}$. Zugleich schlug man im Bundesfinanzministerium bei den Arbeiten an dem eigenen Entwurf eine betont gemächliche Gangart ein. Von Februar bis März fanden dort zahlreiche Besprechungen mit den anderen Bundesressorts, den Ländern, den innerdeutschen Verfolgtenverbänden sowie der Claims Conference statt. Bei dieser Gelegenheit wurden Hunderte von Änderungsvorschlägen vorgebracht, angesichts derer die Einhaltung des Zeitplans kaum mehr möglich $\operatorname{schien}^{419}$. Im Zuge dieser Beratungen verschlechterte sich das Verhältnis zwischen den zuständigen Referenten des Bundesfinanzministeriums und des Bundesjustizministeriums dramatisch. Landgerichtsrätin Becker, die auch an den Verhandlungen in Mehlem und Wassenaar teilgenommen hatte und großen Anteil an der Ausarbeitung des Siegburger Entwurfes besaß, verzweifelte schließlich an der Verzögerungstaktik des Bundesfinanzministeriums und beschwerte sich deshalb, „daß das federführende Bundesressort nicht ernsthaft den ehrlichen Willen hat, das Gesetz noch in dieser Legislaturperiode verabschiedet zu sehen ${ }^{420}$. Letzter Auslöser dieses Protestes war die an sie von dieser Seite ergangene Aufforderung gewesen, das Bundesfinanzministerium dabei zu unterstützen, die Beschäftigung des Bundestags-Rechtsausschusses mit den verschiedenen Entwürfen für ein Bundesentschädigungsgesetz hinauszuschieben ${ }^{421}$. Dort drängte nämlich vor allem die SPD darauf, möglichst bald die Beratungen aufzunehmen, während die Koalitionsvertreter weiterhin lieber den Regierungsentwurf abwarten wollten. Auch Otto-Heinrich Greve (SPD) zürnte deshalb, das Bundesfinanzministerium „sei bestrebt, die Wiedergutmachung solange zu verschleppen, bis der letzte Verfolgte verstorben $\mathrm{sei}^{\text {“ }}{ }^{422}$.

Als der Rechtsausschuß am 17. April schließlich die Beratungen aufnehmen konnte, lag seitens der Bundesregierung immer noch lediglich ein Referentenentwurf vor. Dennoch einigte sich der Rechtsausschuß auf diesen als Grundlage eines Bundesentschädigungsgesetzes. Dazu hatte auch Otto Küster beigetragen, der dort zwar gleichfalls die zeitliche Verschleppung durch das Bundesfinanzministerium kritisierte, aber für den Inhalt des Entwurfs ausgesprochen lobende Worte fand (während er nach der Verabschiedung einer der schärfsten Kritiker war): Der Entwurf des Bundesfinanzministeriums sei insgesamt günstiger für die Verfolgten als der des Bundesrats, ja sogar als seine eigene November-Fassung. Die internationalen Vereinbarungen seien stärker berücksichtigt und dem Gedanken des Schadensersatzes werde mehr Rechnung getragen. Um noch eine Chance zu haben, in der laufenden Legislaturperiode zu einem

${ }^{417}$ Kabinettsvorlage Schäffers, 25.3. 1953, BA, B 136/1131; Blücher an den Präsidenten des Deutschen Bundestags, 7.5. 1953, BA, B 136/1131.

${ }^{418}$ Staatssekretär Ritter von Lex (Bundesinnenministerium) an Staatssekretär Lenz (Bundeskanzleramt), 8.4. 1953, BA, B 136/1131.

419 Siehe Aufzeichnungen über diese Besprechungen in BA, B 126/12532.

\$20 Vermerk Becker für Strauß und Dehler, 7.3. 1953, BA, B 141/617. In einem zusammenfassenden Bericht über die Spannungen mit dem Bundesfinanzministerium schloß Becker: „Läßt man jedoch (sci. das BFM) in der bisherigen Weise weiter gewähren, so halte ich die Tätigkeit im Wiedergutmachungsreferat des Bundesjustizministerium, wie ich glaube, nicht nur für mich, sondern für jeden, der auf Fairness auch im öffentlichen Leben Wert legt und die Wiedergutmachung nicht nur als formelle Äußerlichkeit oder als soziale Spende, sondern als Rechtsnotwendigkeit ansieht, für unmöglich.“ Becker an Dehler, 21.7. 1953, BA, B 141/ 621.

421 Vermerk Beckers für W. Strauß und Dehler, 7.3. 1953, BA, B 141/617.

422 Aktenvermerk Kuschnitzkys vom 7.4. 1953, Bericht über Sitzung des Bundestags-Ausschusses für Rechtswesen und Verfassungsrecht am 27.3. 1953, BA, B 126/12522. 
Entschädigungsgesetz zu kommen, sollte man sich also auf den Entwurf des Bundesfinanzministeriums stützen ${ }^{423}$.

Diese Eloge verwunderte auch den SPD-Abgeordneten Arndt, der jedoch im Interesse der Beschleunigung des Verfahrens ebenfalls einwilligte, den Regierungsentwurf zum Ausgangspunkt zu nehmen ${ }^{424}$. Die als Folge der Verzögerungspolitik des Bundesfinanzministeriums entstandene Zeitnot wirkte nunmehr als Druckmittel auf alle diejenigen Kräfte, die an der baldigen Verabschiedung eines Bundesentschädigungsgesetzes interessiert waren. Ihnen war nun klar, daß dies, wenn überhaupt, allein auf der Grundlage des Regierungsentwurfs noch möglich sein konnte. Küster machte sich später große Vorwürfe, in der entscheidenden Sitzung des Rechtsausschusses zugunsten des Entwurfes des Bundesfinanzministeriums plädiert zu haben, dies sei nur deshalb erfolgt, weil ihm die Claims Conference in der Nacht zuvor zugesetzt hätte, dieses Opfer zu bringen ${ }^{425}$. Tatsache ist, daß die Claims Conference offiziell mitteilte, daß für sie allein der Regierungsentwurf in Frage komme ${ }^{426}$.

Der Rechtsausschuß beriet von April bis Juni ausführlich über den Referentenentwurf des Bundesfinanzministeriums und formulierte dabei eine Vielzahl von Verbesserungsvorschlägen. Die Haltung der Koalitionsparteien war jedoch zwiespältig. Zum einen unterstrichen sie, daß auch sie unbedingt daran interessiert seien, daß das Bundesentschädigungsgesetz noch in der laufenden Legislaturperiode verabschiedet werde. Zugleich wurde von dieser Seite aber erneut gefordert, „daß die Verabschiedung erst dann erfolgen solle, wenn die Bundesregierung eine Vorlage zur Entschädigung der sogenannten gutgläubigen Rückerstattungspflichtigen vorlegt ${ }^{\text {“427. Die Vorbereitungen }}$ hierfür steckten jedoch, wie Kuschnitzky mitteilte, erst in den Anfängen, so daß es nicht möglich war, diese beiden Gesetze zur gleichen Zeit zu erlassen ${ }^{428}$. Hermann Brill begrüßte dies im Rechtsausschuß, anders als die Koalitionsparteien, auch als Ausdruck einer richtigen politischen Prioritätensetzung ${ }^{429}$.

Nachdem nun der Entwurf des Bundesfinanzministeriums seinen Zweck erfüllt hatte, den konkurrierenden Gesetzentwurf des Bundesrats aus dem Rennen zu werfen, signalisierte Schäffer immer offener seinen Wunsch auf Verschiebung des Bundesentschädigungsgesetzes in die nächste Legislaturperiode. Dabei zählte er darauf, daß der Bundesrat ohnehin wegen der im Regierungsentwurf vorgesehenen Kostenaufteilung zwischen Bund und Ländern den Vermittlungsausschuß anrufen würde. ( $\$ 77$ des Entwurfs legte die gesamten Entschädigungslasten, mit Ausnahme gewisser Gruppen Heimatvertriebener, DP's und Nationalverfolgter, den Ländern auf.) Lag der Konflikt aber

423 Protokoll der 252. Sitzung des Bundestags-Ausschusses für Rechtswesen und Verfassungsrecht am 17.4. 1953, BA, B 141/618.

424 Ebenda.

+25 Küster an Böhm, 11.4. 1954, in: Freiburger Rundbrief, September 1954, Nr. 25/28, S. 9. Dort datierte er diese Sitzung allerdings irrtümlicherweise auf den 20. April.

426 Vermerk von Kuschnitzky für Wolff, 22.6. 1953, BA, B 126/12532.

427 Aufzeichnung Blankenhorn für Adenauer, 26.5. 1953, BA, B 136/1131. Siehe auch etwa Weber (CDU) im Protokoll der 252. Sitzung des Bundestags-Ausschusses für Rechtswesen und Verfassungsrecht am 17.4. 1953 sowie Wilhelm Laforet (CDU/CSU) im Protokoll der 254. Sitzung am 4. 5. 1953, BA, B 141/618. Sowic auch Tagebuch-Eintrag von Lenz vom 24. 6. 1953: „Die DP und FDP wollen sich beim Wiedergutmachungsgesetz der Stimme enthalten, weil sie für ein Junktim zwischen beiden Gesetzen sind.“ In: Tagebuch Lenz, S. 657.

${ }^{428}$ Siehe dazu Kuschnitzky im Protokoll der 254. Sitzung des Bundestags-Ausschusses für Rechtswesen und Verfassungsrecht am 4.5. 1953, BA, B 141/618.

${ }^{429}$ Siehe dazu Brill, ebenda. 
erst einmal beim Vermittlungsausschuß - so Schäffers Kalkulation - war an eine Verabschiedung in der laufenden Legislaturperiode nicht mehr zu denken ${ }^{430}$.

Bei den Verfolgtenorganisationen innerhalb und außerhalb Deutschlands herrschte begreiflicherweise größte Empörung über die sich abzeichnende Verschleppung des Bundesentschädigungsgesetzes ${ }^{431}$. Doch auch in Bonn bereitete dies Sorge. Wiederum stand das Auswärtige Amt auf Seiten der Wiedergutmachungsbefürworter. Herbert Blankenhorn warnte Adenauer - den dieses Thema im übrigen kaum tangierte - am 26. Mai eindringlich vor den vor allem in außenpolitischer Hinsicht verheerenden Folgen. Es sei zu befürchten, so Blankenhorn, „daß eine Verschiebung der Verabschiedung des Gesetzes bis zum Zusammentritt eines neuen Parlaments nicht nur als ein Bruch der wiederholt gegebenen Zusagen des Herrn Bundeskanzlers und der Bundesregierung ausgelegt werden, sondern auch einen guten Teil der positiven Auswirkungen der Unterzeichnung und fristgemäßen Ratifizierung des Israel-Vertrages wett machen würden". Eine Verabschiedung durch den Bundestag noch in dieser Legislaturperiode sei deshalb auch aus außenpolitischen Gründen unbedingt erforderlich ${ }^{432}$.

Solche Überlegungen führten dazu, daß wenige Tage später das Kabinett dem Entwurf des Bundesfinanzministeriums zustimmte und ihn nunmehr offiziell an den Bundestag weiterleitete. Auch Schäffer hatte sich dafür ausgesprochen, wobei er allerdings weiterhin auschloß, „daß das Bundesergänzungsrecht noch vor Beginn der nächsten

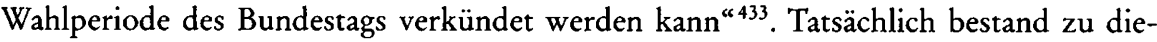
sem Zeitpunkt bei Einhaltung des ordentlichen Gesetzgebungsverfahrens kaum noch eine Chance dafür, zumal der Bundesfinanzminister bereits die Sollbruchstelle der finanziellen Lastenverteilung zwischen Bund und Ländern einkalkuliert hatte ${ }^{434}$.

\section{Verabschiedung als Provisorium}

Doch bald darauf stellte Hermann Brill mit einem ungewöhnlichen Antrag im Rechtsausschuß alle bisherigen Kalkulationen auf den Kopf. Namens der SPD-Fraktion schlug er dort am 18. Juni vor, „den Regierungsentwurf in der Fassung des dritten Referentenentwurfs so, wie er vom Kabinett gebilligt ist, anzunehmen und die Novellierung dieses Entwurfs dem nächsten Bundestag zu überlassen“. Als Eventualvorschläge unterbreitete er daneben die Annahme des Bundesrats-Initiativgesetzentwurfes bzw. die Ausdehnung des Entschädigungsgesetzes der US-Zone auf die britische Zone. Für die SPD-Fraktion bedeutete dies Brill zufolge, „ein außerordentliches Entgegenkommen ... Wir haben uns dazu bereit gefunden, weil wir der Überzeugung sind, daß dieser Bundestag nicht auseinandergehen darf, ohne daß diese Regelung erfolgt ist. “435 Es war klar, daß sich die Diskussion auf den ersten Vorschlag konzentrieren würde. Die Reaktion der Koalitionsparteien war zunächst gemischt. Eugen Gerstenmaier (CDU) stellte sich vorbehaltlos hinter den diesen Vorschlägen zugrundeliegenden Gedanken

430 Sondersitzung des Kabinetts am 20.5. 1953, in: Kabinettsprotokolle der Bundesregierung, Bd. 6, S. $303 \mathrm{ff}$; Becker an Dehler, 22.5. 1953, BA, B 141/620.

431 Siehe dazu etwa Zentralverband der durch die Nürnberger Gesetze Betroffenen Nicht-Jüdischen Glaubens an Adenauer, 23.5. 1953, BA, B 136/1131.

432 Aufzeichnung Blankenhorns für Adenauer, 26.5. 1953, BA, B 136/1131.

433 295. Kabinettssitzung am 29.5. 1953, in: Kabinettsprotokolle der Bundesregierung, Bd. 6, S. 316.

${ }^{434}$ Siche dazu auch Memorandum von Herbert S. Schoenfeldt (Claims Conference), 8. 6. 1953, BA, B 136/1131.

435 Protokoll der 269. Sitzung des Bundestags-Ausschusses für Rechtswesen und Verfassungsrecht am 18.6. 1953, BA, B 141/621. 
und begründete dies damit, daß sich im Schatten des Gesetzes zu Artikel 131 GG „ein Rechts- und Selbstbewußtsein der nationalsozialistischen Reaktion entwickelt (habe), das in umgekehrt proportionalem Verhältnis“ zu dem des deutschen Widerstandes stehe, der immer mehr in die Defensive gedrängt würde. Deshalb sprach er sich entsprechend dem Hauptvorschlag der SPD für die „Annahme des Regierungsentwurfs aus, um einer sich ausbreitenden Resignation bei den Widerstandskämpfern einen gewissen Riegel vorzuschieben “ ${ }^{436}$.

Sein Fraktionskollege Karl Weber stellte diesen Gedanken jedoch auf den Kopf: Er hob die Gefahren des Aufkommens einer neuen Welle des Antisemitismus hervor, denen man am besten dadurch beikomme, daß man, wie im Antrag des Rechtsausschusses vom 3. Juli 1952 festgelegt, zugleich mit dem Entschädigungsgesetz auch die Entschädigung der Rückerstattungsgeschädigten regele. Damit rückte er den Gedanken eines Junktims wieder in den Vordergrund. „Die gleichzeitige Annahme eines solchen Gesetzes“, so Weber, „würde jedenfalls die endgültige Entscheidung für die CDUFraktion erheblich erleichtern.“ Auch werde „man mit dem Bundesentschädigungsgesetz einen sehr viel leichteren Stand in der Öffentlichkeit haben ..., wenn man gleichzeitig auch die anderen Forderungen, die seiner Meinung nach auf derselben Ebene lägen, erfüllen könne. “437 Der DP-Abgeordnete Hans Ewers verstärkte diesen Wink mit der öffentlichen Meinung: „Man müsse sich im klaren sein, daß die Annahme des Bundesentschädigungsgesetzes ohne die gleichzeitige Verabschiedung eines Härteausgleichsgesetzes in der Rückerstattung bei denjenigen vermutlichen Nazigegnern (sic!), die man als Landwirte enteignet habe, um Autobahnen zu bauen oder Rüstungsanlagen zu schaffen und die man in Land entschädigt habe, für das irgendeine öffentliche Stelle als Eigentümer im Grundbuch eingetragen gewesen sei und bei denen sich dann herausgestellt habe, daß dieses Land einige Jahre vorher einem Juden weggenommen worden sei, und die es heute zurückgeben müßten, Entrüstungsstürme hervorrufen werde. “438 Die SPD wies diese Verbindung zwischen der Entschädigung der Verfolgten und der Rückerstattungsgeschädigten empört zurück, und Friedrich Wilhelm Wagner zeigte sich bestürzt darüber, „daß man der Bevölkerung der deutschen Bundesrepublik die Entschädigung derjenigen, die durch den Nationalsozialismus ... verfolgt worden seien ..., akzeptabel machen müsse ${ }^{\text {“439. }}$.

Schwierigkeiten bereitete auch der ausdrückliche Wunsch der SPD, den Regierungsentwurf unverändert zu verabschieden. Kuschnitzky, der wiederum das Bundesfinanzministerium vertrat, bot an, die bisher vom Ausschuß beratenen Ergebnisse noch in den Entwurf einzuarbeiten, und auch einige Koalitionsabgeordnete äußerten entsprechende Anregungen. Doch lehnte dies die SPD-Fraktion kategorisch ab. Arndt erklärte, daß keinerlei Änderung möglich sei, denn eine solche „würde das Zugeständnis enthalten, als ob die Vorlage die Änderungswünsche befriedige und als ob man keine anderen Wünsche habe, und würde damit den Charakter der Notannahme des Gesetzes verändern ... Für die SPD gehe es eben auch darum, durch die En-bloc Annahme zum Ausdruck zu bringen, daß man nichts anderes mehr machen $\mathrm{k}$ ö $\mathrm{n} n$ e. ${ }^{“ 440}$ So sollte also dieses Gesetz mitsamt allen deutlich gewordenen Mängeln verabschiedet werden, um

\footnotetext{
436 Ebenda.

4.37 Ebenda. Siche dazu auch Hans Ewers (DP) und Eduard Leuze (FDP), ebenda.

438 Ebenda.

439 Ebenda.

440 Ebenda.
} 
nur ja nicht die Erfordernis einer grundlegenden Novellierung in der nächsten Legislaturperiode in Frage zu stellen.

Vor diesem Hintergrund entschloß sich Schäffer zu einer Wende um $180 \mathrm{Grad}$. Schnell erkannte er die taktischen Möglichkeiten, die in dieser Situation lagen, und drängte jetzt auf die Beschleunigung des Bundesentschädigungsgesetzes - mit der bauernschlauen Maßgabe, daß gemäß dem Antrag der SPD keinerlei Veränderungen an dem Entwurf vorgenommen werden dürften und daß dies auch die vorgesehene Kostenaufteilung einschließen müsse. Damit wollte er nun dem Bundesrat, der am selben Tage die vorgesehene Kostenverteilung strikt abgelehnt hatte ${ }^{441}$, den Schwarzen Peter zuschieben. Dem CDU/CSU-Fraktionsvorsitzenden Heinrich von Brentano schrieb Schäffer: „Wenn die Kostenverteilung im Sinn des Vorschlags des Regierungsentwurfs durchgehen soll, dann ist die einzige Möglichkeit jetzt die, den Bundesrat unter Zeitdruck zu stellen und ihm die Verantwortung zu überschieben, wenn er den Vermittlungsausschuß anruft und dadurch den Gesetzentwurf vor dem 3. 7. nicht mehr zustandekommen läßt. " ${ }^{442}$ Auf diese Weise gedachte Schäffer den Bundesrat zu erpressen, da dieser kaum bereit sein würde, den Sündenbock für das Scheitern des Entwurfes zu spielen.

Daraufhin gab bei nächster Gelegenheit auch die CDU/CSU-Fraktion ihr Einverständnis mit dem Vorschlag der SPD - unveränderte Annahme des Regierungsentwurfes - bekannt ${ }^{433}$. Der Preis dafür war allerdings, daß auch das Kriegsgefangenenentschädigungsgesetz noch in dieser Legislaturperiode durchgesetzt werden sollte ${ }^{444}$; die Liste der Koppelungsgeschäfte wurde so um eine neue Variante bereichert. Nunmehr peitschte man den Entwurf des Bundesergänzungsgesetzes in ungeheurer Eile durch. Noch am selben Tag fand die erste $e^{445}$, am 2. Juli die zweite und dritte Lesung im Bundestag statt, bei der absprachegemäß keine Änderungsanträge gestellt wurden. Allein die KPD und die DP widersetzten sich diesem Vorgehen ${ }^{446}$. Der Berichterstatter des Rechtsausschusses Weber erklärte, dies stelle etwas in der Parlamentsgeschichte wohl kaum Dagewesenes vor, doch dürfe der erste Bundestag nicht nach Hause gehen, „ohne auf diesem Gebiet eine Regelung geschaffen zu haben“447. Insbesondere Arndt, Greve und Wagner von der SPD, aber auch Gerstenmaier namens der CDU/CSU unterstrichen dabei noch einmal ausdrücklich die Notwendigkeit einer schleunigen Novellierung durch den kommenden Bundestag ${ }^{448}$.

Noch einmal flackerte der Widerstandsgeist Schäffers auf, war er doch mit dieser Entscheidung immer noch nicht ganz glücklich, und so versuchte er, unter anderem im heimatlichen Bayern Helfer dafür zu gewinnen, das Bundesentschädigungsgesetz, aber auch das Gesetz über die Entschädigung der früheren Kriegsgefangenen im Bundesrat in die Zeit nach den Wahlen zu verschleppen ${ }^{449}$. Aber wenige Tage später nahm er

${ }^{441}$ Sitzungsberichte des Deutschen Bundesrats, 110. Sitzung am 19.6. 1953, S. 295-298.

442 Schäffer an v. Brentano, 19.6. 1953, BA, B 126/12523. Siehe auch Schäffer an Ehlers, 19.6. 1953, BA, B 126/ 12523; Schäffer an Laforet, 19.6. 1953, BA, B 126/12523.

443 Protokoll der 270. Sitzung des Bundestags-Ausschusses für Rechtswesen und Verfassungsrecht am 24.6. 1953, BA, B 141/621.

444 Schäffer an Fischer-Menshausen und Kuschnitzky, 25.6. 1953, BA, B 126/12523.

445 Deutscher Bundestag, 275. Sitzung am 24.6. 1953, Stenographische Berichte, Bd. 17, S. 13643 f.

446 Deutscher Bundestag, 279. Sitzung am 2.7. 1953, Stenographische Berichte, Bd. 17, S. 14007-14013.

447 Ebenda, S. 14008.

${ }^{448}$ Schriftliche Erklärungen der Abgeordneten Arndt, Greve und Wagner, ebenda, S. 14046-14048; Gerstenmaier im Deutschen Bundestag, 282. Sitzung am 29.7. 1953, Stenographische Berichte, Bd. 17, S. 14269.

${ }^{449}$ Schäffer an Ringelmann, 3.7. 1953, BayMF, Az. IV-N 403-33, Bd. 5, 1953. 
diesen Vorstoß wieder zurück, da ihm die politischen Gründe für die unverzügliche Verabschiedung des Bundesentschädigungsgesetzes nunmehr durchschlagend schienen ${ }^{450}$. Als Schäffer eine Woche später, am 17. Juli, bei einer Reise nach Washington mit Geoffrey W. Lewis, dem amtierenden Leiter der Deutschlandabteilung des State Departments zusammentraf, wurden ihm diese auch noch einmal bestätigt: Lewis teilte ihm offiziell mit, daß von amerikanischer Seite ein solcher Schritt noch in der laufenden Legislaturperiode gewünscht werde ${ }^{451}$.

Auch der Bundesrat stellte, um weitere Verzögerungen zu verhindern, seine erheblichen Bedenken gegen den Entwurf zurück, forderte aber gleichfalls eine unverzügliche Novellierung durch den kommenden Bundestag ${ }^{452}$. Nachdem den Ländern zuletzt auch noch einige kleinere Zugeständnisse in der Frage der Kostenaufteilung gemacht wurden ${ }^{453}$, konnte die Bundesregierung dem Bundesentschädigungsgesetz schließlich am 25. August die Zustimmung erteilen ${ }^{454}$.

\section{Bilanz: Fortschritte und Defizite}

Unter dem Druck der Verhältnisse - d. h. in erster Linie der durch das Bundesfinanzministerium verursachten Zeitnot - war also ein Bundesentschädigungsgesetz zustandegekommen, das von Anfang an auf breite Kritik stieß und jedenfalls kaum als Visitenkarte eines demokratisch geläuterten Deutschlands taugte. Wie gesagt, war die SPD nur um den Preis, daß dessen Konstruktionsmängel nicht noch notdürftig kaschiert wurden, überhaupt bereit gewesen, dem höchst ungewöhnlichen Verfahren, in dem das schließlich am 1. Oktober 1953 in Kraft getretene Bundesergänzungsgesetz (BErgG) ${ }^{455}$ verabschiedet wurde, zuzustimmen; „das aber freilich in einer Gestalt, von der niemand gemeint hatte, so solle es im Gesetzblatt zu lesen stehen als Deutschlands Wiedergutmachungsgeset ${ }^{\star 456}$.

Gleichwohl brachten die 113 Paragraphen des neuen Gesetzes gegenüber der bisherigen Situation einige Verbesserungen mit sich, die vor allem auf die Umsetzung der im Vierten Teil des Überleitungsabkommens und im Haager Protokoll Nr. 1 enthaltenen Forderungen zurückzuführen waren: So wurden nunmehr empfindliche Lücken geschlossen, die in einigen Ländern vor allem der britischen Zone mit bislang völlig unzureichenden Gesetzen bestanden. Für die Verfolgten in „Nordrhein-Westfalen, Niedersachsen und Schleswig-Holstein (gab es) erst jetzt einen eigentlichen Entschädigungsanspruch ... für Existenzschäden, für die erpreßten Abgaben (das freilich mit einem großen Aber) und für sonstige Vermögensschäden außerhalb der Rückerstat-

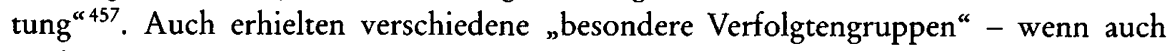
stark eingeschränkte - Ansprüche. Dazu gehörten Verfolgte aus den Vertreibungsge-

450 Hartmann an Ringelmann, 10.7. 1953, BayMF, Az. IV-N 403-33, Bd. 5.

${ }^{451}$ Department of State, Memorandum of Conversation, Saul Kagan u. A.F. Moores (GEA), 23.7. 1953, USNA, RG 59, 262.0041/7-2353; Neue Zeitung, 18. 7. 1953, „Schäffer beim Präsidenten der Weltbank“.

452 11. Sitzung des Bundesrats-Sonderausschusses für Wiedergutmachungsfragen, 10. 7. 1953, BayMF, Az. IVN 403-33, Bd. 5; Sitzungsberichte des Deutschen Bundesrats, 113. Sitzung am 17. 7. 1953, S.364-369; Entschließung des Bundesrats vom 17. 7. 1953, BR-Drucksache Nr. 4661.

453 Deutscher Bundestag, 282. Sitzung am 29.7. 1953, Stenographische Berichte, Bd. 17, S. 14269f. Vgl. auch Féaux de la Croix, Vom Unrecht zur Entschädigung, S. $80 \mathrm{f}$.

454 Kabinettssitzung am 25.8. 1953, Kabinettsprotokolle der Bundesregierung, Bd. 6, S. 436.

455 BGBl I, Nr. 62, 21.9. 1953, S. 1387-1408.

456 Otto Küster, Das Gesetz der unsicheren Hand, in: Freiburger Rundbrief, Februar 1954, Nr. 21/24, S. 3.

457 Vgl. ebenda, S. 4. 
bieten, Staatenlose und politische Flüchtlinge sowie Nationalverfolgte ${ }^{458}$. Dies ist na' türlich noch keine erschöpfende Aufzählung der positiven Neuerungen. Im Vordergrund der zeitgenössischen Rezeption standen aber vor allem die Defizite und auch die Rückschritte. Die Kritik fällt dabei in drei Kategorien: Erstens wurde moniert, daß das Bundesergänzungsgesetz Verschlechterungen gegenüber bisherigen Regelungen mit sich bringe, zweitens, daß es den internationalen Vereinbarungen mit den Alliierten und der Claims Conference nicht gerecht werde, und drittens, daß abgesehen von seiner materiell-rechtlichen Qualität ein eklatanter Mangel an handwerklicher Qualität bestehe. Otto Küster legte insbesondere auf den letzten Punkt großen Nachdruck: „Er bewirkt die Stockung, die Sie schon überall bemerken, er bewirkt die Willkür der Ergebnisse, die empörenden Begründungen, das Dschungel der Scheinprobleme, in denen sich jeder gute Wille festläuft und die die Verwaltungskraft aufzehren, und schließlich die Flucht aller guter Juristen vor einer Sache, in der man keine Arbeit mit dem Gefühl aus der Hand legen kann, hier sei nun nach Menschenkraft wieder ein kleines Stück Recht geschaffen worden. ${ }^{*} 59$

Zugleich hatte aber auch eine Entwicklung ihren vorläufigen Abschluß gefunden, die schon mit den ersten Entschädigungsregelungen nach dem Krieg eingesetzt hatte: Mit dem Bundesergänzungsgesetz, das durch alle folgenden Novellierungen hindurch den Kern des deutschen Entschädigungsrechts bildete, war das Prinzip, daß die Verfolgten keinen zivilrechtlichen Anspruch, sondern einen Anspruch gegen die öffentliche Hand besaßen, endgültig zementiert. Wie Kuschnitzky im Rechtsausschuß des Bundestags betonte, ging dieser "nicht auf volle Schadloshaltung im Sinne des bürgerlichen Rechts, sondern auf Entschädigung nach Maßgabe der im Gesetz normierten Schadenstatbestände und nach Maßgabe der in den festgelegten Grenzen vorgesehenen Entschädigungsregelung “460. Das bedeutete, wie Küster anklagte, daß nicht nach denselben Grundsätzen wiedergutgemacht wurde, nach denen man wiedergutmachen würde, wenn irgendein Straßenpassant durch einen Autobus der Bundespost durch Verschulden des Chauffeurs zu Schaden käme ${ }^{461}$. Ein Rechtsanspruch wurde auf diese Weise durch einen staatlichen Fürsorgeanspruch ersetzt, was Franz Böhm als Symptom dafür ansah, daß sich die deutsche Gesellschaft auf dem Weg vom Rechtsstaat zum Wohlfahrtsstaat befände ${ }^{462}$. So begründete das Bundesentschädigungsgesetz (wie auch die früheren Länderregelungen) nicht nur Ansprüche, sondern vernichtete zugleich auf Staatsdeliktrecht beruhende Ansprüche, aber wohl doch solche, die entgegen Küsters Annahme, daß derartige Forderungen durch deutsche Gerichte realisiert worden wären, falls nicht die Entschädigungsgesetzgebung dazwischen gekommen wäre ${ }^{463}$, nur geringe Durchsetzungschancen gehabt hätten. Dafür sprechen jedenfalls die äußerst mageren Ergebnisse der zivilrechtlichen Forderungen ehemaliger KZ-Zwangsarbeiter gegen die Firmen, die sie während des Krieges beschäftigt hatten ${ }^{464}$.

458 \$67-76, BErgG.

459 Küster, Gesetz der unsicheren Hand, S. 4.

460 Protokoll der 255. Sitzung des Bundestags-Ausschusses für Rechtswesen und Verfassungsrecht, 7.5. 1953, BA, B 141/618.

461 Vgl. Küster, Das andere Grundgesetz, in: Die Gegenwart 8 (1953), S. 295-297.

462 Vgl. Nachwort von Franz Böhm zu Küster, Wiedergutmachung als elementare Rechtsaufgabe, S. 21.

463 Vgl. Küster, Wiedergutmachung als elementare Rechtsaufgabe, S. 15.

464 Vgl. Benjamin B. Ferencz, Lohn des Grauens. Die verweigerte Entschädigung für jüdische Zwangsarbeiter. Ein Kapitel deutscher Nachkriegsgeschichte, Frankfurt usw. 1981; Constantin Goschler, Streit um Almosen. Die Entschädigung der KZ-Zwangsarbeiter durch die deutsche Nachkriegsindustrie, in: Dachauer Hefte 2 
Neben dieser grundsätzlichen Erwägung nannte Küster auch eine Reihe von Punkten, in denen das Gesetz hinter dem schon früher Erreichten oder dem Versprochenen zurückgeblieben war: So hatte der Verfolgte keinen Anspruch, wenn er nicht bewies, daß „persönlich gegen ihn eine amtlich gebilligte Maßnahme gerichtet wurde“. Auch die Hinterbliebenen von Verfolgten, die den Freitod wählten, erhielten "nichts ohne den Beweis, daß das amtlich gebilligt worden war". Gleichfalls ohne Entschädigung blieb, etwa wenn jemand von seinem verhetzten Arbeitgeber ohne amtliche Nachhilfe entlassen wurde. Verfolgte, die ihre Altersversorgung verloren hatten, weil ihre Versorgungskasse zerschlagen worden war, wurden „auf Gewährungen aus dem Härtefonds verwiesen." Im Gegensatz zu allen verfolgten Beamten, die ab 1. April 1951 volle Entschädigung und für die Zeit dahin maximal 25.000 DM erhielten, galt dieser Betrag für alle verfolgten Nichtbeamten als Höchstbetrag der Entschädigung. Auch wurde die Erstattung der Sonderabgaben, die 1938 nach der Reichkristallnacht Juden abgepreßt worden waren, praktisch ausgeschlossen. Als „kleine Neckerei von der Art, wie sie schon der Gauleiter liebte“, bezeichnete Küster schließlich, daß „Existenzschädigungen ab 1933 nicht nur zur Einkommenssteuer, sondern auch zum Notopfer Berlin herangezogen werden ${ }^{\alpha 465}$. Auch die Liste der Kritikpunkte ist hiermit natürlich bei weitem noch nicht erschöpft.

Auffälligerweise spielte eine markante Einschränkung des Kreises der Wiedergutmachungsberechtigten gegenüber dem Entschädigungsgesetz der US-Zone im Gegensatz zu heute in der zeitgenössischen Diskussion kaum eine Rolle: Schränkte das USEG ein, keinen Anspruch auf Entschädigung habe, wer der nationalsozialistischen Gewaltherrschaft Vorschub geleistet habe ${ }^{466}$, hieß es nun zusätzlich „oder einer anderen Gewal-

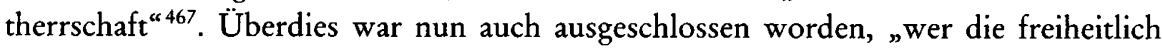
demokratische Grundordnung bekämpft" ${ }^{\text {“468. }}$. Allein die KPD protestierte gegen diese auf die Kommunisten zielenden Neuerungen ${ }^{469}$, während sonst ein hohes Maß an allgemeiner Zustimmung herrschte.

Gotthard Jasper zufolge sei es unklar gewesen, ob hiermit der generelle Ausschluß der Kommunisten von den Wiedergutmachungsleistungen intendiert gewesen sei oder ob nur besonders aktive Gegner der freiheitlich-demokratischen Grundordnung der Bundesrepublik ausgeschlossen werden sollten ${ }^{470}$. Die vorangegangenen Erörterungen im Bundestags-Rechtsausschuß zeigen jedoch ganz eindeutig, gegen wen sich diese Klauseln richten sollten: Dort erläuterte Kuschnitzky, einer der Mitautoren des Gesetzes, am 7. Mai 1953, daß der Ausschluß von Personen, die die freiheitlich-demokratische Grundordnung bekämpften, auf das Entschädigungsgesetz von Berlin (West) zurückging. „Die Vertreter des Landes Berlin hätten in den Besprechungen großen Wert darauf gelegt, daß die Bestimmung so übernommen werde, wie sie sich in Berlin bestens

(1986), S. 175-194; Wolfgang Benz, Der Wollheim-Prozeß. Zwangsarbeit für I.G. Farben in Auschwitz, in: Herbst/Goschler (Hrsg.), Wiedergutmachung, S. 303-326.

${ }^{465}$ Küster, Wiedergutmachung als elementare Rechtsaufgabe, S. $5 \mathrm{f}$.

466 $\$ 1$ (1) 1 , USEG.

t67 $\$ 1$ (4) 1, BErgG.

$468 \int 1$ (4) 4, BErgG.

469 Siehe etwa Oskar Müller (KPD) im Deutschen Bundestag, 279. Sitzung am 2. 7. 1953, Stenographische Berichte, Bd. 17, S. 14013.

470 Vgl. Gotthard Jasper, Die disqualifizierten Opfer. Der Kalte Krieg und die Entschädigung für Kommunisten, in: Herbst/Goschler (Hrsg.), Wiedergutmachung, S. 367. 
bewährt habe. “471 Hiergegen wurden im Rechtsausschuß massive Bedenken vorgebracht, da die Berliner Formulierung nur aus der besonderen Kampfsituation in Berlin zu erklären sei, während eine solche Formulierung für ein Bundesentschädigungsgesetz zu weitgehend $\operatorname{se}^{472}$. Zwar hatte auch der zum Vergleich herangezogene Bundesratsentwurf eines Bundesentschädigungsgesetzes eine entsprechende Bestimmung vorgesehen. Jedoch präzisierte dieser, daß derjenige keinen Entschädigungsanspruch haben sollte, der „kraft Urteils des Bundesverfassungsgerichts ein Grundrecht verwirkt hat, weil er es zum Kampf gegen die freiheitliche demokratische Grundordnung mißbraucht hat, oder wegens eines Vergehens gegen diese Grundordnung rechtskräftig zu Freiheitsstrafen verurteilt worden ist ${ }^{\star 4}{ }^{43}$. Damit waren recht enge Kriterien für die Verwirkung des Entschädigungsanspruches aufgestellt worden.

Kuschnitzky beschwichtigte deshalb, „daß die Formulierung (sci. des Regierungsentwurfes) auch gar nicht so gemeint sei, daß jedes Mitglied der KPD vom Wiedergutmachungsanspruch ausgeschlossen werde. Man habe es vielmehr auf die aktive Tätigkeit, auf das Bekämpfen der freiheitlichen demokratischen Grundordnung abgestellt. Man wolle jedoch nicht SED-Mitgliedern, die nunmehr über die Zonengrenze in die Bundesrepublik strömten, nachdem sie in der der Ostzone jahrelang mitgemacht hätten ..., auch noch Entschädigungsleistungen zubilligen“. Im Hinblick auf die Formulierung "oder einer anderen Gewaltherrschaft" "sei auch an Personen gedacht, die jetzt aus der Tschechoslowakei kämen und dort dem Gottwald-Regime gedient hätten “ ${ }^{\text {474 }}$.

Im Kern bestand somit ein breiter Konsens darüber, daß diese Bestimmung in erster Linie Funktionäre der SED oder anderer kommunistischer Regimes sowie betont aktiv auftretende Funktionäre und nicht einfache Mitglieder der KPD treffen sollte, auch war ausschließlich die Rede von kommunistischer Betätigung nach 1945. In diesem Sinne legte auch der führende Kommentar von Georg Blessin und Hans Wilden, Oberregierungsräte im Bundesfinanz- bzw. Bundesjustizministerium, die neuen Ausschlußbestimmungen aus $^{475}$. Doch wurde die endgültige Entscheidung über die genaue Auslegung dem Bundesverfassungsgericht überlassen ${ }^{476}$. Jasper zufolge entwickelte die Rechtsprechung eine Auslegung, die teilweise wesentlich restriktiver war, als es in der Intention der Gesetzesautoren lag. Natürlich ist dies nicht vom stark antikommunistischen Meinungsklima vor allem der fünfziger Jahre zu trennen. Erst durch spätere Novellierungen des Bundesentschädigungsgesetzes erfolgte hier eine Korrektur ${ }^{477}$.

Überblickt man also die Spanne von den ersten Entschädigungsgesetzen auf Länderebene, insbesondere dem maßstabbildenden USEG, zum ersten Bundesentschädigungsgesetz, so werden markante Veränderungen des Berechtigtenkreises deutlich, die unter Einfluß innen- und außenpolitischer Faktoren zustandekamen: In der Frühzeit lag der Schwerpunkt - neben den rassisch Verfolgten - auf den politisch Verfolgten; die Ent-

471 Protokoll der 255. Sitzung des Bundestags-Ausschusses für Rechtswesen und Verfassungsrecht am 7.5. 1953, BA, B 14t/618.

472 Siehe etwa Wolff $u$. Obergerichtsrat Lenz, ebenda.

473 Bundesrats-Drucksache 413/52, Entwurf eines Bundesentschädigungsgesetzes.

474 Protokoll der 255. Sitzung des Bundestags-Ausschusses für Rechtswesen und Verfassungsrecht am 7.5. 1953, BA, B 141/618.

475 Vgl. Georg Blessin u. Hans Wilden, Bundesentschädigungsgesetze. Kommentar, München u. Berlin 1954, S. $100-102$.

476 Kuschnitzky im Protokoll der 255. Sitzung des Bundestags-Ausschusses für Rechtswesen und Verfassungsrecht am 7.5. 1953, BA, B 141/618.

477 Vgl. Jasper, Entschädigung für Kommunisten, S. 368-379. 
schädigung bildete hier geradezu ein Gegengewicht zur Rückerstattung, die ihre Hauptbedeutung für jüdische Verfolgte besaß. Doch mit dem BErgG hatten die politisch Verfolgten relativ gesehen an Bedeutung verloren und waren zum Teil sogar von der Ausgrenzung bedroht. Damit einher ging die Verlagerung auf im Ausland lebende Berechtige; dorthin gingen nach einer neueren Schätzung schließlich etwa 80 Prozent der Entschädigungsleistungen ${ }^{478}$. Dies korrespondierte auch mit einer Verschiebung bei den Hauptakteuren unter den Verfolgtenorganisationen: Die VVN war seit Anfang der fünfziger Jahre zur Bedeutungslosigkeit herabgesunken, während nun die Claims Conference für viele Jahre einen bedeutenden Einfluß auf die Durchführung und Verbesserung der Entschädigungsgesetzgebung in der Bundesrepublik ausübte.

\section{Abschied vom alliierten Engagement?}

Eine Zäsur bedeutete das Bundesergänzungsgesetz aber auch im Hinblick auf das alliierte Engagement, das für die Anfänge der Wiedergutmachung eine so bedeutende Rolle gespielt hatte. Die Alliierten hatten sich nach Abschluß des Überleitungsabkommens mit weiteren Schritten im Bereich der Entschädigung zunächst zurückgehalten. Doch im Juni 1953 regten die Briten einen alliierten Vorstoß in der Angelegenheit des soeben vorbereiteten Bundesentschädigungsgesetzes a ${ }^{479}$. Darauf reagierten zunächst auch die USA positiv, denn dort wünschte man, daß das vorgesehene Gesetz gemäß den Bestimmungen des Überleitungsabkommens das Mindestniveau des US-Zonen-Gesetzes erreichen sollte ${ }^{480}$. Bei der Alliierten Hohen Kommission wurde jedoch registriert, daß das geplante Bundesgesetz teils günstiger, teils ungünstiger als das USEG war. Da aber die Claims Conference im Hinblick auf die dort implizierten Verbesserungen darauf drängte, daß das Gesetz selbst mit den offensichtlichen Mängeln noch in der laufenden Legislaturperiode verabschiedet werden sollte ${ }^{481}$, wurden die Bedenken zunächst zurückgestellt.

Zugleich beschloß die Alliierte Hohe Kommission, nach Verabschiedung des Gesetzes der deutschen Bundesregierung einen Brief zu schicken, worin die Beanstandungen moniert werden sollten. Doch über deren Umfang gingen die Meinungen weit auseinander. Wünschte die amerikanische Seite allein diejenigen Punkte zu bemängeln, in denen das Bundesentschädigungsgesetz hinter den Forderungen des Vierten Teils des Überleitungsabkommens zurückblieb, so wollten London und Paris nunmehr bei dieser Gelegenheit weitergehende Wünsche präsentieren. Dabei wurden diejenigen Punkte, mit denen sich Briten und Franzosen bei den ISG-Verhandlungen nicht hatten durchsetzen können, erneut aufgetischt. Dies betraf vor allem die Ausweitung des entschädigungsberechtigten Kreises auf ausländische Opfer des Nationalsozialismus, die in ein deutsches Konzentrationslager oder als $Z$ wangsarbeiter verschleppt worden waren. Dahinter stand auf britischer Seite der Druck polnischer Exilgruppen, während in Frankreich vor allem ein erhebliches Interesse an der Entschädigung der ehemaligen französischen Zwangsarbeiter bestand ${ }^{482}$. Das State Department zeigte sich jedoch un-

\footnotetext{
${ }^{478}$ Vgl. Karl Heßdörfer, Die finanzielle Dimension, in: Herbst/Goschler (Hrsg.), Wiedergutmachung, S. 59.

479 Knox Lamb (HICOG) an State Department, 13.11. 1953, USNA, RG 59, 262.0041/11-1353.

480 John F. Dulles an HICOG, 13.7. 1953, USNA, RG 59, 262.0041/7-353.

481 Frederick G. Hulse an State Department, 27.7. 1953, Anlage 3: Draft of Tripartitely Agreed Paper on Federal General Compensation Law, 23.6. 1953, USNA, RG 59, 262.0041/7-2753.

${ }^{482}$ James B. Conant an Dulles, 24. 7. 1953, USNA, RG 59, 262.0041/7-2453. Vgl. dazu auch oben, Abschnitt III.
} 
nachgiebig und wies alle Forderungen, die über die Erfüllung des Vierten Teils des Überleitungsabkommens hinausgingen, zurück. Außenminister Dulles wies darauf hin, daß die Angelegenheit im Zusammenhang der alliierten Vorbesprechungen zur Revision des Besatzungsstatuts auf höchster Ebene geklärt worden sei und es keinen Grund dafür gebe, nunmehr von der auf der Washingtoner Außenministerkonferenz vom September 1951 festgestellten Linie abzuweichen: „British proposal would open Federal Republic to liability for fantastic sums of money and indirectly would reopen entire reparation problem. ${ }^{c 483}$ Dies war keine gute Ausgangssituation für einen alliierten Kompromiß.

Nahezu ein halbes Jahr diskutierte die Alliierte Hohe Kommission über den Inhalt des geplanten Briefes an Adenauer und stritt dabei um jedes Komma. Während Briten und Franzosen die Bundesrepublik zu weitergehenden Leistungen auffordern wollten, hatten aus amerikanischer Sicht die Forderungen an die Deutschen mit der Erfüllung der im Überleitungsabkommen festgehaltenen Bestimmungen ein Ende; alles, was darüber hinaus ging, war für sie Sache einer unabhängigen Entscheidung der Bundesrepublik, zu der sie nur durch ihr eigenes Gewissen veranlaßt werden könnte ${ }^{484}$. In diesem Zusammenhang registrierte die amerikanische Hohe Kommission mit Wohlgefallen, daß sich auf deutscher Seite starke Kräfte regten, die auf eine Verbesserung des Bundesentschädigungsgesetzes drängten, namentlich im Bundesrat. Dies wurde als ein beruhigendes Zeichen dafür gewertet, daß man die Angelegenheit nun in der Hand der Deutschen belassen könne und ein alliiertes Engagement nicht mehr erforderlich sei ${ }^{485}$.

Auch als Vertreter der britischen und französischen Botschaft am 13. Oktober in dieser Sache im State Department vorstellig wurden, wurden sie erneut auf den amerikanischen Willen zur Begrenzung des Engagements auf dem Feld der Wiedergutmachung verwiesen: „From the beginning it had been the view of this Government that the Allies would be well advised to confine themselves to general comments on the moral obligation of the German people and the Federal Government to compensate victims of Nazi persecution and avoid getting involved in the details of, and hence in the responsibility for, the precise measures taken by the German authorities to discharge this obligation. ${ }^{486}$ Wieder wird die amerikanische Taktik deutlich, und sie ähnelt der im Zusammenhang der Wassenaar-Verhandlungen verfolgten: Moralischer Druck auf die Deutschen, aber keine spezifischen Forderungen. So hatte das State Department Schäffer am 17. Juli den Wunsch nach schleuniger Verabschiedung des Bundesentschädigungsgesetzes unterbreitet ${ }^{47}$, während der von britischer und französischer Seite geäußerte Wunsch nach Intervention in die Details dieser Regelung von selber Stelle strikt abgelehnt wurde. Dabei erfolgte regelmäßig der Hinweis auf die finanziellen Risiken der britischen und französischen Forderungen. Gefährlich schien in diesem Zusammenhang insbesondere, daß auf diese Weise auch Ansprüche seitens der Sowjetunion oder ihrer osteuropäischen Satelliten provoziert werden könnten, lebte doch ein

483 Dulles an HICOG, 28.7. 1953, USNA, RG 59, 262.0041/7-2453.

${ }^{484}$ Dulles an HICOG, 8. 10. 1953, USNA, RG 59, 262.0041/9-2453.

485 Siehe etwa Knox Lamb (HICOG) an State Department, 13.11. 1953, USNA, RG 59, 262.0041/11-1353.

${ }^{486}$ Lewis (Department of State), Memorandum of Conversation, Lewis, Reinstein u: William A. Fowler mit Frederick J. Leishman (brit. Botschaft) u. Henri Ruffin (franz. Botschaft), 13.10. 1953, USNA, RG 59, 262.0041/10-1353.

487 Vgl. oben, Abschnitt V.3. 
beträchtlicher Teil der Opfer des Nationalsozialismus hinter dem Eisernen Vorhang ${ }^{488}$.

So dokumentierte das Schreiben der Alliierten Hohen Kommission an Adenauer vom 10. Dezember 1953, in dem die Wünsche der drei Westmächte an die deutsche Entschädigungsgesetzgebung ausgeführt wurde, schließlich den verbliebenen alliierten Minimalkonsens. Darin wurde erstens darauf hingewiesen, daß das Bundesergänzungsgesetz in einigen Punkten hinter den Anforderungen des Überleitungsabkommens zurückblieb - so weit herrschte ja auch Einigkeit unter den Alliierten. Zum zweiten hieß es aber, daß eine große Zahl von Verfolgten des Nationalsozialismus, darunter viele im Ausland lebende, noch gänzlich ohne Ansprüche sei. Die Entschädigung dieser Opfer bleibe eine moralische Verpflichtung der Bundesrepublik, doch erhob die Alliierte Hohe Kommission keine konkreten Forderungen, auf welche Weise diese zu erfüllen sei $^{489}$. Anders als Féaux de la Croix glaubt, war damit nicht die Möglichkeit impliziert, daß es sich die Alliierten auch anders überlegen könnten ${ }^{490}$ - tatsächlich markierte dieses Schreiben - sehr zum Verdruß Frankreichs und Großbritanniens - den Abschied von gemeinsamen alliierten Interventionen zugunsten von Verbesserungen der bundesdeutschen Entschädigungsgesetzgebung.

Die Note führte schließlich zu einer Besprechung der Alliierten Hohen Kommission mit deutschen Sachverständigen am 13. Dezember 1954. Gemeinsam vertraten dort die Alliierten nur die Forderung nach Beseitigung der Defizite des Bundesergänzungsgesetzes gegenüber dem Vierten Teil des Überleitungsabkommens, wozu sich die deutsche Seite auch positiv äußerte. Dagegen argumentierten Briten und Franzosen mit ihrer nunmehr präzisierten Forderung nach Einbeziehung der sogenannten Westverfolgten ins Bundesentschädigungsgesetz nicht mehr auf der Grundlage eines alliierten Konsenses. Auf deutscher Seite wollte man in dieser Frage keinesfalls nachgeben ${ }^{491}$. Dabei kam ihr zu Hilfe, daß anders als man dort glaubte ${ }^{492}$, die Alliierten sich nicht mehr auf gemeinsamen Druck verständigen konnten.

Dementsprechend lag es auch in der Konsequenz dieser Entwicklung, daß Frankreich und Großbritannien nach der Auflösung der Alliierten Hohen Kommission 1955 zusammen mit sechs weiteren westeuropäischen Staaten im Juni 1956 auf direktem Wege die Forderungen zur Entschädigung der Westverfolgten an die Bundesrepublik erhoben. Diese Aktion, der sich später weitere vier Staaten anschlossen, mündete schließlich in die elf sogenannten Globalabkommen mit den Weststaaten, die Anfang der sechziger Jahre abgeschlossen wurden ${ }^{493}$. Das französisch-britische Ansinnen auf Entschädigung nichtdeutscher Verfolgter des Nationalsozialismus hatte sich somit aus dem Zusammenhang des alliierten Besatzungsregimes herausgelöst und in einem anderen politischen Bezugsrahmen, dem der europäischen Integration, schließlich zumindest teilweise Erfolg.

Den Rückzug insbesondere ihrer amerikanischen „Schutzmacht“ aus der direkten

${ }^{488}$ Vgl. ebenda. Siehe auch F.A.O. Schwarz, 24.9. 1953, USNA, RG 59, 262.0041/9-2453.

489 Alliierte Hohe Kommission an Adenauer, 10.12. 1953, (Entwurf vom 29. 10. 1953), Anlage zu Knox Lamb an State Department, 13.11. 1953, USNA, RG 59, 262.0041/11-1353.

490 Vgl. Ernst Féaux de la Croix, Staatsvertragliche Ergänzungen der Entschädigung, in: ders. u. Helmut Rumpf, Der Werdegang des Entschädigungsrechts unter national- und völkerrechtlichem und politologischem Aspekt, München 1985, S. 202.

491 Conant an Dulles, 14. 12. 1954, USNA, RG 59, 262.0041/12-1454. Vgl. auch Féaux de la Croix, Staatsvertragliche Ergänzungen, S. $202 \mathrm{f}$.

492 Féaux de la Croix (Staatsvertragliche Ergänzungen, S. 203 f.) vertritt weiterhin die entgegengesetzte deutsche Einschätzung, wonach gemeinsamer alliierter Druck in dieser Angelegenheit bestanden habe.

${ }^{493}$ Vgl. ebenda, S. 204-288. 
Verantwortung für die Wiedergutmachung bekamen auch die jüdischen Organisationen zu spüren. Die amerikanische Hohe Kommission bemühte sich zwar noch, einige „Restposten“ abzuwickeln, zu denen neben der korrekten Durchführung der alliierten Rückerstattungsgesetze auch der Erlaß eines Gesetzes zur Entschädigung der rückerstattungsrechtlichen Geldverbindlichkeiten des Deutschen Reiches gehörten ${ }^{494}$. Doch hielt sie sich dabei strikt an den Rahmen des Überleitungsabkommens, obwohl es wegen des Widerstandes der französischen Nationalversammlung gegen die EVG-Verträge nicht ratifiziert worden war. Auch Hendrik George van Dam, Generalsekretär des Zentralrates der Juden in Deutschland, erhielt bei einem Besuch im State Department im Frühjahr 1954 die Auskunft, es sei US-Politik, soviel Verantwortung als möglich den Deutschen zu überlassen und so zu handeln, als wenn die Abkommen in Kraft seien. Zugleich lehnte es die amerikanische Politik auch konsequent ab, sich als Mittler zwischen den verschiedenen jüdischen Interessen zu betätigen ${ }^{495}$.

Doch bestätigte auch Adenauer dem Präsidenten der Claims Conference Goldmann auf dessen Bitte hin, daß die Bundesrepublik unter allen Umständen diejenigen Teile der Bonner Verträge beachten werde, die mit der Rückerstattung und Entschädigung der Verfolgten des Nationalsozialismus zu tun hatten ${ }^{496}$. Bald stellte die Claims Conference jedoch ihrerseits Forderungen, die über das im Überleitungsabkommen bzw. im Haager Gesetzgebungsprogramm Festgelegte hinausgingen und wurde dabei zum Motor der weiteren Entwicklung. Dabei war sie jedoch weitgehend auf sich alleine gestellt - die amerikanische Hohe Kommission unterstützte sie dabei nur soweit es im Rahmen ihrer eigenen Bestrebungen lag ${ }^{497}$. Das Ende der Besatzungszeit war hier also deutlich spürbar: Anders als früher konnten die jüdischen Organisationen nun nicht mehr auf massive Unterstützung ihrer Forderungen rechnen, sondern mußten versuchen, mit Hilfe moralischer Argumente zu überzeugen oder auch mit der Möglichkeit wirtschaftspolitischer Beeinträchtigungen zu drohen. Das schloß nicht aus, daß es auch in Zukunft zu punktueller diplomatischer Unterstützung seitens der USA kam. Doch handelte es sich dabei nun um indirekten, moralischen Druck, während zuvor auch direkter, politischer Druck zur Erreichung konkreter Ziele ausgeübt worden war. Dies trug letztlich auch dem gewandelten Charakter der deutsch-amerikanischen Beziehungen Rechnung.

Bezeichnend für diese Veränderungen ist, unter welchen Umständen John McCloy wieder in der Wiedergutmachungs-Angelegenheit auftauchte: In quasi ehrenamtlicher Funktion unterstützte er die Claims Conference seit 1954 bei ihrem Kampf um Entschädigung für ehemalige Zwangsarbeiter bei Krupp und anderen deutschen Industrieunternehmungen. Mit dieser inoffiziellen Tätigkeit setzte sich McCloy für bessere Beziehungen zu Deutschland ein ${ }^{498}$. Was nach dem Kriege als ein wichtiges Ziel der amerikanischen Deutschlandpolitik begonnen hatte, war somit nunmehr zu einem Stoff für Goodwill-Aktionen eines Elder-Statesman geworden.

494 Siehe etwa Conant an Goldmann, 27.7. 1954, USNA, RG 59, 262.0041/7-2854.

495 Department of State, Office of German Affairs, Memorandum of Conversation, Horst Pelckmann (deutsche Gesandtschaft), van Dam, Lewis, Cecil B. Lyon, 24. 3. 1954, USNA, RG 59, 262.0041/3-2454.

496 Adenauer an Goldmann, 21.9. 1954, USNA, RG 59, 262.0041/11-1754.

497 Siehe etwa Knox Lamb (HICOG) an State Department, 18. 8. 1954, USNA, RG 59, 262.0041/8-1854.

${ }^{498}$ Interview mit John J. McCloy am 23. 2. 1972 (Anm. 242). Vgl. auch Ferencz, Lohn des Grauens, S. $107 \mathrm{ff}$. 